\title{
Impact of carbon dioxide sequestration in depleted gas- condensate reservoirs
}

Richard M. Ramharack

West Virginia University

Follow this and additional works at: https://researchrepository.wvu.edu/etd

\section{Recommended Citation}

Ramharack, Richard M., "Impact of carbon dioxide sequestration in depleted gas-condensate reservoirs" (2010). Graduate Theses, Dissertations, and Problem Reports. 2136.

https://researchrepository.wvu.edu/etd/2136

This Thesis is protected by copyright and/or related rights. It has been brought to you by the The Research Repository @ WVU with permission from the rights-holder(s). You are free to use this Thesis in any way that is permitted by the copyright and related rights legislation that applies to your use. For other uses you must obtain permission from the rights-holder(s) directly, unless additional rights are indicated by a Creative Commons license in the record and/ or on the work itself. This Thesis has been accepted for inclusion in WVU Graduate Theses, Dissertations, and Problem Reports collection by an authorized administrator of The Research Repository @ WVU. For more information, please contact researchrepository@mail.wvu.edu. 


\title{
IMPACT OF CARBON DIOXIDE SEQUESTRATION IN DEPLETED GAS- CONDENSATE RESERVOIRS
}

\author{
Richard M. Ramharack \\ Thesis submitted to the \\ College of Engineering and Mineral Resources \\ At West Virginia University \\ In partial fulfillment of the requirements \\ For the degree of \\ Master of Science \\ In \\ Petroleum and Natural Gas Engineering
}

Approved by

Kashy Aminian, PhD. Chair

Daniel E. Della-Giustina, PhD.

Samuel Ameri, M.S.

Department of Petroleum and Natural Gas Engineering

Morgantown, West Virginia

2010

Keywords: Gas-condensate, CMG GEM, Carbon Dioxide Sequestration, Liquid recovery, Phase behavior

Copyright 2010 Richard M. Ramharack 


\begin{abstract}
IMPACT OF CARBON DIOXODE SEQUESTRATION IN DEPLETED GASCONDENSATE RESERVOIRS
\end{abstract}

\title{
Richard M. Ramharack
}

Depleted gas-condensate reservoirs are becoming important targets for carbon dioxide sequestration. Since depleted below the dew point, retrograde condensate has been deposited in the pore system and may be temporarily or permanently trapped in the reservoir, causing severe reductions in gas production rates and the permanent loss of a large portion of the volatile and valuable condensate liquids. Carbon dioxide injection in the depleted gas-condensate reservoirs may allow enhanced condensate recovery by liquid revaporization and reservoir repressurization or pressure maintenance

The purpose of this research study was to develop a gas-condensate reservoir model using a compositional simulator to investigate the impact carbon dioxide injection on enhanced condensate recovery and to determine the increase in the amount of carbon dioxide being sequestered due to condensate recovery. A practical injection schedule was developed where carbon dioxide is both used in repressuring the depleted reservoir followed by cycling in order to achieve an effective and efficient enhanced recovery schedule.

The injection schedule has shown to increase recovery by $63 \%$ and achieve a total liquid recovery of more than $90 \%$. Also, enhanced condensate recovery has shown to increase the amount of carbon dioxide being sequestered into a depleted gas-condensate reservoir by $15 \%$. 


\section{ACKNOWLEDGEMENTS}

Thank you God for the many opportunities your have given me. I know that through You all things are possible.

To my advisor and professor, Dr. Kashy Aminian, thank you for your continuous supervision during my graduate program. I am grateful to have worked with you. I respect and admire your professionalism, level of expertise and appreciate your guidance throughout my program.

To Prof. Sam Ameri thank you for expressing sincere interest in everything I did at WVU and thank you for making this transition into graduate life as smooth as possible. I also appreciate your participation and enthusiasm to be part of my committee. My gratitude is also extended to Dr. Ilkin Bilgesu and to Dr. Daniel E. Della-Giustina for their help and support. Thank you both for your involvement and commitment towards being a part of my committee.

Special thanks to all the faculty and staff of the department of Petroleum and Natural Gas Engineering, with special mention of Ms. Beverley Matheny who was always so helpful and welcoming.

To the Fulbright organization and Laspau, I am eternally grateful, without which I would not have had this opportunity to pursue my Masters degree. Thank you all for your support and guidance during my stay in the United States; special thanks to Renee and Megan who were always there when I needed advice.

I will like to express special thanks and gratitude to the many lifelong friendships that I have forged here and for the many memories I will carry with me.

To my family back home, thank you for all your love and constant support. To my sister Sally, I dedicate this to you. 


\section{TABLE OF CONTENTS}

ABSTRACT

ACKNOWLEDGEMENTS ...................................................................................................... ii

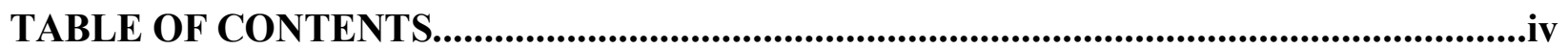

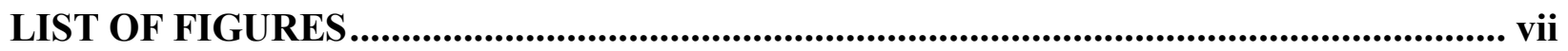

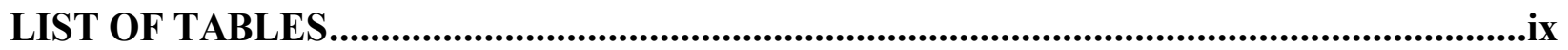

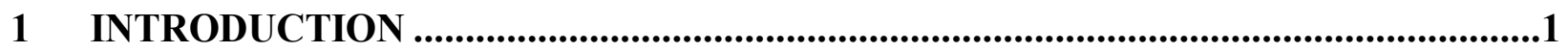

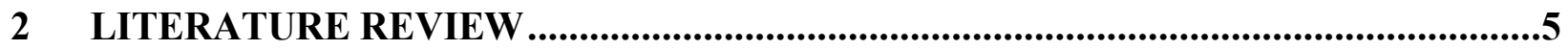

2.1 Carbon Dioxide (CO2) Sequestration .......................................................................

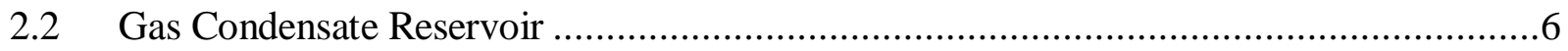

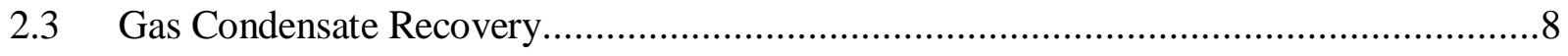

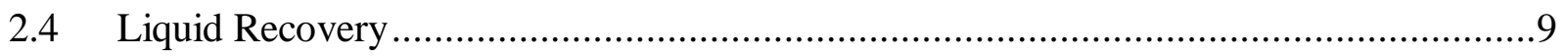

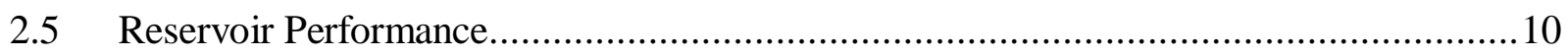

2.6 Pressure-Volume-Temperature (PVT) Analysis .......................................................12

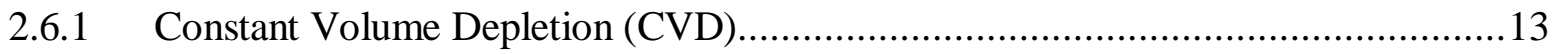

2.6.2 Constant Composition Expansion (CCE) ....................................................... 13

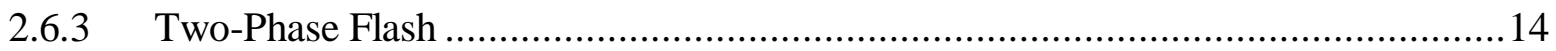

2.7 Revaporization for Retrograde Condensate ………….............................................14

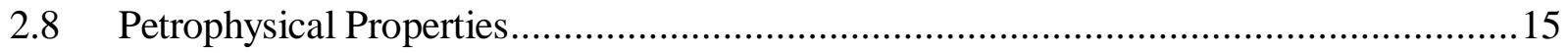

2.9 Previous Carbon Dioxide-Gas-Condensate Studies ......................................................16

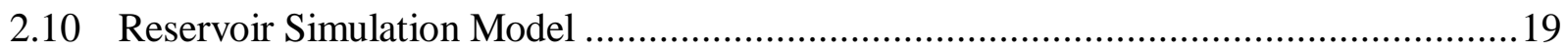

3 OBJECTIVE AND METHODOLOGY .........................................................................21

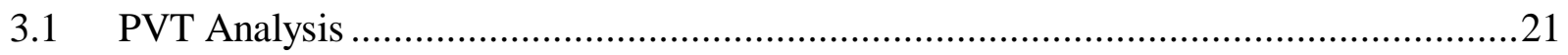

3.1.1 Constant Volume Depletion (CVD) ................................................................2 


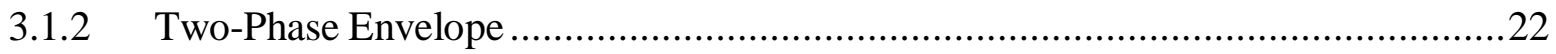

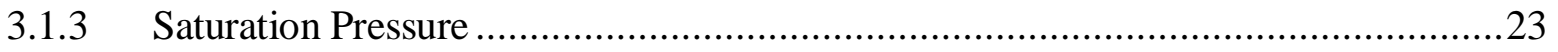

3.1.4 GEM

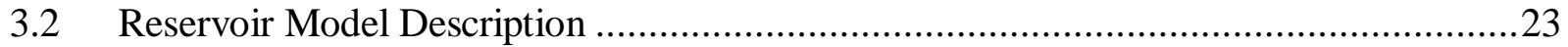

3.3 Relative Permeability................................................................................... 25

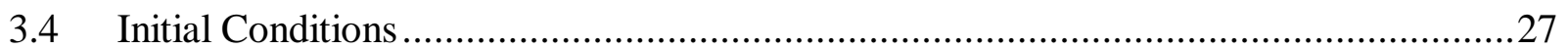

Production and Injection Wells ...................................................................28

3.6 Initial Reservoir Conditions ........................................................................29

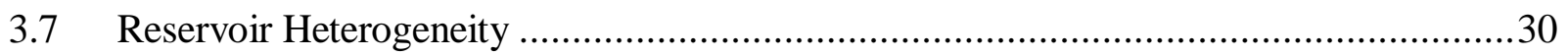

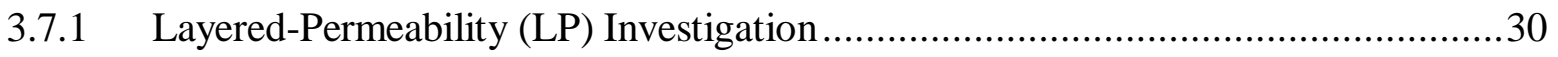

3.7.2 Streak-Permeability (SP) Investigation ................................................... 31

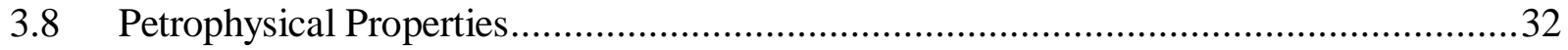

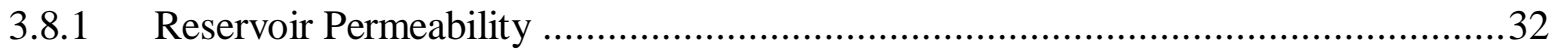

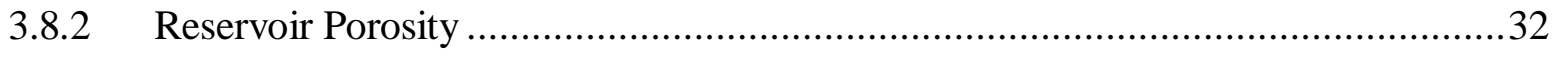

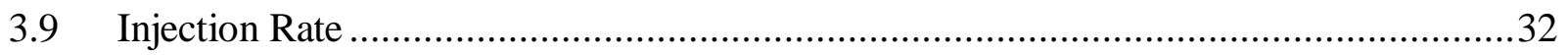

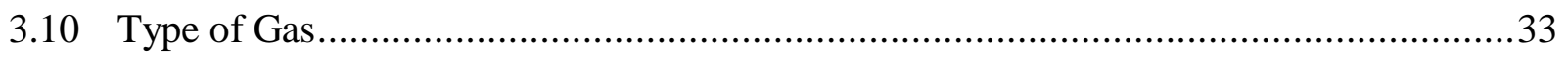

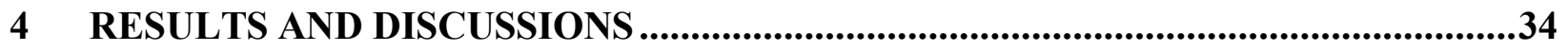

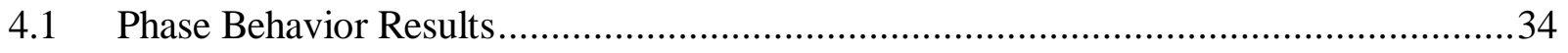

4.1.1 Pressure-Temperature (PT) Diagram ................................................. 34

4.1.2 Saturation Pressure ............................................................................ 35

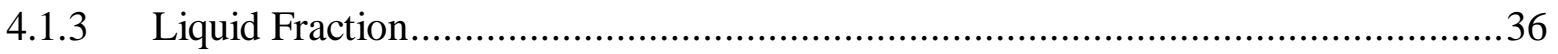

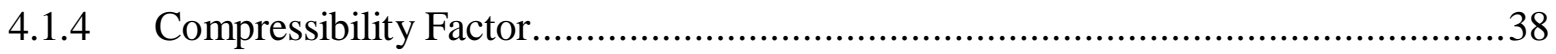

4.2 Impact of Reservoir Heterogeneity on Liquid Recovery .......................................39

4.3 Impact of Reservoir Heterogeneity on Oil Saturation ...........................................4 43

4.4 Impact of Petrophysical Properties on Liquid Recovery and Oil Saturation..................51 
4.5 Impact of Injection Rate on Liquid Miscibility.

4.6 Impact of Injection Gas on Liquid Recovery...................................................57

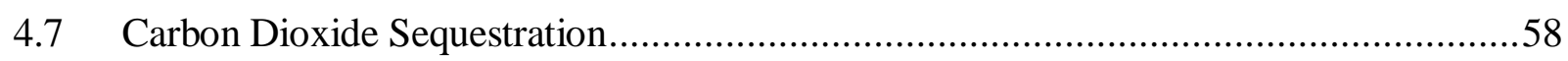

5 CONCLUSIONS AND RECOMMENDATIONS .....................................................61

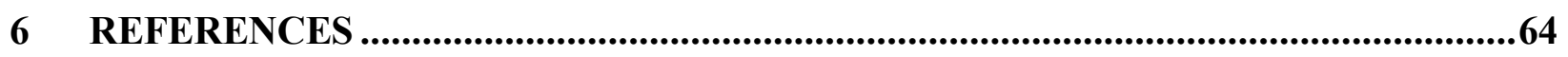

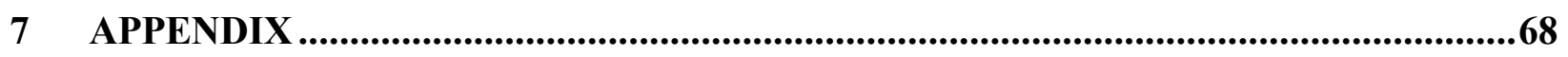

APPENDIX A: Additional PVT Results................................................................68

APPENDIX B: BC screen shots at the end of injection ..................................................70

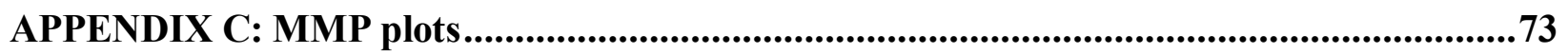

APPENDIX D: LPL-L1 screen shots at the end of injection period ...................................76

APPENDIX E: LPL-L5 screen-shots at the end of injection period .....................................79

APPENDIX F: SP-5L screen-shots at the end of injection period .......................................82

APPENDIX G: Pressure-Temperature Diagram for pure CO2 ........................................85 


\section{LIST OF FIGURES}

Figure 2.1: World and US CO2 Emissions (Impacts of the Kyoto Protocol on the US Energy Markets and Economic Activity, 1998)

Figure 2.2: US Greenhouse Gas Emissions in 2001 as reported by the Energy Information Administration (Impacts of the Kyoto Protocol on the US Energy Markets and Economic Activity,

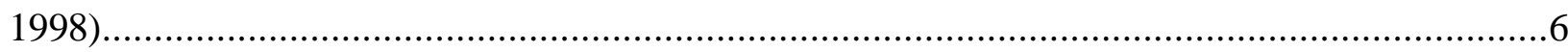

Figure 2.3: Phase Diagram of Gas Condensate............................................................

Figure 2.4: Liquid drop-out behavior in gas condensate (Danesh, 2007) ................................ 10

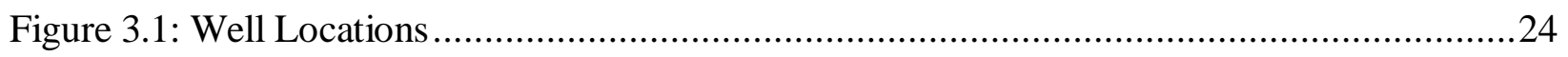

Figure 3.2: Oil-water relative permeability curves...........................................................26

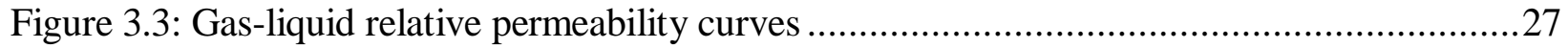

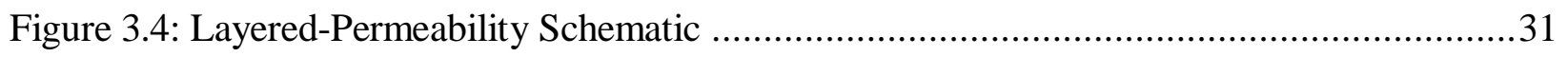

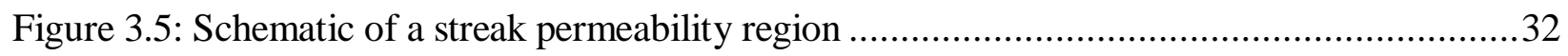

Figure 4.1: Effects of CO2-GC mixture on two-phase envelope for $\mathrm{CO} 2$ mole fraction - 0 mole \%

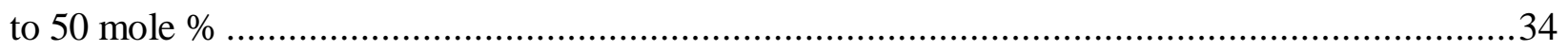

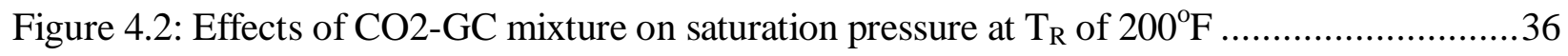

Figure 4.3: Effects of CO2-GC mixture on Liquid Recovery ..................................................3

Figure 4.4: Effects of CO2-GC mixture on gas compressibility (z-factor) ...............................38

Figure 4.5: Liquid Recovery Factor comparison for BC and LP cases .................................40

Figure 4.6: Liquid Recovery Factor comparison for LPL cases.........................................41

Figure 4.7: Liquid Recovery Factor comparison for SP cases ........................................42

Figure 4.8: Average Liquid Saturation comparison for BC and LP cases .............................44

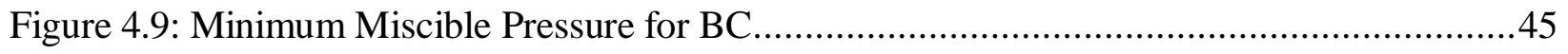

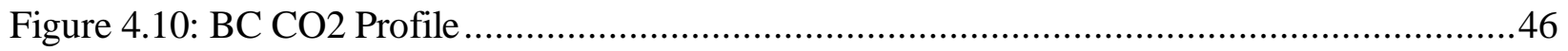

Figure 4.11: Average liquid Saturation comparison for BC and LPL cases ............................47

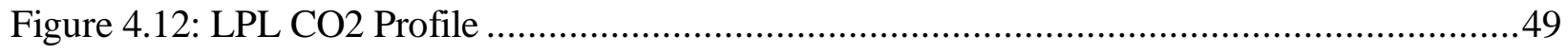

Figure 4.13: Average liquid Saturation comparison for BC and SP cases .............................50

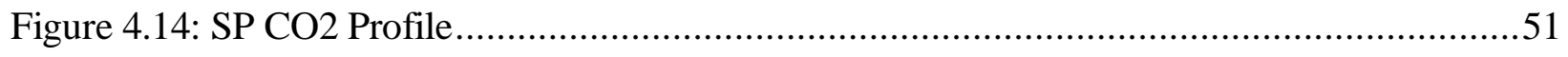

Figure 4.16: Average Liquid Saturation comparison porosity cases ....................................53 
Figure 4.17:Liquid Recovery Factor comparison for permeability cases ..............................54

Figure 4.18: Average Liquid Saturation comparison for permeability cases ............................55

Figure 4.19: Average Liquid Saturation comparison for gas injection rate cases.......................56

Figure 4.20: Liquid Recovery Factor comparison for gas injection rate cases..........................56

Figure 4.21: Liquid Recovery Factor comparison for injection gas cases ..............................57 


\section{LIST OF TABLES}

Table 2.1: Classification of Gas-condensates based on the performance of a reservoir at initial

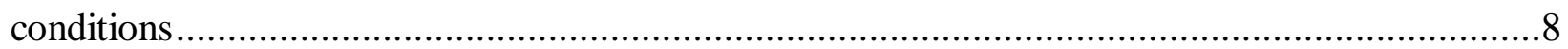

Table 2.2: Composition and other properties of typical single phase reservoir fluids ...................9

Table 3.1 Gas-condensate Composition ........................................................................24

Table 3.2: Relative Permeability Tables...............................................................................25

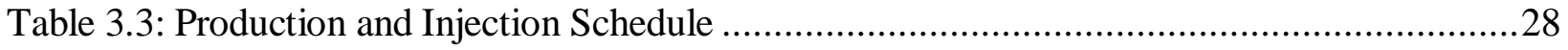

Table 3.4: Initial reservoir conditions calculated by GEM Simulator ...................................29

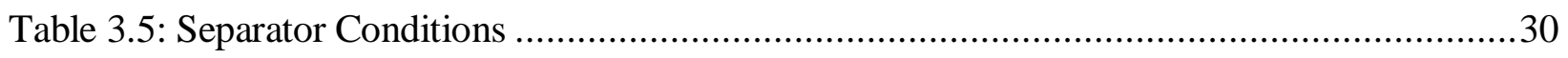

Table 3.6: Production and Injection Schedule for a rate of 45.5 MMSCFD .............................33

Table 4.1: Produced Wet Gas composition for BC and LP cases at the start of cycling ...............40

Table 4.2: Produced Wet Gas composition for BC and SP cases at the start of cycling ...............42

Table 4.3: Produced Wet Gas composition for LPL cases at the start of cycling .......................48

Table 4.4: Produced Wet Gas composition for SP cases at the start of cycling ........................51

Table 4.5: Produced Wet Gas Composition for Various Injection Gas at Start of Cycling............58

Table 4.6: Volume of CO2 sequestered in a Depleted Gas-Condensate reservoir ......................59

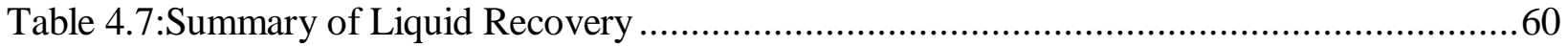

Table 4.8:Volume of CO2 stored after Enhanced Condensate Recovery (ECR) .......................60 


\section{INTRODUCTION}

At the Copenhagen Climate Conference 2009, the latest data presented on carbon dioxide emissions shows that the US is no longer the number one emitter of carbon dioxide, having been overtaken by China. The latest figures compiled up to 2007 by the US Energy Information Administration have China emitting 6,283.56 million metric tons as compared with 6,006.71 million metric tons emission of carbon dioxide into the atmosphere by the US. China and US alone account for $40 \%$ of the global carbon dioxide emission. This number has been on a steady increase since the industrial era, leading to concerns of global warming and the ensuing climatic changes. Sequestration of carbon dioxide in depleted gas reservoirs, with storage capacity estimated to be 140 billion metric ton carbon worldwide (Carbon Dioxide Utilization, 1997) is considered as a possible solution.

Greenhouse gases such as carbon dioxide trap solar heat energy when released to the atmosphere, which causes an increase in the earth's surface temperature. This phenomenon is known as global warming, and it is believed to be a negative influence on weather patterns, coastlines and ecosystem changes. As such this is of grave concern for the entire world. For this reason the United

Nations Framework Convention on Climatic Change (UNFCCC) sought to address the problem in December 1997 in Kyoto, Japan. (UNFCC: Protocol adopted by the Third Conference of Parties (COP-3) to the United Nations Framework Convention on Climate Change, 1997). Given the increasingly large volume of carbon dioxide emitted annually, a plan was developed for mitigation of anthropogenic carbon dioxide emission to the atmosphere. The agreement to decrease emissions to $5.2 \%$ less than 1990 emission levels by 2008 to 2012 was ratified by 193 countries.

Carbon dioxide is one of the by-products of burning fossil fuels - the by-products being released to the atmosphere. According to the US Energy Information Administration's in 2006 fossil fuels such as natural gas, fuel oil, and coal contribute to the $86 \%$ of the world's energy, with an annual growth rate of $20 \%$. With this ever dependence on fossil fuels, it has been recommended that 
carbon dioxide be captured from the flue gas among other sources from carbon dioxide emitting plants and dispose in a more environmentally friendly manner.

Carbon dioxide capture would require extra energy expenditure that could increase energy cost to 40\% above current levels. (International Energy Agency Greenhouse Gas Program. Sponsored by European Union Commission, 20 countries and multiple companies). Carbon capture involves separating carbon dioxide from hydrocarbon gases, dehydrating and compressing carbon dioxide, transporting it via pipeline to injection site, re-compressing if applicable, injecting it into geological reservoirs and monitoring its movement and behavior after sequestration. Apart from carbon dioxide capture, the economics of sequestration largely depend on the amount of carbon dioxide, distance and reservoir properties, the cost of which could vary from below US\$5 to over US\$20 per metric ton of carbon dioxide (Nguyen, 2003).

Based on the attractiveness of enhanced oil and gas recovery in depleted reservoirs, geologic sequestration of carbon dioxide is a viable option for storage of carbon dioxide and for additional revenue from hydrocarbon recovery.

The positive results obtained by many researchers on enhanced oil recovery from carbon dioxide injection have been the driving force for carbon dioxide sequestration in increasing energy demands.(Willhite, 1998). The criteria for a candidate gas condensate formation include injectivity, storage capacity, and containment. A minimum depth of $800 \mathrm{~m}$ is recommended to ensure the safety of potable water aquifers. At this depth carbon dioxide will reach supercritical state (carbon dioxide critical point is at $1071 \mathrm{psi}$ and $87.9^{\circ} \mathrm{F}$ ), wherein the density of carbon dioxide is 600 to $800 \mathrm{~kg} / \mathrm{m} 3$ and is optimal for storage. A maximum cutoff depth of $3300 \mathrm{~m}$ is also suggested to keep the compression costs reasonable. (Xie, 2009)

The accumulation and entrapment of a lean gas such as methane in gas condensate reservoirs demonstrates the capability of these reservoirs for gas containment for long periods of time. By virtue of their proven records of gas production, depleted gas condensate reservoirs have demonstrated to have both 
- The available volume, and

- The integrity of gas containment.

Since depleted below the dew point, retrograde condensate has been deposited in the pore system. Carbon dioxide injection in the depleted gas condensate reservoirs may allow enhanced gas recovery by liquid revaporization byreservoir repressurization or pressure maintenance.

The higher density of carbon dioxide relative to gas condensate means that carbon dioxide will tend to migrate downward. The larger viscosity of carbon dioxide ensures that displacement of hydrocarbon gas phase by carbon dioxide will be a displacement with a favorable mobility ratio. Furthermore, pressure diffusivity is typically several orders of magnitude larger than molecular diffusivity, making mixing by repressurization occur much faster than by molecular diffusion.(Freeze \& Cherry, 1979) There are some disadvantages to carbon dioxidesequestration:

- Carbon dioxide is expensive to transport and it is not always available.

- Poor sweep and gravity segregation can result in no production under certain conditions.

- Carbon dioxide containing moisture can be very corrosive. (Grigg, 2005 )

The purpose of this research was to evaluate how does carbon dioxide injection affects liquid recovery and how does liquid recovery impacts carbon dioxide sequestration. On the basis of the objective, the research comprise carrying out PVT studies, using a compositional simulator to develop a gas-condensate reservoir with an effective and efficient injection plan to improve condensate recovery and evaluate the impact of condensate recovery on carbon dioxide sequestration.

Data for model development was selected based on typical parameters for a gas-condensate reservoir. Once the model was developed, a practical injection schedule was developed so as to enhanced liquid recovery The intention of developing the schedule was not only to enhance the liquid recovery but to create additional pore space in the reservoir to sequester more carbon dioxide. Various factors were also investigated based on the injection schedule developed and 
recovery factor attained, which included the impact of reservoir heterogeneity, petrophysical parameters and injection rates, so that a better understanding on how carbon dioxide interacts, affects and impact liquid recovery and ultimately sequestration. 


\section{LITERATURE REVIEW}

\subsection{Carbon Dioxide (CO2) Sequestration}

According to the Kyoto Protocol, industrialized countries target to reduce their collaborative emissions of greenhouse gases $(\mathrm{CO} 2$, methane $(\mathrm{C} 1)$, nitrous oxide $(\mathrm{N} 2 \mathrm{O})$, hydroflourocarbons (HFC), perflourocarbons, (PFC) and sulfur hexafluoride (SF6)) at least $5.2 \%$ below the 1990 level by the period $2008-2012$. Figure 2.1 below shows the current $\mathrm{CO} 2$ emissions and the projected $\mathrm{CO} 2$ emissions with and without compliances to the Kyoto protocol. (Impacts of the Kyoto Protocol on the US Energy Markets and Economic Activity, 1998)

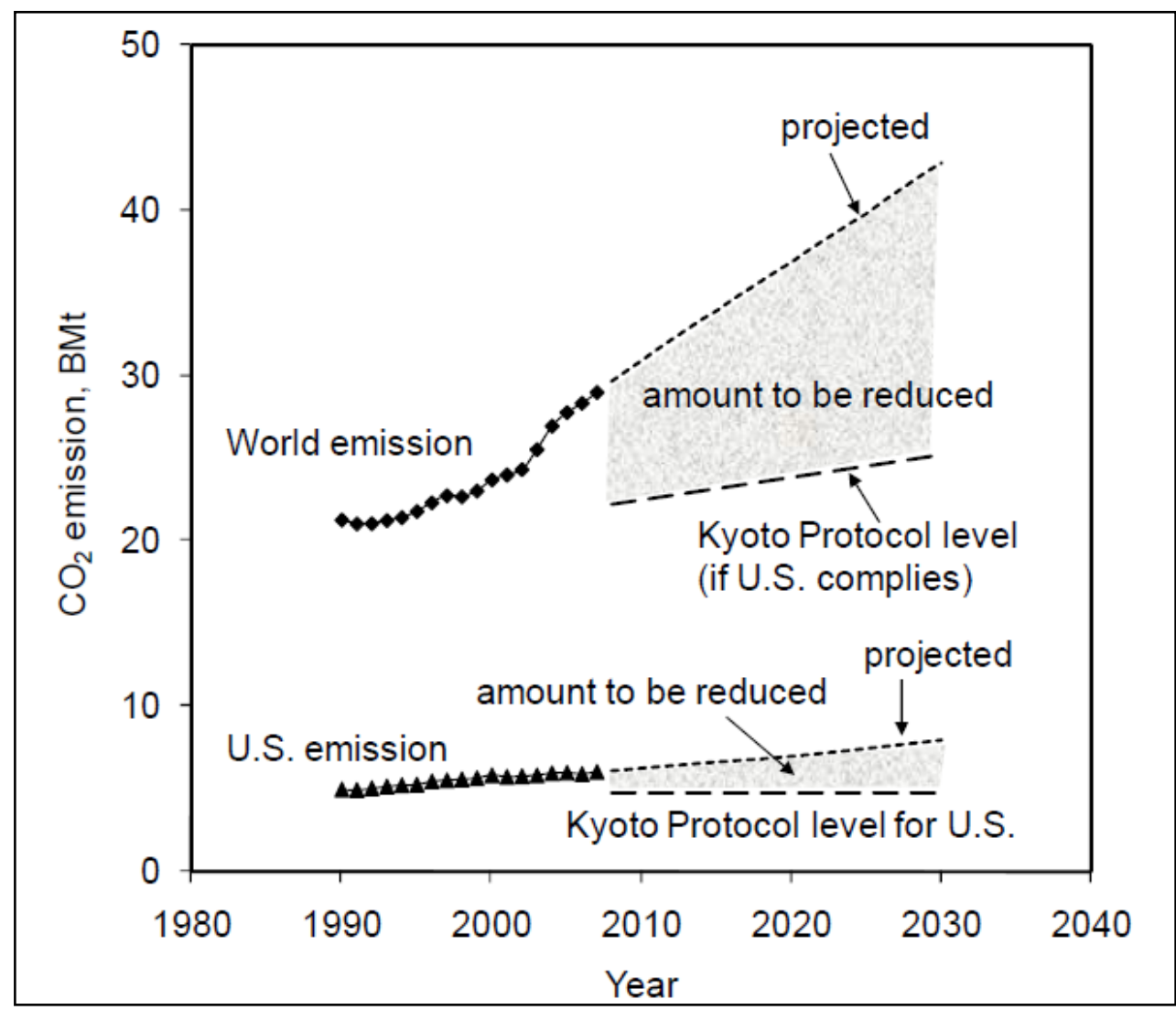

Figure 2.1: World and US CO2 Emissions (Impacts of the Kyoto Protocol on the US Energy Markets and Economic Activity, 1998) 
Based on the Global Warming Potential (GWP), which measures the absorptive heat of each greenhouse gas, $\mathrm{CO} 2$ has the lowest GWP. However, according the US greenhouse gases emissions in 2001, CO2 contributes to $82 \%$ (Figure 2.2). (Carbon Dioxide Utilization, 1997). Thus with the ever increasing demand, the increasing reliance on carbon-based fossil fuels and the environmental concerns $\mathrm{CO} 2$ poses, there is a greater urgency to capture and store $\mathrm{CO} 2$. Geological sequestration into natural reservoirs has been one such option to capture and store $\mathrm{CO} 2$, due to its massive capacity and relatively mature technology.

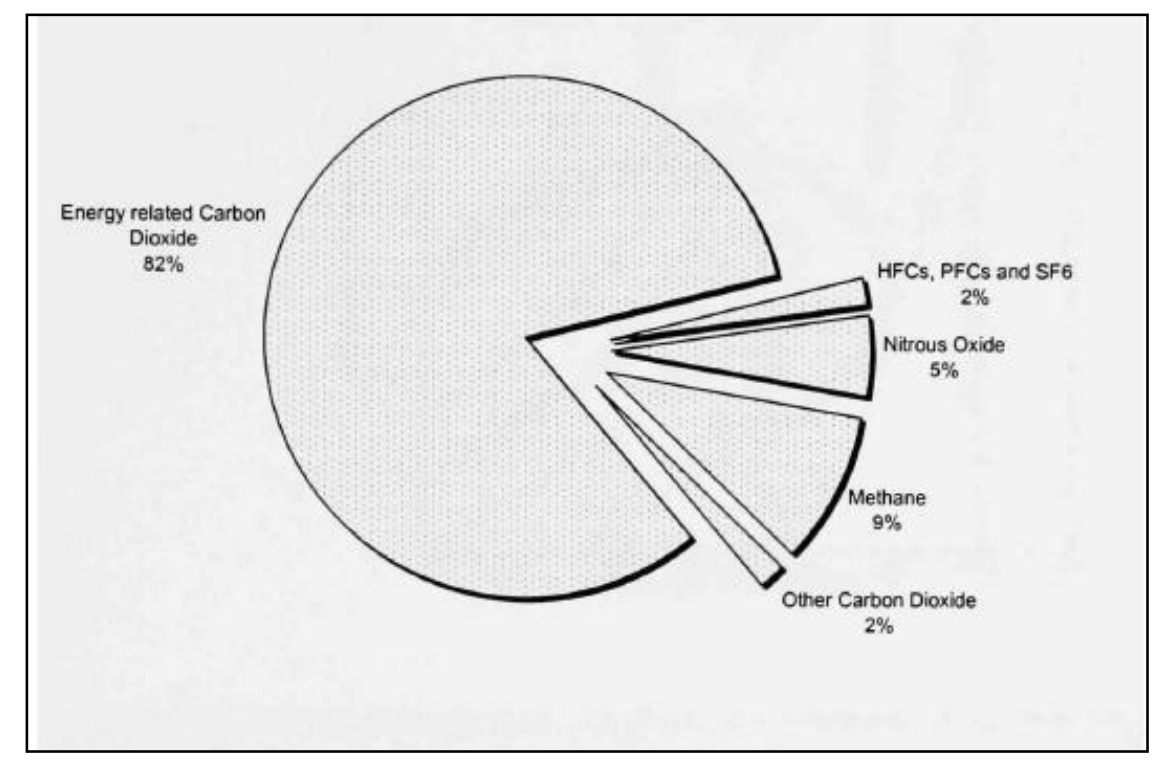

Figure 2.2: US Greenhouse Gas Emissions in 2001 as reported by the Energy Information Administration (Impacts of the Kyoto Protocol on the US Energy Markets and Economic Activity, 1998)

\subsection{Gas Condensate Reservoir}

A typical gas condensate phase diagram is shown in Figure 2.3. From this figure, it can be seen that the presence of heavy hydrocarbons expands the phase envelope relative to a wet gas; hence the reservoir temperature lies between the critical point and the cricondentherm. During pressure depletion the gas will drop out liquid by a process called retrograde condensation as shown from point 1 to 2 in Figure 2.3. Further condensation will occur in surface separators due to cooling. The amount of potentially condensable hydrocarbons in the reservoir increases with the richness of the gas, as heavy compounds shift the critical temperature towards the reservoir temperature. A gas with a cricondentherm near the reservoir temperature will behave very much like a wet gas. Most 
known gas-condensate reservoirs are in the range of 3000-6000 psi and 200 to $400{ }^{\circ} \mathrm{F}$. These pressure and temperature ranges, together with wide composition ranges, provide a great variety of conditions for the physical behavior of gas condensate deposits. Gas-to-liquid ratios (GOR) range between 3200 to 150,000 SCF/STB.(McCain Jr. \& Bridges, 1994 )The producing GOR remains constant until the pressure falls below the dew point and increases thereafter.

The concentration of the heptanes plus fractions is generally less than 12.5 mole $\%$ in the gas condensate fluid as fluids containing more than that almost always behave liquid-like in the reservoir. There are cases where condensate composition is as high as 15.5 mole $\%$ and oil as low as 10 mole \% of heptanes fractions. (Moses, 1986)

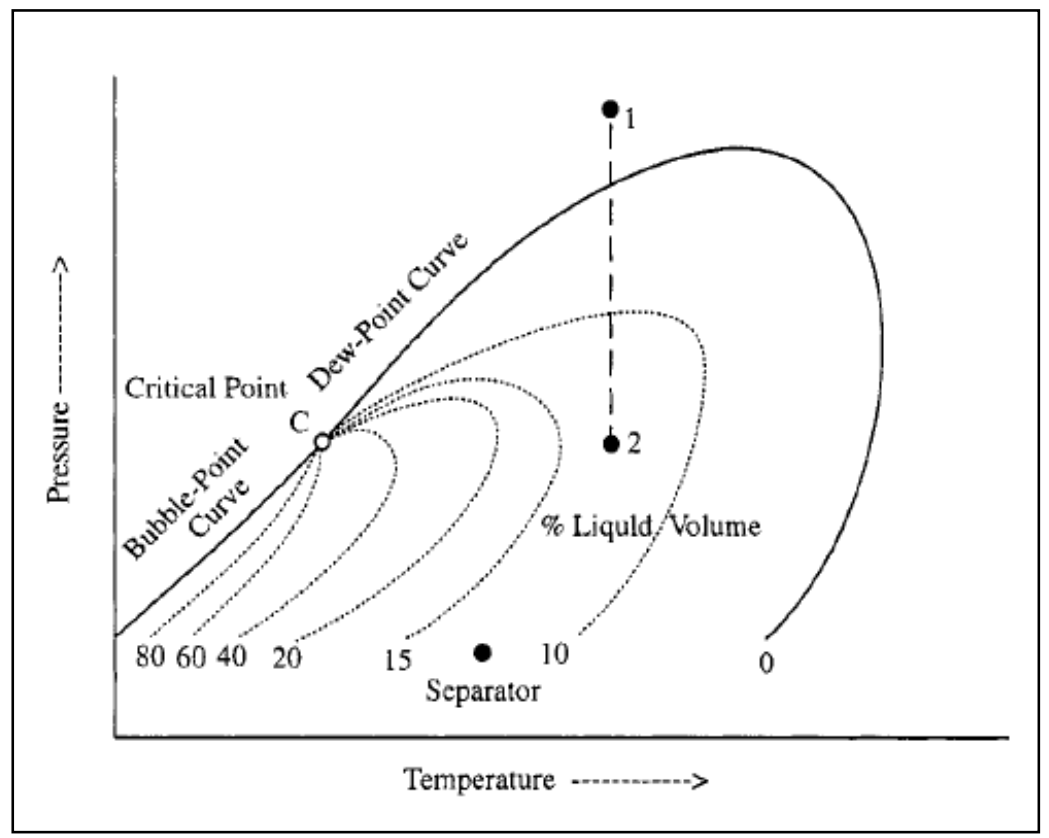

Figure 2.3: Phase Diagram of Gas Condensate

Condensate can either be water-white or dark. Dark condensates usually have high specific gravity and associated with high dew point. Condensate specific gravity ranges from 0.74 to 0.84 (60 to 40 ${ }^{\circ}$ API). (Kilgren, 1966).

Traditionally gas-condensate reservoirs are classified based on molecular weight of the heptanes plus fractions, GOR, tank gravity and liquid color. GOR has been the more widely accepted 
classification as the others show weak correlation with the API gravity of the stock tank liquid (Craft, Hawkins, \& Terry, 1991). However, there has been some inadequacy of classifying reservoirs solely based on the surface GOR and thus in order to properly classify reservoirs depend on (a) the composition of the hydrocarbon accumulation and (b) the temperature and pressure of the accumulation in the earth. As such Table 2.1 below gives a rough classification, which can be made on the performance of the reservoir at initial conditions.

Table 2.1: Classification of Gas-condensates based on the performance of a reservoir at initial conditions

\begin{tabular}{|c|c|c|l|}
\hline Pressure (psia) & Temperature $\left({ }^{\circ} \mathrm{F}\right)$ & GOR (SCF/STB) & \multicolumn{1}{|c|}{ Characteristic } \\
\hline$<8000$ & $<225$ & $\approx 15000$ & No Liquid Present \\
\hline- & - & $6000-15000$ & Retrograde Behavior \\
\hline- & - & $3000-6000$ & $\begin{array}{l}\text { Volatile Oil or Retrograde } \\
\text { gas condensate }\end{array}$ \\
\hline- & - & $<3000$ & Oil (Volatile or otherwise) \\
\hline$>8000$ & - & 2000 & Retrograde gas condensate \\
\hline
\end{tabular}

\subsection{Gas Condensate Recovery}

Since the late 1930s gas condensate reservoirs have grown in importance; Compared with dry gas reservoirs of which total recovery is around $80 \%$ of gas initially in place, gas condensate by pressure depletion can also have recoveries in the range of $80 \%$ of dry gas initially in place. However, as much as $50-60 \%$ of the liquefiable hydrocarbon is generally lost due to retrograde condensation.(Cole, 1969)

Table 2.2 gives a general idea of the mole compositions and some additional properties of five single phase reservoir fluids. From this table the GOR is one the main characteristics that defines 
the fluid. For example GORs greater that 100,000 SCF/STB are commonly associated with lean/dry gas. As mentioned before as pressure declines in black oil, volatile oil and some gas condensate reservoirs there is generally a considerable increase in GOR, owing to the mechanisms that control the relative flow of oil and gas to the wellbore. GOR can also be increased by both completing in the oil zone or both the oil zone and gas cap. In the former, the GOR is increased due to the downward coning of gas from the overlying gas cap.

Table 2.2: Composition and other properties of typical single phase reservoir fluids

(Craft, Hawkins, \& Terry, 1991)

\begin{tabular}{|c|c|c|c|c|c|}
\hline \multicolumn{6}{|c|}{ Mole composition and other properties of typical single-phase reservoir fluids } \\
\hline Component & $\begin{array}{c}\text { Black } \\
\text { Oil }\end{array}$ & $\begin{array}{c}\text { Volatile } \\
\text { Oil }\end{array}$ & $\begin{array}{c}\text { Gas- } \\
\text { Condensate }\end{array}$ & Dry Gas & Gas \\
\hline $\mathrm{C}_{1}$ & 48.83 & 64.36 & 87.07 & 95.85 & 86.67 \\
\hline $\mathrm{C}_{2}$ & 2.75 & 7.52 & 4.39 & 2.67 & 7.77 \\
\hline $\mathrm{C}_{3}$ & 1.93 & 4.74 & 2.29 & 0.34 & 2.95 \\
\hline $\mathrm{C}_{4}$ & 1.60 & 4.12 & 1.74 & 0.52 & 1.73 \\
\hline $\mathrm{C}_{5}$ & 1.15 & 2.97 & 0.83 & 0.08 & 0.88 \\
\hline $\mathrm{C}_{6}$ & 1.59 & 1.38 & 0.60 & 0.12 & \\
\hline \multirow[t]{2}{*}{$\mathrm{C}^{+}$} & 42.15 & 14.91 & 3.80 & 0.42 & \\
\hline & 100.00 & 100.00 & 100.00 & 100.00 & 100.00 \\
\hline Mol. wt. $\mathrm{C}_{7}^{+}$ & 225 & 181 & 112 & 157 & \\
\hline GOR, SCF/bb] & 625 & 2000 & 18,200 & 105,000 & Inf. \\
\hline Tank gravity, ${ }^{\circ} \mathrm{API}$ & 34.3 & 50.1 & 60.8 & 54.7 & \\
\hline Liquid color & $\begin{array}{c}\text { Greenish } \\
\text { black }\end{array}$ & $\begin{array}{c}\text { Medium } \\
\text { orange }\end{array}$ & $\begin{array}{l}\text { Light } \\
\text { straw }\end{array}$ & $\begin{array}{l}\text { Water } \\
\text { white }\end{array}$ & \\
\hline
\end{tabular}

\subsection{Liquid Recovery}

Figure 2.4 shows a common characteristic of gas condensate fluids. As can be seen the liquid drop-out reaches a maximum and then decreases by vaporization during pressure depletion. This behavior may imply that when the reservoir pressure increases sufficiently, the condensate will be recovered by revaporization. However, by the time the pressure falls below the dew point, the original phase diagram is no longer valid as the system composition changes during the production period. 
Condensation and loss of valuable compounds in reservoirs could be avoided by maintaining the reservoir pressure above the fluid dew point. Such mechanism includes gas cycling, nitrogen injection and $\mathrm{CO} 2$ sequestration. Partial pressure maintenance is more common to minimize the losses of condensate, where it is economical to do so.

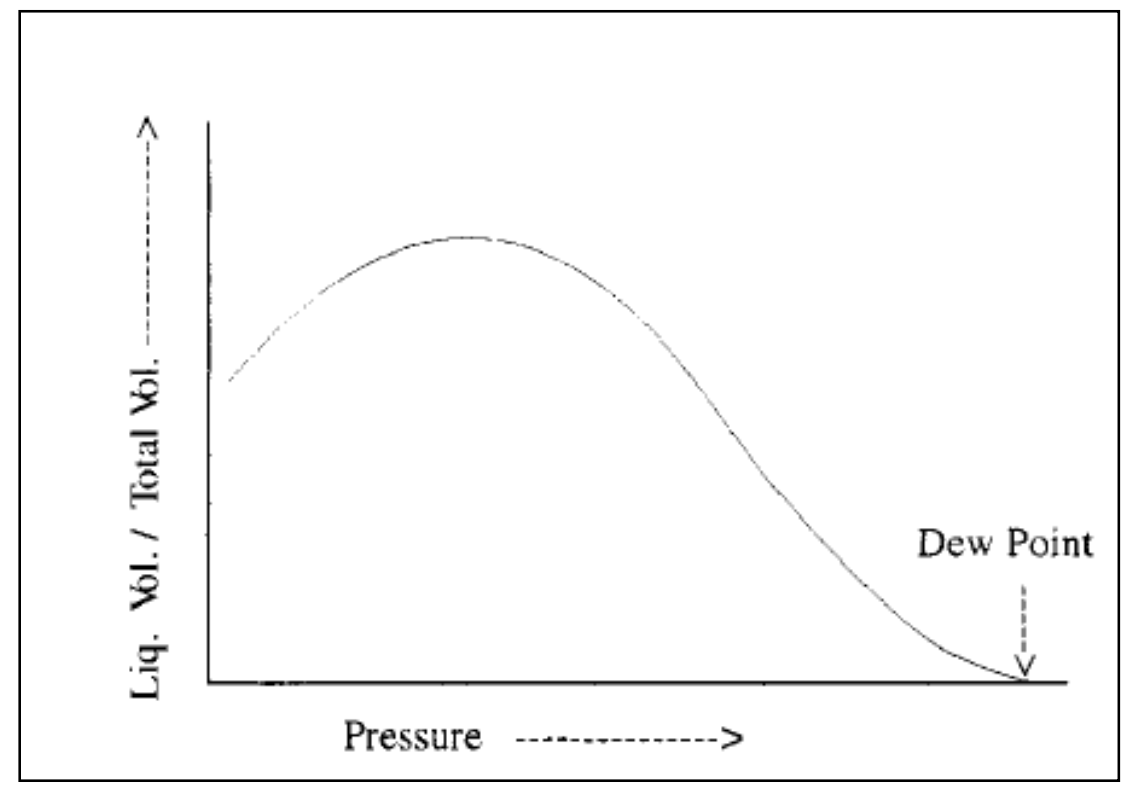

Figure 2.4: Liquid drop-out behavior in gas condensate (Danesh, 2007)

\subsection{Reservoir Performance}

Predicting reservoir performance in gas condensate reservoir during pressure depletion is necessary in evaluating new fields and determining reserves. The predicted performance is used in economic decision making regarding future recovery processes. Constant Volume Depletion (CVD) test is one such predictive tool used on bottom hole samples or surface recombined samples where the reservoir is above dew point pressure to measure reservoir performance. In such cases where limited data is available, Equation of State (EOS) and empirical correlation are used to predict the depletion performance of gas condensate reservoirs. They can also be used to study phase behavior of petroleum reservoir fluids and to check the validity of the PVT data, (Conrad \& Gravier, 1980) and measured saturation pressure (Raghavan \& JR., 1996). 
Over the years a number of equations of states ((Redlich \& Kwong, 1949),(Soave, 1972),(Peng \& Robenson, 1976),(Zudkevitch) and(Martin, 1979)) have been published in the literature to model reservoir fluid phase behavior in general and gas condensate in particular. In predicting the performance of simple hydrocarbon systems, predominantly oil, the EOS is good. However its limitations are evident when modeling phase behavior of complex hydrocarbons such as volatile oils and gas-condensates especially in the retrograde region. (Saker, Danesh, \& Todd, 1991)

Using EOS to determine phase behavior calculations are desirable because experimental determination is lengthy and expensive. The degree of confidence in EOS results increases as EOS is tuned to match experimentally measured data or actual field data. Once the EOS is tested against actual data for a given fluid, it is generally assumed that it can be used to describe the phase behavior of that fluid at any condition, (Al-Mahros \& Tojoa, 1987). Comparative studies between EOS results and laboratory PVT data for various kinds of reservoir fluids have been reported. ((Firoozbadi, Hekim, \& Katz, 1978),(Besserer \& Serra, 1979),(Williams \& Zana, 1980),(Vogel \& Yarborough, 1980),(Whitson \& Torp, 1983),(Coats K. , 1985),(Coats \& Smart, 1986),(Douglas \& Bohle, 1987),(Drohm, Goldthrope, \& Trengove, 1988),(Bette \& Heineman),(Chaback \& Williams, 1994),(Furniual, 1993)).

Whitson et al studied the splitting of heptane plus fraction as the key factor in attaining significant match between laboratory data and EOS results. The degree of splitting the heptane plus fraction depends on the anticipated recovery process. Coats et al emphasized on regression analysis of some of the EOS parameters to match the saturation pressure or the PVT data. Firoozbadi and Katz et al used methane interaction coefficient to study gas-condensate behavior, dew point pressure and percentage liquid dropout. They correlated binaries between methane and petroleum fractions and used these binaries to predict dew point pressure for gas-condensate. Peneloux et al used three possibilities in predicting the EOS properties of gas-condensates:

1. Methane interaction only,

2. Methane, ethane, and propane

3. All the alkanes lighter than C6,as adjustable parameters of the EOS 
They noticed that the observed difference between the results of using the three possibilities were not significant. Coats et al reported that EOS is generally not a good predictive tool for simulating the behavior of gas-condensate and extensive splitting of heptane plus fraction to match the laboratory data is generally unnecessary. Their results showed the poor prediction ability of the EOS without adjustment or regression of the EOS parameters. However, the EOS capability improved when EOS parameters were regressed than when it was adjusted or the plus fractions were split. Whitson et al showed that relatively small differences in critical properties and accentric factor can result in significant differences in EOS predictions. Describing petroleum fractions constituting heptane plus fraction is a typical problem, which can result in significant effects to EOS predictions. Results of Whitson's work suggested that heptane plus characterization has significant influence on EOS predictions of the reservoir fluid behavior and as such he deduced that it would be difficult to make objective conclusions about which heptane plus characterization scheme is the best.

\subsection{Pressure-Volume-Temperature (PVT) Analysis}

PVT tests are designed to study and quantify the phase behavior and properties of a reservoir fluid at simulated recovery conditions. The effect of interstitial water on the phase behavior of hydrocarbon fluids are ignored in most tests and the PVT tests are conducted in the absence of water. The majority of tests are depletion experiments, where the pressure of the single phase test fluid is lowered in successive steps either by increasing the fluid volume or removing part of it. The reduction of pressure results in formation of a second phase, except in dry and wet gas mixtures. (Danesh, 2007)

The prime information from PVT tests is the ratio of phase volume at reservoir conditions to that at surface conditions, and the solubility of gas in oil. The information is generally sufficient in studies of black oil reservoirs, and the approach is referred to as the black oil method. Compositional studies, where detailed information on the fluid constituents is used to estimate fluid properties, are often conducted for gas-condensate and volatile oil reservoirs. (Danesh, 2007) 
The compositional analysis of gas-condensate fluids is conducted generally in more details than that of oil. The compositional data are used often in phase behavior models, particularly in reservoir simulation. The fluid is commonly analyzed by flashing it at the atmospheric pressure and measuring the composition of the stabilized gas and liquid phases. The fluid heavy fraction is analyzed to identify major components, and also to characterize it by extended carbon groups, as the results of phase behavior models are very sensitive to the heavy end description of gascondensate systems. The following are typical PVT analysis tests performed on gas-condensate fluids: (Danesh, 2007)

\section{- Constant Volume Depletion}

- Constant Composition Expansion

- Two-phase Flash

\subsubsection{Constant Volume Depletion (CVD)}

Constant volume depletion is used to replicate the depletion of retrograde gas-condensate reservoirs. A sample of gas is placed in a cell at reservoir temperature and dew point or saturation pressure of the fluid. Starting at the dew point pressure, the volume of the cell is expanded to a predetermined lower pressure and then it is returned to the original volume by releasing gas. After equilibrium conditions have been restored in the cell, the retrograde liquid volume is measured, and the process is repeated starting at the new pressure until the final pressure is achieved. At each pressure decrement, the volume of gas released and the composition of gas are determined. By simulating reservoir depletion of retrograde condensate reservoirs to a minimum or depleted pressure, it is possible to determine the composition of the remaining reservoir fluid in the gas and liquid phases.

\subsubsection{Constant Composition Expansion (CCE)}

This test involves measuring the pressure/volume relations of the reservoir fluid at reservoir temperature with a visual cell. The usual PVT cell allows the visual observation of the condensation process resulting from changing the pressures. The CCE test is designed to provide the dew point pressure at the reservoir temperature and the total relative volume of the reservoir 
fluid (relative to the dew point volume) as a function of pressure. The relative volume is equal to one at dew point.

This procedure is achieved by adjusting the pressure to a value equal to or greater than the initial reservoir pressure. Temperature is set to the reservoir temperature. Pressure is reduced by increasing the volume of the cell in increments. No gas or liquid is removed from the cell. At each step, the pressure and total volume of the reservoir fluid (oil and gas) are measured. Additional data that can be determined include the liquid phase volume, oil and gas densities, viscosities,

compressibility factors or single phase compressibility above the saturation pressure. The procedure is also called flash vaporization, flash liberation, flash expansion or constant mass expansion.

\subsubsection{Two-Phase Flash}

Isothermal flash calculations determine the quantity of the liquid and gas phases at constant temperature for a determined pressure range. These calculations are performed on hydrocarbon gas mixtures in order to quantify results from the pressure-temperature diagrams. Plots from flash calculations give insight into the equilibrium phases present, gas and/or liquid, and the proportions of each. From these plots, it is possible to define the dew point curve and bubble point curve of a gas mixture.

\subsection{Revaporization for Retrograde Condensate}

Revaporization simply means increasing the pressure in retrograde gas-condensate reservoirs by gas injection $(\mathrm{C} 1, \mathrm{~N} 2$ or $\mathrm{CO} 2)$ to allow the condensed liquid to revaporize so that it can be recovered. When the injected dry gas comes into contact with gas-condensate, this leads to enrichment of the dry gas due to mass transfer, which has been found experimentally to vaporize both intermediate and some heavy hydrocarbons.(Luo, Li, Zheng, Chen, Dai, \& Liu, 2001). Gas injection can be done in schemes: full pressure or partial pressure maintenance. Full pressure is where the gas is cycled continuously while condensate is being withdrawn in order to maintain reservoir pressure above the saturation pressure. Whereas in partial maintenance the reservoir is 
depleted to a certain pressure below saturation pressure and then gas injection starts to revaporize the liquid condensate in the porous reservoirs. It was found that full pressure maintenance yielded a higher condensate recovery than partial pressure maintenance, $(\mathrm{Li}, \mathrm{Zheng}$, Dai, Luo, Chen, \& Liu, 2001 ), but the cost incurred by full pressure maintenance may be higher than that of partial pressure maintenance due to high pressure/high temperature condensate reservoirs. (Li, Zheng, Dai, Luo, Chen, \& Liu, 2001 )

Although many new strategies have been proposed for exploitation of gas-condensate reservoirs (Hernandez, Farrouq Ali, \& Brentsen, 1999), gas injection is still a widely applied development method.(Klotz, 1953). After Standing's et al. and Weinaug's et al. pioneering studies on the revaporization of gas-condensate, many researchers have pursued this phenomenon and the possible influence factors (Oxford \& Huntington, 1953), (Smith \& Yarborough, 1968),(Sigmund \& Cameron, 1977), (Moses \& Wilson, 1981),(Donohoe \& Buchanan, 1981),(Goricnik, Sarapa, \& Csisko, 1995),(Chaback \& Williams, 1994), (Sänger \& Hagoort, 1998)), revealing the mechanism occurred in gas-condensate reservoirs in the course of gas injection. There are various viewpoints and arguments on the possibility of revaporization, as well as the mechanism and the extent of revaporization.

Weinaug et al. believed that condensate can be vaporized completely if the amount of dry gas injected is enough. Oxford et al. assumed that the dry gas injected is in equilibrium with the condensate. Smith et al. found that the production rate has little effect on the equilibrium of fluids in the porous media. Also, Sigmund et al. found that carbon dioxide and methane are more effective in revaporization than nitrogen.

\subsection{Petrophysical Properties}

Petrophysics is the study of the physical and chemical properties that describe the occurrence and behavior of rocks, soils and fluids. In petroleum engineering the following is what is listed as conventional petrophysical properties:

1. Lithology: Indentifies rock type 
2. Water Saturation: The fraction of the pore space occupied by water

3. Porosity:

This is defined as the interconnected pore volume or void space in a rock that contributes to fluid flow or permeability in a reservoir. It can be defined as effective porosity, which excludes isolated pores and pore volume occupied by water adsorbed on clay minerals or other grains or total porosity, which is the total void space in the rock whether or not it contributes to fluid flow. Effective porosity is typically less than total porosity. As such it is a function of estimating the inplace hydrocarbon from Equation 4.2 2.1 below.

$$
I H I P=\frac{1540 A h \varphi\left(1-S_{w c}\right) P_{i}}{z_{i} T}
$$

Equation 2.1

Where, IHIP is defined as the initial hydrocarbon-in-place, A - reservoir area, $\mathrm{h}$ - pay zone thickness, $\Phi$ - porosity, $S_{\mathrm{wc}}-$ initial water saturation, $\mathrm{P}_{\mathrm{i}}-$ initial reservoir pressure, $\mathrm{z}_{\mathrm{i}}-$ initial compressibility factor, $\mathrm{T}$ - reservoir temperature

\section{Permeability:}

This is defined as the quantity of fluid (usually hydrocarbon) that can flow from the rock as a function of time and pressure. Absolute permeability is defined as the ability to flow or transmit fluids through a rock, conducted when a single fluid, or phase, is present in the rock.

\subsection{Previous Carbon Dioxide-Gas-Condensate Studies}

Very little has been done with regard to carbon dioxide sequestration into gas-condensate reservoirs.

At the fourteenth symposium on "Improved Oil Recovery" - Adisoemarta et al. presented a paper on compressibility factor (z-factor) measurements at various compositions of $\mathrm{CO} 2$ with hydrocarbon (HC) gas mixtures. Their experiments were performed at three temperatures of $100^{\circ} \mathrm{F}$, $160^{\circ} \mathrm{F}$ and $220^{\circ} \mathrm{F}$ and pressures ranges from 50 psia to 5000 psia as representative of depleted gas 
reservoirs (DGRs) for the sole purpose of measured z- factor data. They categorized gas types by representative compositional analysis for three types of gas reservoirs (dry gas, wet gas and retrograde gas) in order to analyze the various phase behavior to be encountered in gas reservoirs.

Their results were then used to interpret the expected phase behavior to be encountered in the geologic storage of $\mathrm{CO} 2$ in gas reservoirs. Also, the $\mathrm{z}$-factor measurements of the $\mathrm{CO} 2$-retrograde gas mixtures were used to evaluate the impact on enhanced oil and condensate recovery. They concluded that:

1. The laboratory measured $\mathrm{CO} 2 \mathrm{z}$-factor is much lower than hydrocarbon gas mixtures at the specified temperatures and pressures, which will offer the opportunity to store larger surface volumes of $\mathrm{CO} 2$ than hydrocarbon gases.

2. Five times the storage is possible depending on pressure, temperature and hydrocarbon gas composition.

Shtepani presented a paper on "CO2 Sequestration in Depleted Gas/Condensate Reservoirs". The objective of this paper was to discuss an approach that relates primarily to the laboratory and modeling studies that precede compositional simulations and field pilot testing of $\mathrm{CO} 2$ sequestration in depleted gas-condensate reservoirs. In addition to PVT experiments performed, he performed a special core flood test, designed to determine the micro-scale conformance of the $\mathrm{CO} 2$ displacement, to identify $\mathrm{CO} 2$ breakthrough characteristics at density and compositional level during liquid revaporization and repressurization process and to evaluate the recovery performance. From his laboratory experiments he found that:

1. Properties of depleted gas-condensate reservoirs and of $\mathrm{CO} 2$ are favorable for repressurization and enhanced gas recovery processes.

2. Several important factors such as the core length, injection rate can have a great effect on the mechanism, stability and on the breakthrough and ultimate recoveries.

3. Large scale factors such as reservoir heterogeneity and reservoir scale fingering cannot be represented in core displacement experiments. 
He also performed a Constant Composition Expansion (CCE) experiment and measured the saturation pressure and the liquid dropout on four different CO2-gas-condensate mixtures with 20, 40, 60 and 80 mole \% CO2 additions, respectively. At 80 mole \% CO2 addition there was no retrograde liquid observed and the mixture was in single phase gas.

Adbullah et al. investigated the fractional condensate recovery and relative permeability following super critical carbon dioxide (SCCO2) injection, methane injection and their mixtures. They performed their investigations at $5900 \mathrm{psi}$ and $95-160{ }^{\circ} \mathrm{C}$ at a constant flowing velocity of $10 \mathrm{~cm} / \mathrm{h}$. The results demonstrated that:

1. SCCO2 injection appears to offer less capillary instabilities and better mobility ratios resulting in a delayed breakthrough and favorable condensate sweep efficiency (79\% recovery and 0.62 Pore Volume (PV) Breakthrough (BT)) as opposed to the injection of SCCO2-methane mixtures, or pure methane injection (45\% recovery and $0.27 \mathrm{PV}$ BT).

2. The relative permeability curves to condensate improve following SCCO2 injection due to decrease in condensate-to-gas viscosity ratio.

3. On the gas-gas side, experiments confirmed that the greater the methane concentration in the reservoir gas (i.e. less $\mathrm{CO} 2$ contamination) the better relative permeability and sweep efficiency data become at the flooding temperatures and pressures.

Barrufet et al. investigated "The Storage Capacity for CO2 Sequestration of a Depleted GasCondensate Reservoir and a Saline Aquifer". In conformance with other reviewed literature they reiterated that the condensate that has dropped out from the gas phase during natural depletion will revaporize due to repressurization of the reservoir and by miscibility with the injected $\mathrm{CO} 2$.

They also found that when the CO2 stream contains impurities such as nitrogen or methane, the storage capacity of the reservoir decreases proportionally to the impure stream's compressibility factor and its concentration of impurities. He demonstrated that the mass of $\mathrm{CO} 2$ sequesterd per pore volume in the equivalent aquifer model is about 13 times lower that of the depleted gascondensate reservoir model, which he attributed due to the aquifer's low overall compressibility. 


\subsection{Reservoir Simulation Model}

Computer Modelling Group (CMG) is the largest independent developers of reservoir simulation software providing practical solutions for oil/gas reservoir modeling and simulation, advanced Windows ${ }^{\mathrm{TM}}$ software, advanced oil recovery (EOR/IOR) processes, reservoir engineering, consulting, training and technical support for clients around the world. From CMG's suite of software tools the following were used in this research: WinProp, Builder, Results 3D, Results Graph and Results Report

"WinProp" is a Microsoft Windows ${ }^{\mathrm{TM}}$ based software application designed for modeling the phase behavior and properties of reservoir fluids. It is CMG's equation of state multiphase equilibrium and properties determination program. This comprehensive EOS engineering tool assists engineers in understanding the distribution of properties within their reservoir fluid system under various depletion scenarios, and the interaction with injected fluids, from small-scale lab experimentation, to large-scale field effects. It features techniques for characterizing the heavy end of a petroleum fluid, lumping of components, matching laboratory PVT data through regression, simulation of first and multiple contact miscibility, phase diagrams generation, asphaltene and wax precipitation modeling, compositional grading calculations as well as process flow simulation.

The "Builder" series is a set of applications used in the preparation of reservoir simulation models. It is way for reservoir modelers to design and prepare reservoir models faster and in a more efficient manner. It also has a Windows interface, which organizes data in a systematic way, unconstrained by simulator keywords.

CMG's GEM is a general EOS based compositional reservoir simulator for modeling the flow of three-phase, multi-component fluids. It is a robust, fully compositional simulator used to model any type of reservoir where the importance of the fluid composition and their interactions are essential to the understanding of the recovery process

GEM provides extensive well management options, plus a flexible set of surface separator facilities, including EOS and gas plant separator stages, enabling the modeling of flow from the sand face to the outlets of the separator trains. 
GEM simulates a variety of structurally complex and varying fluid combinations beyond the conventional black oil simulators as well as K-value compositional simulators. Whether one is dealing with laboratory scale projects, pilot areas, elements of symmetry, of full-scale field studies, GEM will effectively model:

- Single and multi-component CBM recovery

- Gas-condensate recovery

- Volatile oil reservoirs

- $\mathrm{CO} 2$ and hydrocarbon injection

- Gas cycling and re-cycling

- WAG processes

- Numerous other reservoir management processes

"Results" is CMG's set of post-processing applications designed for visualizing and reporting simulator output. "Results" users can efficiently analyze the output from CMG simulators, prepare $2 \mathrm{D}$ and $3 \mathrm{D}$ plots, generate various informative graphs, and prepare tables of required information to be included in a study report.

"Results" is currently composed of three modules:

- Results 3D - 2D and 3D views.

- Results Graph - user-definable XY graphs

- Results Report - user-definable tabular reports 


\section{OBJECTIVE AND METHODOLOGY}

The goal of this study was to investigate the impact of carbon dioxide sequestration in a gascondensate reservoir using a compositional simulator. More specifically, the objective of this study is to evaluate the impact of carbon dioxide injection on condensate recovery and subsequent increase in the amount of carbon dioxide sequestered. The following procedure was developed to achieve the objective:

- To investigate the phase behavior of various mixtures of gas-condensate and carbon dioxide fluids.

- To develop a practical model with an efficient and effective injection plan to improve liquid recovery.

- To evaluate the impact of reservoir heterogeneity, petrophysical properties, and injection rate on liquid recovery.

- To compare the use of methane and nitrogen as injection gases to carbon dioxide and their impact on liquid recovery.

- To quantify the amount of carbon dioxide sequestered due to pore space availability from enhanced liquid recovery.

\subsection{PVT Analysis}

For this research all PVT analysis was simulated using WinProp in order to evaluate the behavior of $\mathrm{CO} 2$ gas-condensate mixture at initial conditions. The following applications were used based on the objectives of this study:

- Constant Volume Depletion

- Two-phase Envelope

- Saturation Pressure

- General EOS Model (GEM) 


\subsubsection{Constant Volume Depletion (CVD)}

The CVD test was performed at a reservoir temperature of $200^{\circ} \mathrm{F}$. Five depletion pressure levels ranging from 4000 psi to 500 psi were selected to perform the test. An initial guess of 3000 psi was used for the saturation pressure Separator conditions were left as default; that is 2-stage separator at $450 \mathrm{psi}$ and $100 \mathrm{psi}$ and $75^{\circ} \mathrm{F}$ temperature. The feed composition was set to one, which meant that the CVD analysis was only performed on the gas-condensate. Various mixtures of gas-condensate and $\mathrm{CO} 2$ with $\mathrm{CO} 2$ being added in 10 mole $\%$ increments of total mixture up to 50 mole $\%$ of total mixture were investigated using CVD. This was done by varying the feed fraction of the primary composition (zero mole\% $\mathrm{CO} 2$ in total mixture).

\subsubsection{Two-Phase Envelope}

This gives a visual description of the phases that exist at reservoir conditions. Fluids outside the two-phase envelope are either single phase liquid, single phase gas, or critical fluid. Within the envelope; there is a mixture of the two phases. Two-phase envelope generates the boundaries between the single-phase and two-phase regions. The bubble point envelope corresponds to the boundary between a single-phase liquid region and a two-phase vapor-liquid region; the dew point envelope corresponds to the boundary between the single-phase vapor region and the two-phase region. There are two main classes of diagrams that can be generated: X-Y phase envelopes and pseudo-ternary phase diagrams.

For the purpose of this investigation, X-Y phase envelopes were used. These diagrams are displayed on regular cartesian coordinates. There are three options for X-Y phase envelopes:

- Pressure-temperature,

- Pressure-composition,

- Temperature-composition. 


\subsubsection{Saturation Pressure}

This test estimated the saturation pressure for the gas-condensate composition used. A reservoir pressure of $200{ }^{\circ} \mathrm{F}$ along with an initial saturation pressure guess of 3000 psi determined the saturation pressure of this gas-condensate. A saturation pressure of 3881 psi was estimated.

\subsubsection{GEM}

This writes PVT data in a format ('*.gem’ file) usable to CMG GEM EOS Simulator model that will be used in developing the reservoir model. This application requires a specific temperature to generate the '*.gem' file. The reservoir temperature is selected as this temperature.

\subsection{Reservoir Model Description}

"Builder" was used in the development of the reservoir model. The basis of the model was to simulate a depleted retrograde gas-condensate reservoir. A 20 × 20 grid system with 5 layers was used in this analysis. The base case (BC) model was a homogeneous one with permeability in the ' $i$ ' and ' $j$ ' being the same and ' $k$ ' direction one tenth that of ' $i$ '.

Data entry in the model included defining the actual grid size and grid properties, rock properties, importing the gas-condensate composition developed in WinProp and the EOS used; the initial conditions for simulation and number of wells, well trajectories and constraints. Table 3.1 below shows the gas-condensate composition that was generated in WinProp and imported into Builder as the initial reservoir composition.

Two wells (Prod_1 and Inj_1) located in grid blocks $\left(17,3,1: 5^{1}\right)$ and $(6,15,1: 5)$ respectively, both of which are perforated in all layers are used for reservoir depletion and carbon dioxide sequestration. Figure 3.1 below shows the well locations. The location of the injection well is selected such that to achieved even and efficient distribution of $\mathrm{CO} 2$ throughout the reservoir.

${ }^{1}$ 1:5: All 5 layers are perforated 
Prod_1 well is located at a location that is both far from the Inj_1 well and centralized, i.e. not at the reservoir boundary.

Table 3.1 Gas-condensate Composition

\begin{tabular}{|c|c|}
\hline Component & Mole Fraction \\
\hline $\mathrm{C} 1$ & 0.7304 \\
\hline $\mathrm{C} 2$ & 0.0857 \\
\hline $\mathrm{C} 3$ & 0.0453 \\
\hline $\mathrm{NC} 4$ & 0.0340 \\
\hline $\mathrm{NC} 5$ & 0.0189 \\
\hline FC6 & 0.0164 \\
\hline $\mathrm{CO} 2$ & 0.0005 \\
\hline FC10 & 0.0688 \\
\hline $\mathrm{N} 2$ & 0.0000 \\
\hline
\end{tabular}

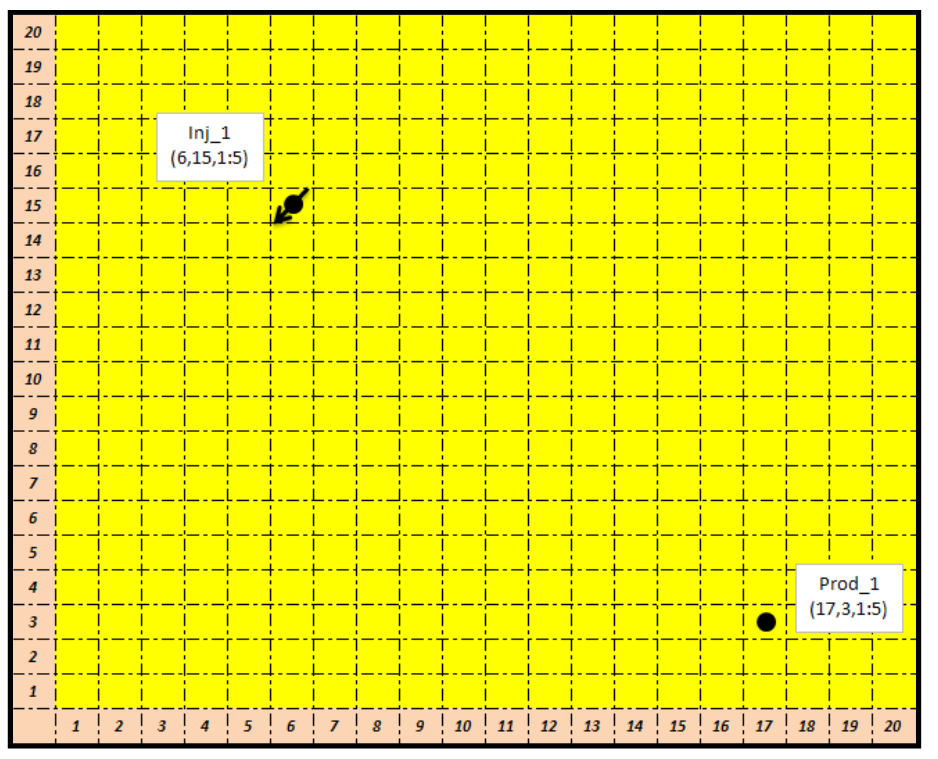

Figure 3.1: Well Locations

A 5 layer Cartesian rectangular $20 \times 20$ grid system was developed. The array properties were selected based on conditions typical for a depleted retrograde gas-condensate field. Below lists the array properties used as data entry into the BC model. 


\begin{tabular}{|l|r|}
\hline Array Property & Value \\
\hline i thickness & $240 \mathrm{ft}$ \\
\hline j thickness & $240 \mathrm{ft}$ \\
\hline k thickness (total) & $130 \mathrm{ft}$ \\
\hline Grid Top & $7545 \mathrm{ft}$ \\
\hline Porosity & $13 \quad \%$ \\
\hline Permeability i & $150 \mathrm{md}$ \\
\hline Permeability j & $150 \mathrm{md}$ \\
\hline Permeability k & $15 \mathrm{md}$ \\
\hline
\end{tabular}

A typical rock compressibility value of $4 \times 10^{-6} \mathrm{psi}^{-1}$ was assumed in order for the model to run. The Peng-Robinson EOS was used for this model with a reservoir temperature of $200{ }^{\circ} \mathrm{F}$.

\subsection{Relative Permeability}

A rock type is defined in 'Builder' by including rock type properties, relative permeability tables and hysteresis-modeling. No data were available to define the rock fluid properties. The water-oil and the liquid -gas relative permeability tables were selected from the Third SPE Comparative Solution Project: Gas Cycling of Retrograde Gas Condensate Reservoirs, SPE 12278 (Kenyon \& G. Alda, 1987). "Smooth Table" is a self explanatory tool used to smooth the unedited relativity permeability curves in order to make them acceptable for reservoir simulation. The data obtained had a connate water saturation of $16 \%$; however this was modified to a connate saturation of $28 \%$. No capillary pressure was incorporated into the model. Table 3.2, Figure 3.2 and Figure 3.3 show the data and relative permeability curves used for model development.

Table 3.2: Relative Permeability Tables

\begin{tabular}{|c|c|c|c|c|c|}
\hline \multicolumn{3}{|c|}{ Gas-Liquid } & \multicolumn{3}{c|}{ Water-Oil } \\
\hline SI & Krg & Krog & Sw & Krow & Krw \\
\hline 0.28 & 0.740 & 0.000 & 0.28 & 0.740 & 0.000 \\
\hline 0.30 & 0.680 & 0.000 & 0.30 & 0.680 & 0.002 \\
\hline 0.32 & 0.620 & 0.000 & 0.32 & 0.620 & 0.010 \\
\hline 0.34 & 0.562 & 0.000 & 0.34 & 0.562 & 0.020 \\
\hline
\end{tabular}




\begin{tabular}{|l|l|l|l|l|l|}
\hline 0.36 & 0.505 & 0.000 & 0.36 & 0.505 & 0.033 \\
\hline 0.38 & 0.450 & 0.000 & 0.38 & 0.450 & 0.049 \\
\hline 0.40 & 0.400 & 0.000 & 0.40 & 0.400 & 0.066 \\
\hline 0.44 & 0.348 & 0.005 & 0.44 & 0.348 & 0.090 \\
\hline 0.48 & 0.300 & 0.012 & 0.48 & 0.300 & 0.119 \\
\hline 0.52 & 0.260 & 0.025 & 0.52 & 0.260 & 0.150 \\
\hline 0.56 & 0.222 & 0.040 & 0.56 & 0.222 & 0.186 \\
\hline 0.60 & 0.187 & 0.060 & 0.60 & 0.187 & 0.227 \\
\hline 0.64 & 0.156 & 0.082 & 0.64 & 0.156 & 0.277 \\
\hline 0.68 & 0.126 & 0.112 & 0.68 & 0.126 & 0.330 \\
\hline 0.72 & 0.100 & 0.150 & 0.72 & 0.100 & 0.390 \\
\hline 0.76 & 0.078 & 0.196 & 0.76 & 0.078 & 0.462 \\
\hline 0.80 & 0.058 & 0.250 & 0.80 & 0.058 & 0.540 \\
\hline 0.84 & 0.040 & 0.315 & 0.84 & 0.040 & 0.620 \\
\hline 0.88 & 0.026 & 0.400 & 0.88 & 0.026 & 0.710 \\
\hline 0.92 & 0.013 & 0.513 & 0.92 & 0.013 & 0.800 \\
\hline 0.96 & 0.005 & 0.650 & 0.96 & 0.005 & 0.900 \\
\hline 1.00 & 0.000 & 0.800 & 1.00 & 0.000 & 1.000 \\
\hline
\end{tabular}

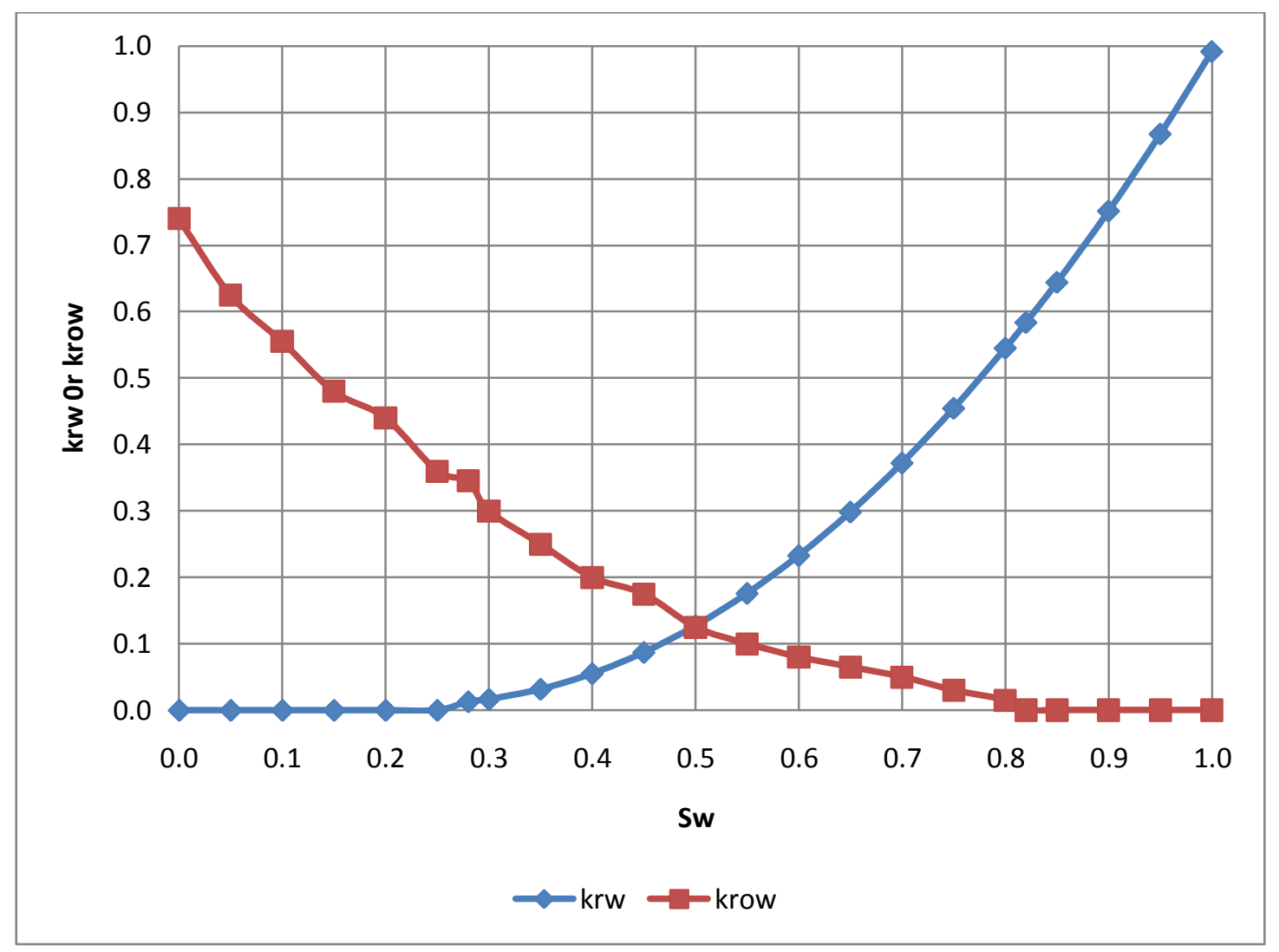

Figure 3.2: Oil-water relative permeability curves 


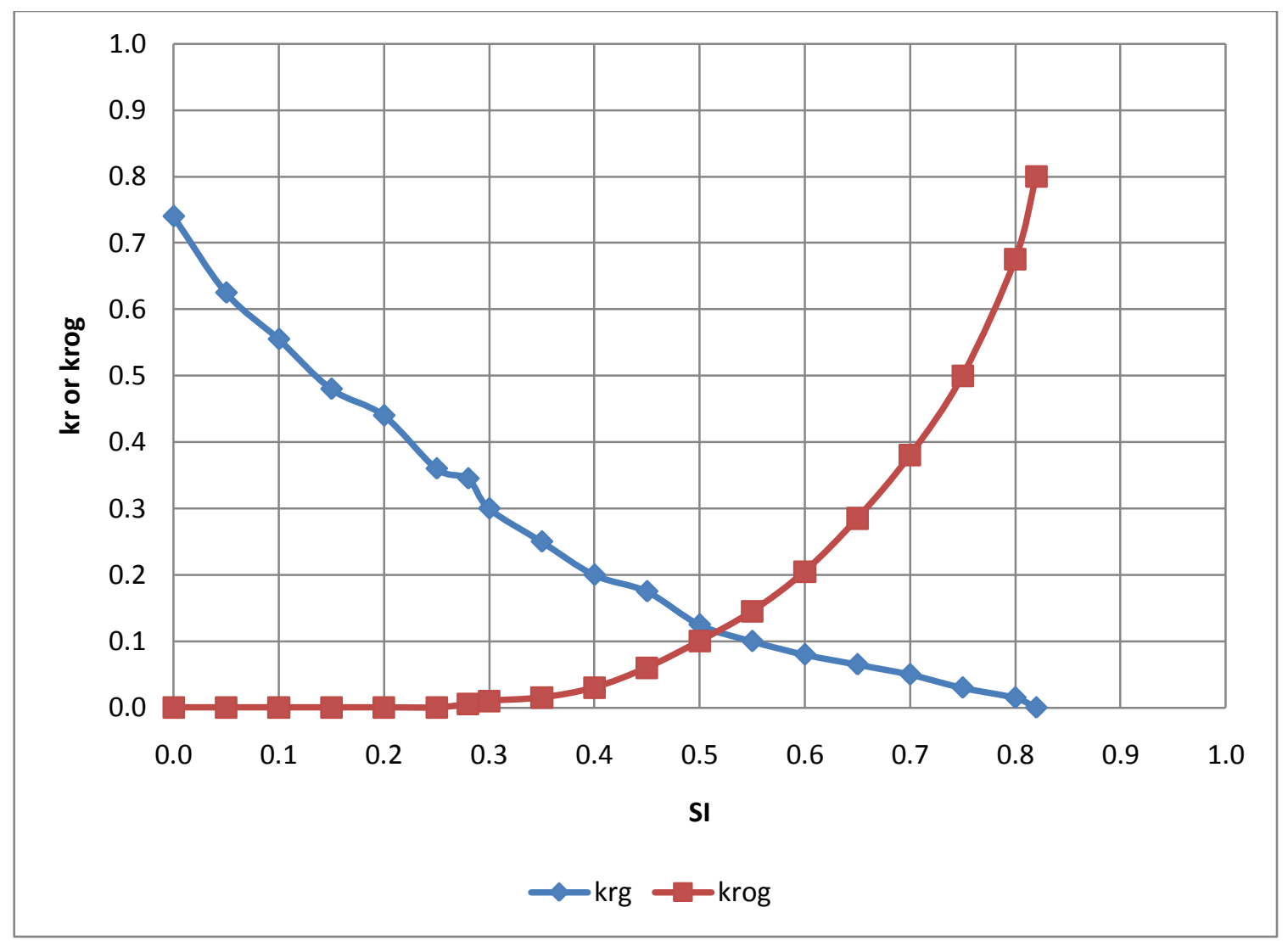

Figure 3.3: Gas-liquid relative permeability curves

\subsection{Initial Conditions}

The calculation methods were set as "Block saturation at each grid block average over the depth interval spanned by the grid block". Gravity-capillary equilibrium was performed for a reservoir initially containing water and gas with no transition zone between the water and gas. Phase pressure correction was added, as a default, to ensure that the reservoir was initially in gravitational equilibrium. The following lists the initialization region parameters:

\begin{tabular}{|l|rl|}
\hline Reference Pressure & 4500 & $\mathrm{psi}$ \\
\hline Water-Gas Contact & 12000 & $\mathrm{ft}$ \\
\hline Water Saturation below contact & 20 & $\%$ \\
\hline
\end{tabular}


A contact depth was required and was chosen lower than the grid bottom in reference to ensure that no water is attached to reservoir as a drive mechanism. Additionally a gas-cap composition was required and this composition was selected from WinProp (Insert Composition). The gas-cap initialization contained no residual oil saturation.

\subsection{Production and Injection Wells}

Table 3.2 below shows the production and injection schedule for the base case (BC) model. Year 1986 is the start of simulation. Firstly, the reservoir is depleted to an abandonment pressure of 500 psia (Prod_1); 22 years are required for such depletion (1986-2008). After which, on the basis of not exceeding the gas cap pressure of 4500 psia and ensuring an injection period of 2 years, an injection rate of 110 MMSCFD pure CO2 is thus used to pressurize the reservoir, (Inj_1: 20082010).

Once reservoir repressurization is achieved, cycling is commenced. A cycling rate of 110 MMSCFD is used for a 5 year period, (2010-2015). More CO2 is then injected into the reservoir at the same rate to achieve a final bottom hole pressure of 4500 psia. $(1 / 2 / 2015-4 / 21 / 2015)$

Table 3.3: Production and Injection Schedule

\begin{tabular}{|c|c|c|c|c|c|}
\hline \multirow{2}{*}{ Well } & \multicolumn{2}{|c|}{ Year } & Duration & \multicolumn{2}{c|}{ Constraint } \\
\cline { 2 - 5 } & Start (open) & $\begin{array}{c}\text { Stop } \\
\text { (closed) }\end{array}$ & (Days) & $\begin{array}{c}\text { Surface Gas } \\
\text { Rate } \\
\text { (mmscfd) }\end{array}$ & $\begin{array}{c}\text { Bottomhole } \\
\text { Pressure } \\
\text { (psia) }\end{array}$ \\
\hline Prod_1 & $1 / 1 / 1986$ & $1 / 1 / 2008$ & 8035 & 10 & 500 \\
\hline Inj_1 & $1 / 1 / 2008$ & $1 / 2 / 2010$ & 732 & 110 & 4500 \\
\hline Prod_1:Cycle & $1 / 2 / 2010$ & $1 / 2 / 2015$ & 1826 & 110 & - \\
\hline Inj_1: Cycling & $1 / 2 / 2010$ & $1 / 2 / 2015$ & 1826 & 110 & - \\
\hline Inj_1 & $1 / 2 / 2015$ & $4 / 21 / 2015$ & 109 & 110 & 4500 \\
\hline
\end{tabular}

As can be seen in Table 3.2, a cycling period of 5 years is selected. The objective here is to recover as much of the condensed vapors in short period of time. Longer cycle periods did not impact the 
liquid recovery that significantly. The amount of liquid recovered at the end of cycle period will be the basis of comparison with other simulation runs.

\subsection{Initial Reservoir Conditions}

The following tables summarize the initial reservoir conditions. Initially the reservoir fluid is single phase gas. Once the reservoir pressure drops below the dew point pressure, 3881 psi, condensate will start dropping out in the reservoir.

A 3-stage separator, having conditions stated in the Table 3.4 below, was used to separate the surface liquid and gas.

Table 3.4: Initial reservoir conditions calculated by GEM Simulator

\begin{tabular}{|c|c|}
\hline Reservoir & \\
\hline Ave. Pressure, psia & $4.51 \times 10^{3}$ \\
\hline Ave. Porosity & 0.13 \\
\hline Total Bulk Reservoir Volume, res ft3 & $3.00 \times 10^{9}$ \\
\hline Total Pore Volume, res $\mathrm{ft} 3$ & $3.89 \times 10^{8}$ \\
\hline Total Hydrocarbon Pore Volume, res ft3 & $2.80 \times 10^{8}$ \\
\hline Gas Phase & \\
\hline Ave. gas saturation & 0.72 \\
\hline Ave. gas phase pressure, psia & $4.51 \times 10^{3}$ \\
\hline Ave. gas phase $\mathrm{z}$ factor & 0.88190 \\
\hline Shrinkage factor, OGIP/std vol of free gas & 0.80766 \\
\hline Total moles, mol & $9.18 \times 10^{10}$ \\
\hline Water Phase & \\
\hline Ave. water saturation & 0.28 \\
\hline Total moles of dissolved hydrocarbon, mol & 0 \\
\hline Total moles, mol & $1.74 \times 10^{11}$ \\
\hline Fluid Properties & \\
\hline
\end{tabular}




\begin{tabular}{|c|c|}
\hline Relative gas volume, res ft3/std ft3 & 0.00456 \\
\hline Solution gas-oil-ratio, std ft3/std bbl & 0 \\
\hline Original Gas in Place, OGIP, std ft3 & $6.15 \times 10^{10}$ \\
\hline In Gas Zone & 0 \\
\hline Dissolved Gas in Oil Zone & 0 \\
\hline Dissolved Gas in Water Zone & $6.15 \times 10^{10}$ \\
\hline Total OGIP & $1.97 \times 10^{7}$ \\
\hline Original Water in Place, OWIP, std bbl & \\
\hline
\end{tabular}

Table 3.5: Separator Conditions

\begin{tabular}{|c|c|c|c|c|}
\hline Stage & Pressure & Temperature & Output & Destination \\
\hline & psia & degF & Liquid & Vapor \\
\hline 1 & 800 & 80 & OIL & Input to Stage 2 \\
\hline 2 & 100 & 60 & OIL & Input to Stage 3 \\
\hline 3 & 14.7 & 60 & OIL & GAS \\
\hline
\end{tabular}

\subsection{Reservoir Heterogeneity}

PVT studies do not account for the impact of porous media on CO2 sequestration. Such impact includes non-uniform mixing in the reservoir. To study the impact on porous media, reservoir heterogeneities such as layered-permeability and permeability streaks are incorporated into the reservoir model and then simulated. The simulation runs are then compared with the $\mathrm{BC}$ run to evaluate the impact of porous media on $\mathrm{CO} 2$ sequestration.

\subsubsection{Layered-Permeability (LP) Investigation}

In this model one of the layers of the $\mathrm{BC}$ is modified, whereby creating a region of high permeability. Figure 3.4 below is a sketch of how the layered-permeability looks. As shown in this figure, layer 3-permeability is changed from $150 \mathrm{md}$ to $1500 \mathrm{md}$ permeability. The thickness of each layer is also modified to represent a thin-high permeable layer. $10 \mathrm{ft}$ is used for the high 
permeability layer. The thickness of the other 4 layers is changed to $30 \mathrm{ft}$ so that the total grid thickness remains the same as the total thickness of the BC. The wells are perforated in all layers.

\begin{tabular}{|c|c|c|}
\hline 5 & $150 \mathrm{md}$ & $30 \mathrm{ft}$ \\
\hline 4 & $150 \mathrm{md}$ & $30 \mathrm{ft}$ \\
\hline 3 & $1500 \mathrm{md}$ & $10 \mathrm{ft}$ \\
\hline 2 & $150 \mathrm{md}$ & $30 \mathrm{ft}$ \\
\hline 1 & $150 \mathrm{md}$ & $30 \mathrm{ft}$ \\
\hline
\end{tabular}

Figure 3.4: Layered-Permeability Schematic

Apart from the thin-high permeable layer, other layered-permeability scenarios are also investigated. For these scenarios, all layers have the same thickness of $26 \mathrm{ft}$ and the highpermeable layer location is changed through the 5 layers.,

\subsubsection{Streak-Permeability (SP) Investigation}

In this model, the permeability in the blocks connecting the production and injection wells (Prod_1 and Inj_1) are changed 1500 md in all layer creating a region of high permeability called streakpermeability as illustrated in Figure 3.5. All layers have the same thickness of $26 \mathrm{ft}$.

Another streak-permeability case where only layer 3 had the 24 block-1500md streak is also investigated for comparative purposes. 


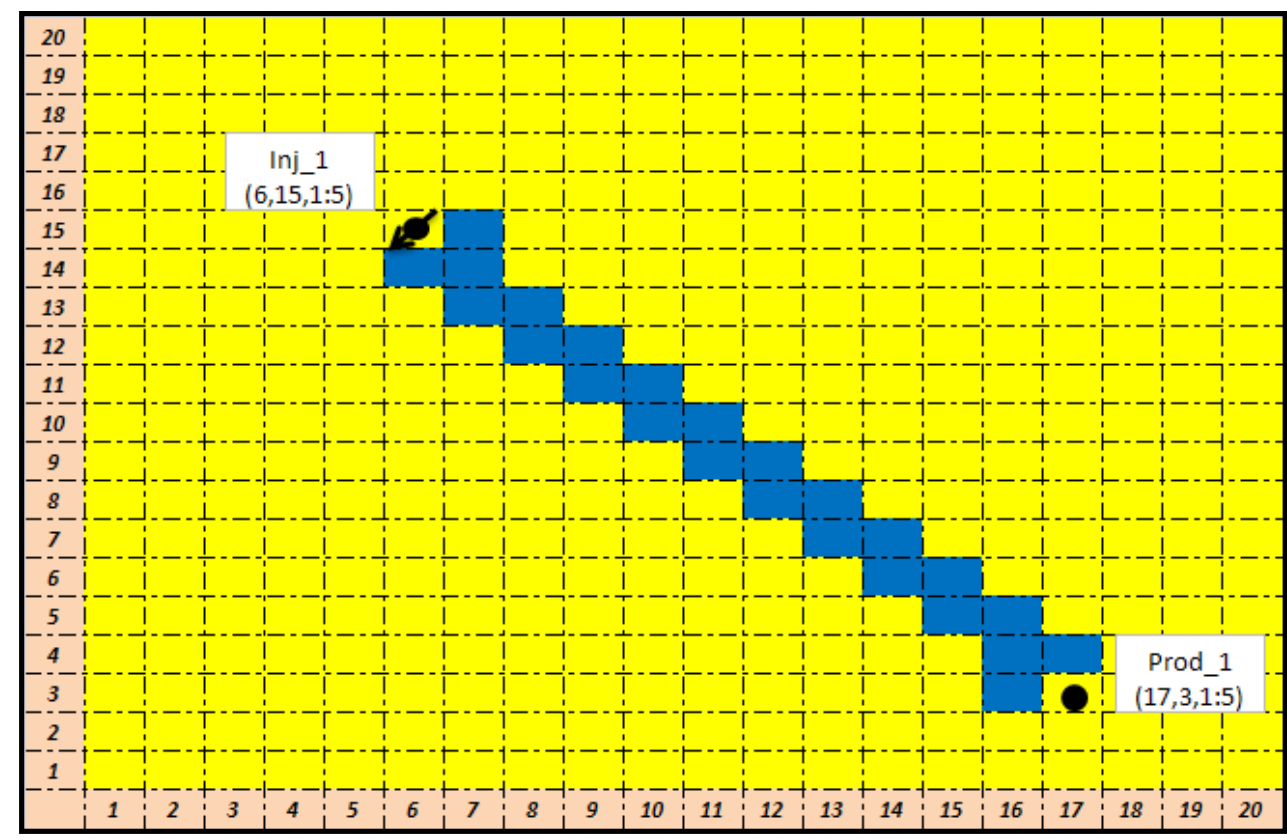

Figure 3.5: Schematic of a streak permeability region

\subsection{Petrophysical Properties}

\subsubsection{Reservoir Permeability}

Two cases with reservoir permeability of $250 \mathrm{md}$ and $70 \mathrm{md}$ are also investigated to evaluate the effects of permeability of carbon dioxide sequestration.

\subsubsection{Reservoir Porosity}

Two cases with formation porosity of $16 \%$ and $20 \%$ are also used to compare with the $\mathrm{BC}$ model of $13 \%$.

\subsection{Injection Rate}

For comparison a slower injection rate of 45.5MMSCFD for comparison with the base case of 110 MMSCFD was considered. Table 3.6 below lists the production and injection schedule in. 
Table 3.6: Production and Injection Schedule for a rate of 45.5 MMSCFD

\begin{tabular}{|c|c|c|c|c|c|}
\hline \multirow{2}{*}{ Well } & \multicolumn{2}{|c|}{ Year } & Duration & \multicolumn{2}{c|}{ Constraint } \\
\cline { 2 - 6 } & Start (open) & $\begin{array}{c}\text { Stop } \\
\text { (closed) }\end{array}$ & (Days) & $\begin{array}{c}\text { Surface Gas } \\
\text { Rate } \\
\text { (mmscfd) }\end{array}$ & $\begin{array}{c}\text { Bottomhole } \\
\text { Pressure } \\
\text { (psia) }\end{array}$ \\
\hline Prod_1 & $1 / 1 / 1986$ & $1 / 1 / 2008$ & 8035 & 10 & 500 \\
\hline Inj_1 & $1 / 1 / 2008$ & $12 / 4 / 2012$ & 1799 & 45.5 & 4500 \\
\hline Prod_1:Cycle & $12 / 4 / 2012$ & $1 / 1 / 2025$ & 4411 & 45.5 & - \\
\hline Inj_1: Cycling & $1 / 1 / 2025$ & $10 / 6 / 2055$ & 11235 & 45.5 & - \\
\hline Inj_1 & $1 / 1 / 2025$ & $10 / 6 / 2055$ & 11235 & 45.5 & 4500 \\
\hline
\end{tabular}

\subsection{Type of Gas}

To compare the use of carbon dioxide for enhanced liquid recovery in gas-condensate reservoirs, nitrogen and methane gases are used to pressurize the reservoir to 4500 psia and during cycling. As with the BC a 5 year cycle period is used at which point simulation ceases. 


\section{RESULTS AND DISCUSSIONS}

\subsection{Phase Behavior Results}

The following shows the graphical results for the PVT analyses using WinProp:

\subsubsection{Pressure-Temperature (PT) Diagram}

PT diagrams were generated for carbon dioxide- gas-condensate (CO2-GC) mixtures, illustrating the variation of phase behavior over a range of temperatures and pressures. Conditions of pressure and temperature that fall within the envelope exhibit a fluid mixture of liquid and vapor. Outside of the two phase region fluids are either single-phase liquid, single-phase gas or a critical fluid depending on the relative position of the critical point. Figure 4.1 below shows PT results obtained when mixing various compositions from 10 mole $\%$ to 50 mole $\%$ of carbon dioxide with gas condensate. The following can be observed from Figure 4.3:

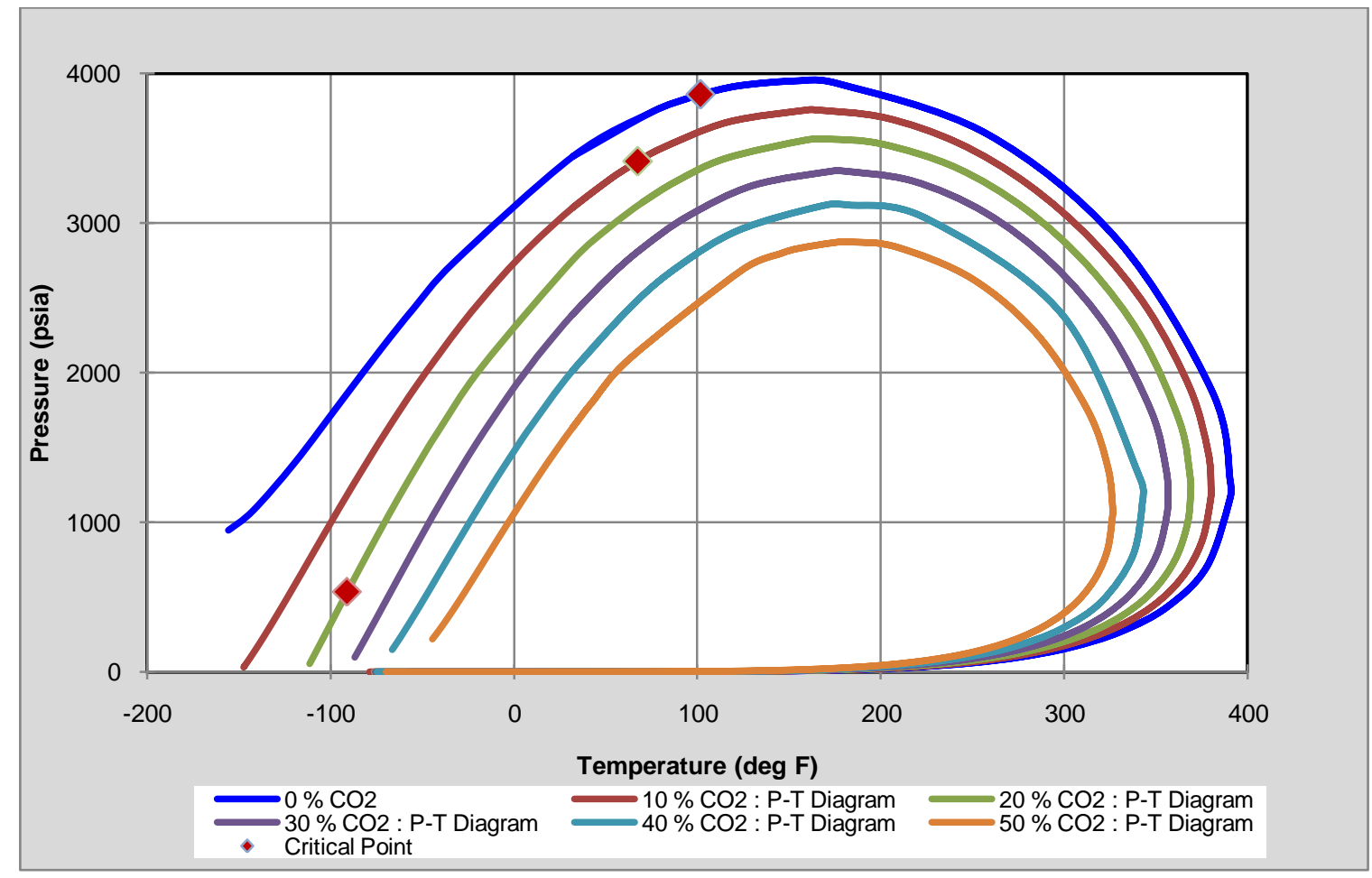

Figure 4.1: Effects of CO2-GC mixture on two-phase envelope for $\mathrm{CO} 2$ mole fraction - 0 mole \% to 50 mole \% 
- PT envelope decreases with increasing carbon dioxide concentration

- Cricondentherm decreases with increasing carbon dioxide concentration

- Cricondenbar decreases with increasing carbon dioxide concentration

- Both the critical temperature and critical pressure decreases with carbon dioxide concentration

The trends observed in Figure 4.3 show the relative "drying-effect" of carbon dioxide, which is explained by the shrinking two phase envelope, when increasing carbon dioxide concentration. The shrinking of the two-phase envelope indicates that partial revaporization of the condensed liquid into the gaseous phase: this phenomenon increasing with increasing carbon dioxide concentration. The lowering of the cricondentherm with increasing carbon dioxide concentration suggests a tendency for the removal of the two phase region: That is when the cricondentherm drops below the reservoir temperature allowing for the presence of only one phase, gas. However, condensate will still be produced, though in the surface separators as the conditions of the separator warrants condensate formation (Table 3.4). The trend of decreasing cricondenbar with increasing carbon dioxide indicates an easier tendency for liquid to move into its vapor phase.

All these trends emphasize the "drying-effect" of carbon dioxide. The trends also show that the immobile liquid is recovered by revaporization as explained by the shrinking two phase envelope. With regard to the objective of this study, more space becomes available with the recovery of the revaporized liquid, thus allowing for more carbon dioxide to be sequestered and stored.

\subsubsection{Saturation Pressure}

The saturation pressure is the pressure of a substance in which its vapor is in equilibrium with its liquid. This means that during pressure depletion condensation/liquid drop-out first occurs at this pressure. Figure 4.3 illustrates the general trend, which is with increasing carbon dioxide concentration the saturation pressure decreases. The saturation pressure decreases from 3,881psi (saturation pressure of the initial reservoir) to $1,853 \mathrm{psi}$ at carbon dioxide concentration of 50 mole $\%$. This suggests that liquid drop occurs are lower pressures with increasing carbon dioxide concentration or conversely more reservoir fluid is present in the gaseous phase. 
The trend shows that pressurizing the reservoir with carbon dioxide sequestration causes the condensate to revaporize, thus providing enhanced condensate recovery. Ultimately with the enhanced recovery, more pore space within the reservoir is available for carbon dioxide storage.

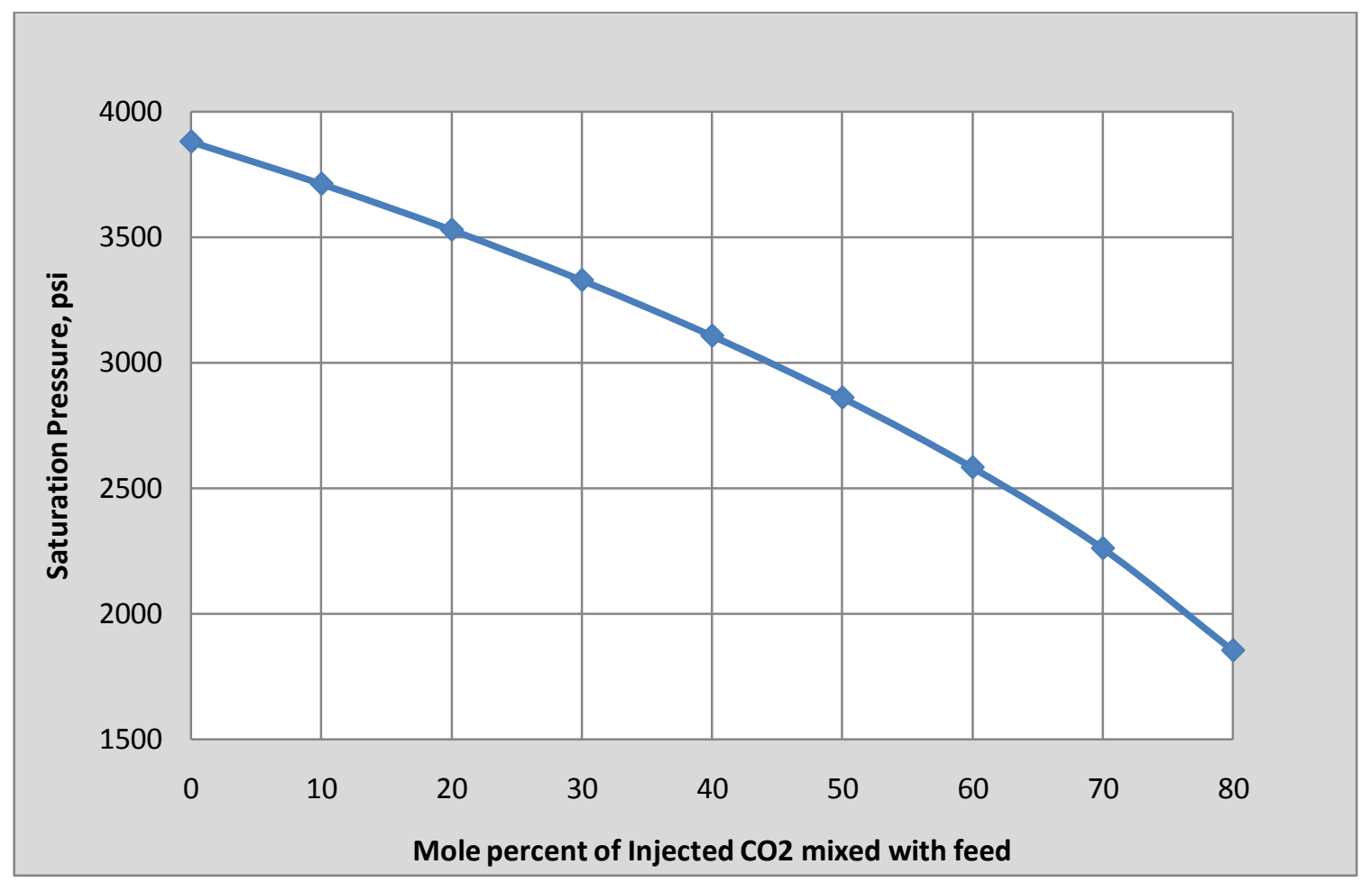

Figure 4.2: Effects of CO2-GC mixture on saturation pressure at $\mathrm{T}_{\mathrm{R}}$ of $200^{\circ} \mathrm{F}$

\subsubsection{Liquid Fraction}

Figure 4.3 shows the liquid recovery trend with increasing carbon dioxide concentration in the carbon dioxide- gas-condensate mixture. Initially from Figure 4.3 as pressure decreases, no liquid is present until a point, saturation pressure, is reach where liquid begins to form. The liquid volume increases to maximum followed by a decrease until abandonment pressure. The initial liquid increase phenomenon is representative of the retrograde behavior of gas-condensate fluid; the liquid decrease, after which, is a typical behavior that is observed during pressure depletion for liquid to vaporize. It is observed that all curves in Figure 4.3 show similar trends, however, with increasing carbon dioxide concentration, liquid recovery decreases and the pressure at which liquid 
begins to form also decreases. The maximum liquid formed decreases from $20 \%$ cell volume in the initial reservoir to $0.6 \%$ cell volume at carbon dioxide concentration of 80 mole $\%$.

Figure 4.3 also shows the "drying-effect' of carbon dioxide when mixed with a gas-condensate fluid. The liquid formed as a result of pressure depletion is being revaporized by the repressurization of the reservoir by carbon dioxide sequestration and as the concentration of the carbon dioxide increases more liquid is revaporized as is illustrated in Figure 4.3 by a decrease in $\%$ cell-liquid volume. This means that more condensate can be recovered as it is mobile in the vapor phase and thus recovered. More pore space is therefore available for carbon dioxide sequestration and storage.

Figure 4.3 also shows the decreasing saturation pressure with carbon dioxide concentration as evident by when liquid starts dropping out of the vapor phase. As explained earlier, this decreasing saturation increases the ultimate storage of carbon dioxide.

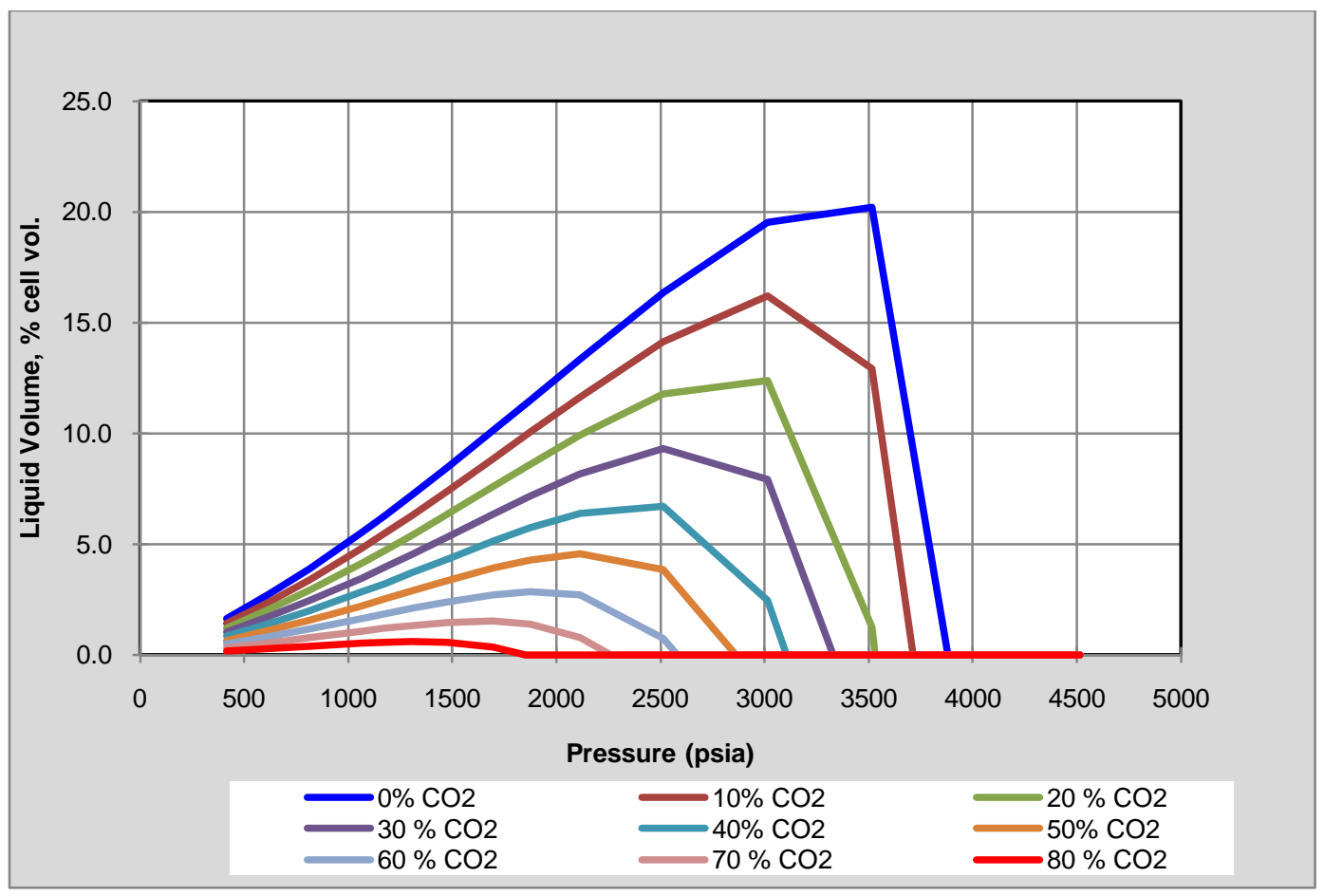

Figure 4.3: Effects of CO2-GC mixture on Liquid Recovery 


\subsubsection{Compressibility Factor}

The compressibility factor for the carbon dioxide-gas-condensate mixture was estimated using the Peng-Robinson EOS for two-phase flash calculations for $200^{\circ} \mathrm{F}$ and pressure range of 500 to 4500 psia. The trend observed in Figure 4.4 below shows that with increasing carbon dioxide concentration the carbon dioxide-gas-condensate mixture compressibility factor decreases.

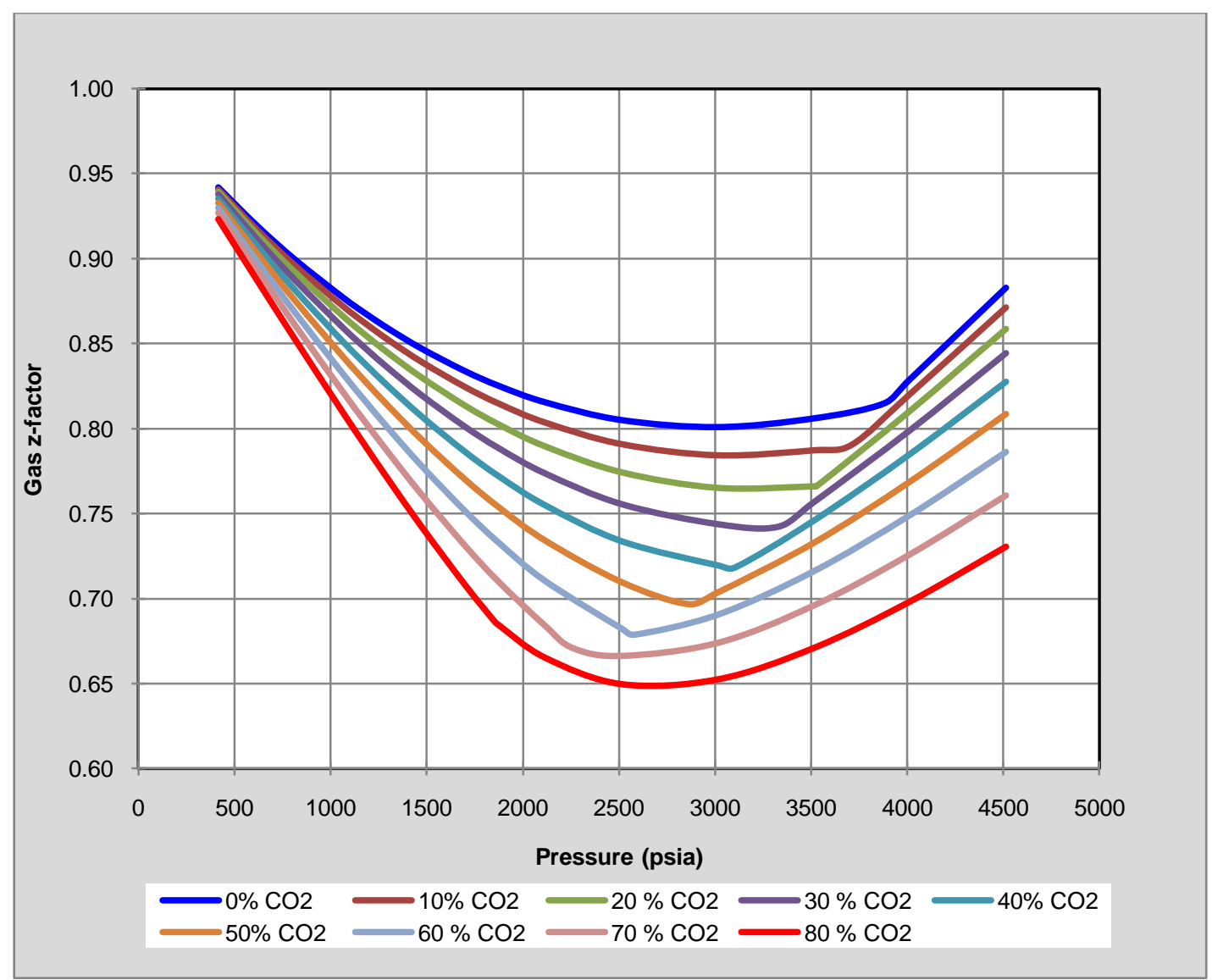

Figure 4.4: Effects of CO2-GC mixture on gas compressibility (z-factor)

For a compressibility factor less than one, the actual gas volume is less than the ideal volume of the gas. Conversely, if the compressibility factor is greater than one, the actual volume of the gas is greater than the ideal volume. The importance of this to carbon dioxide sequestration is realized by considering the formation volume factor $\left(\mathrm{B}_{\mathrm{g}}\right)$. The compressibility factor is directly proportional to $\mathrm{B}_{\mathrm{g}}$ as such if the compressibility factor of a gas sample increases for a given pressure and temperature, the formation volume factor increases (equation 4.1). 


$$
B_{g}=\frac{P_{s c} z_{r} T_{1}}{P_{v} \cdot Z_{s c} T_{s c}}
$$

Equation 4.1

Where 'sc' and ' $r$ ' are standard condition and reservoir condition respectively.

It is the objective of sequestration to inject and store as much carbon dioxide as the reservoir can support, hence for carbon dioxide sequestration operations, it is desirable to have a low formation volume factor. Therefore it is preferable to have a larger surface volume occupying the same reservoir pore volume. With the addition of carbon dioxide there is a decreasing compressibility factor, thus allowing more carbon dioxide gas to compress into the pore spaces.

\subsection{Impact of Reservoir Heterogeneity on Liquid Recovery}

Figure 4.5 presents the results obtained when investigating reservoir heterogeneity through a high permeable layer. The high permeable layer located in layer 3, with a permeability of $1500 \mathrm{md}$ is compared with the BC. Two LP cases were investigated; a high-permeable layer with thickness of $10 \mathrm{ft}$ (LP-L3:10ft) and 26ft (LP-L3:26ft) Figure 4.5 shows the liquid recovery factor for the BC and the two LP cases. From this figure, the BC shows that after the 5-year cycle period a liquid recovery of $92.3 \%$ is obtained.

LP-L3:10ft and LP-L3:26ft however, took longer cycling times to achieve the liquid recovery of 92.3\%; the former taking 8 years whilst the latter taking 13 years to attain the same recovery. From this basis it can be seen that reservoir heterogeneity via high permeable layer negatively impacts the liquid recovery.

Table 4.1 provides the composition of the produced gas at the start of cycling for each case., This can be used to explain the reason/reasons why the LP cases exhibit longer recovery periods. At the start the of the cycle period it can be seen (Table 4.1) that the percentage of $\mathrm{CO} 2$ in the $\mathrm{BC}$ is 37.6 mole \% as compared to 69.3 mole \% in LP-L3:10ft and 79.1 mole \% in LP-L3:26ft. This seems to indicate that the ability of the $\mathrm{CO} 2$ to displace reservoir fluid decreases as more $\mathrm{CO} 2$ is channeled through high permeability layer. 


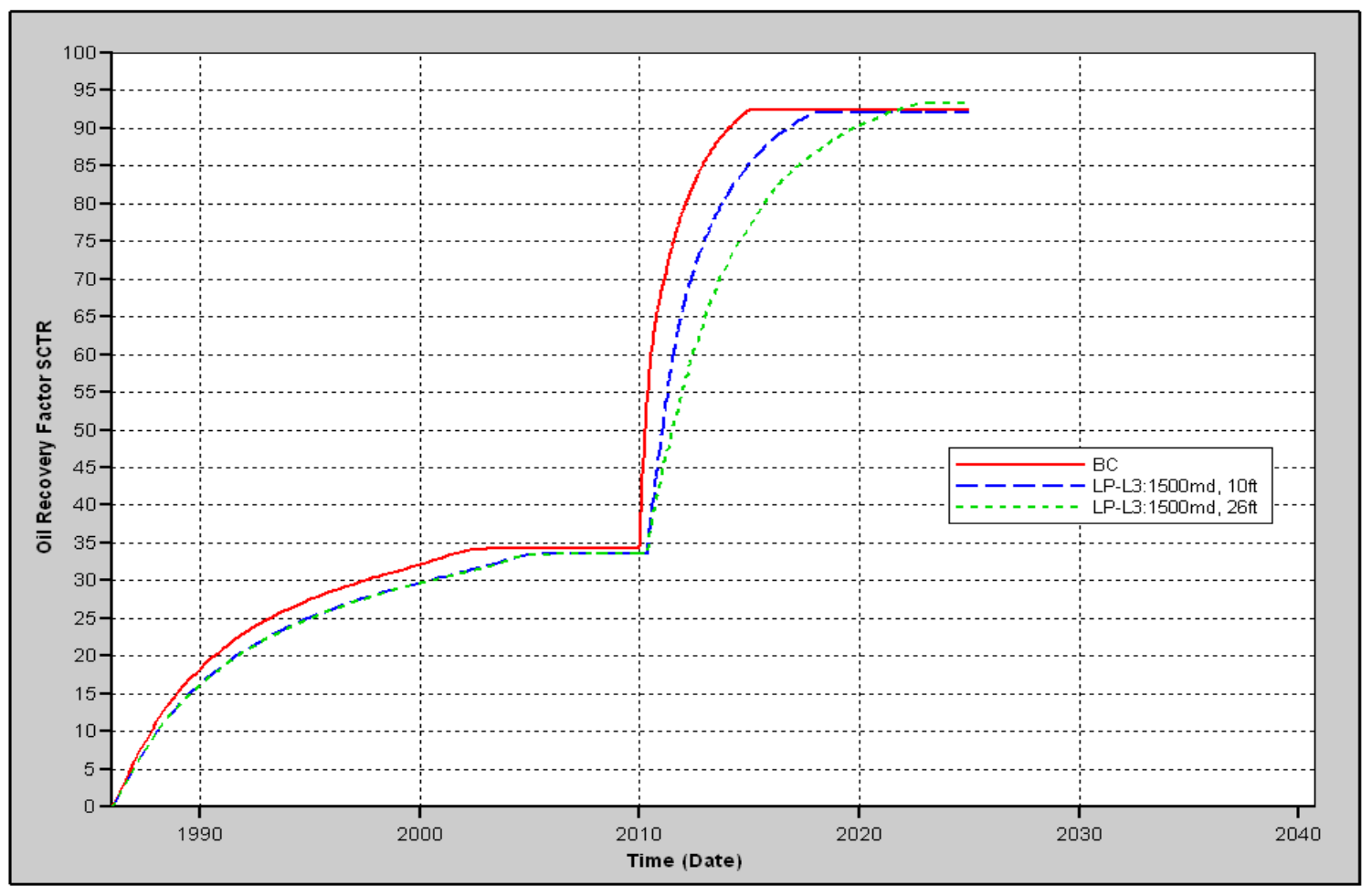

Figure 4.5: Liquid Recovery Factor comparison for BC and LP cases

An increase in the high permeable layer thickness from $10 \mathrm{ft}$ to $26 \mathrm{ft}$ showed a 10 mole $\%$ increase in $\mathrm{CO} 2$ being cycled out in the produced gas. The thicker the high permeable layer, LP-L3:26ft, the greater the volume of $\mathrm{CO} 2$ that will be channeled through this layer towards the production well. In effect this decreases the molecular diffusion throughout the reservoir, the dispersion that is required to vaporize the liquid and enrich the $\mathrm{CO} 2$ for enhanced liquid recovery.

Table 4.1: Produced Wet Gas composition for BC and LP cases at the start of cycling

\begin{tabular}{|c|c|c|c|}
\hline Component & \multicolumn{3}{|c|}{ Produced Wet Gas Composition, \% } \\
\hline & BC & LP-L3:10ft & LP-L3:26ft \\
\hline C1 & 37.931 & 17.710 & 9.891 \\
\hline C2 & 5.728 & 2.520 & 1.437 \\
\hline C3 & 3.672 & 1.597 & 0.957 \\
\hline NC4 & 3.231 & 1.459 & 0.936 \\
\hline NC5 & 1.974 & 0.972 & 0.668 \\
\hline FC6 & 1.782 & 0.967 & 0.711 \\
\hline CO2 & $\mathbf{3 7 . 5 7 2}$ & $\mathbf{6 9 . 2 5 1}$ & $\mathbf{7 9 . 1 1 3}$ \\
\hline FC10 & 8.111 & 5.524 & 6.288 \\
\hline
\end{tabular}


The location of the high permeable layer was varied through the 5 layers (L1 to L5: L1-bottom layer; L5- top layer). In these cases each layer had a thickness of $26 \mathrm{ft}$. Figure 4.6 shows the effect on high permeable layer's location on liquid recovery. Little impact is observed from this figure as the difference between the lowest and highest liquid recovery is $3 \%$. Layer 1 (bottom layer) has the highest recovery, which can be attributed to more liquid in this layer due to gravitational effects.

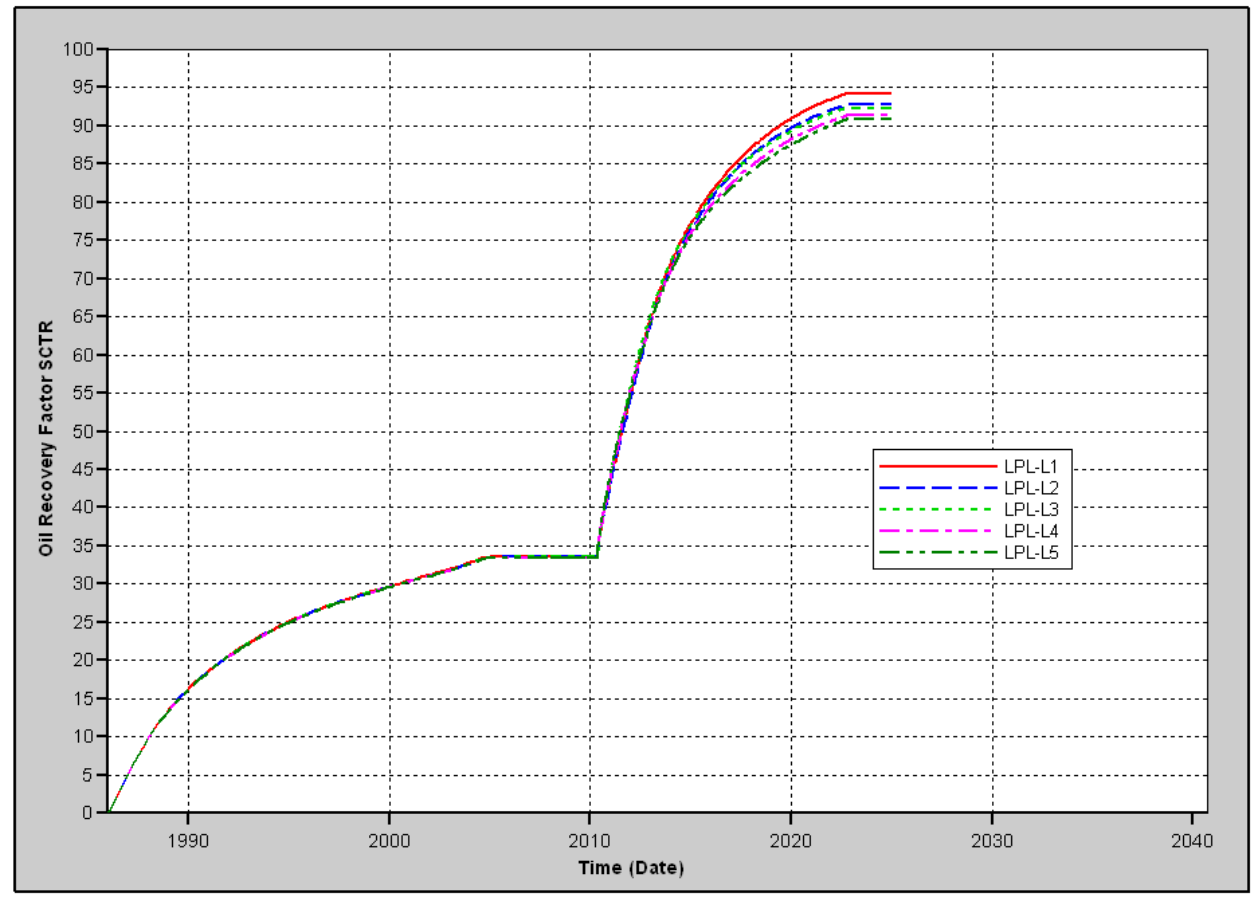

Figure 4.6: Liquid Recovery Factor comparison for LPL cases

Figure 4.7 shows the liquid recovery factor when the $\mathrm{BC}$ is compared with various streakpermeability cases. This figure shows 3 plots, $\mathrm{BC}$ and $2 \mathrm{SP}$ cases. Figure 3.5 shows a schematic of the streak. For comparison SP-5L represents the streak being located in all 5 layers connecting the injection and production wells, while SP-L3 indicates the streak located in layer 3 only.

For the 5-year cycle period and a recovery factor of $92.3 \%$ in the $\mathrm{BC}, \mathrm{SP}-5 \mathrm{~L}$ took 10 years to achieve such recovery whilst SP-L3 took 8.5 years 


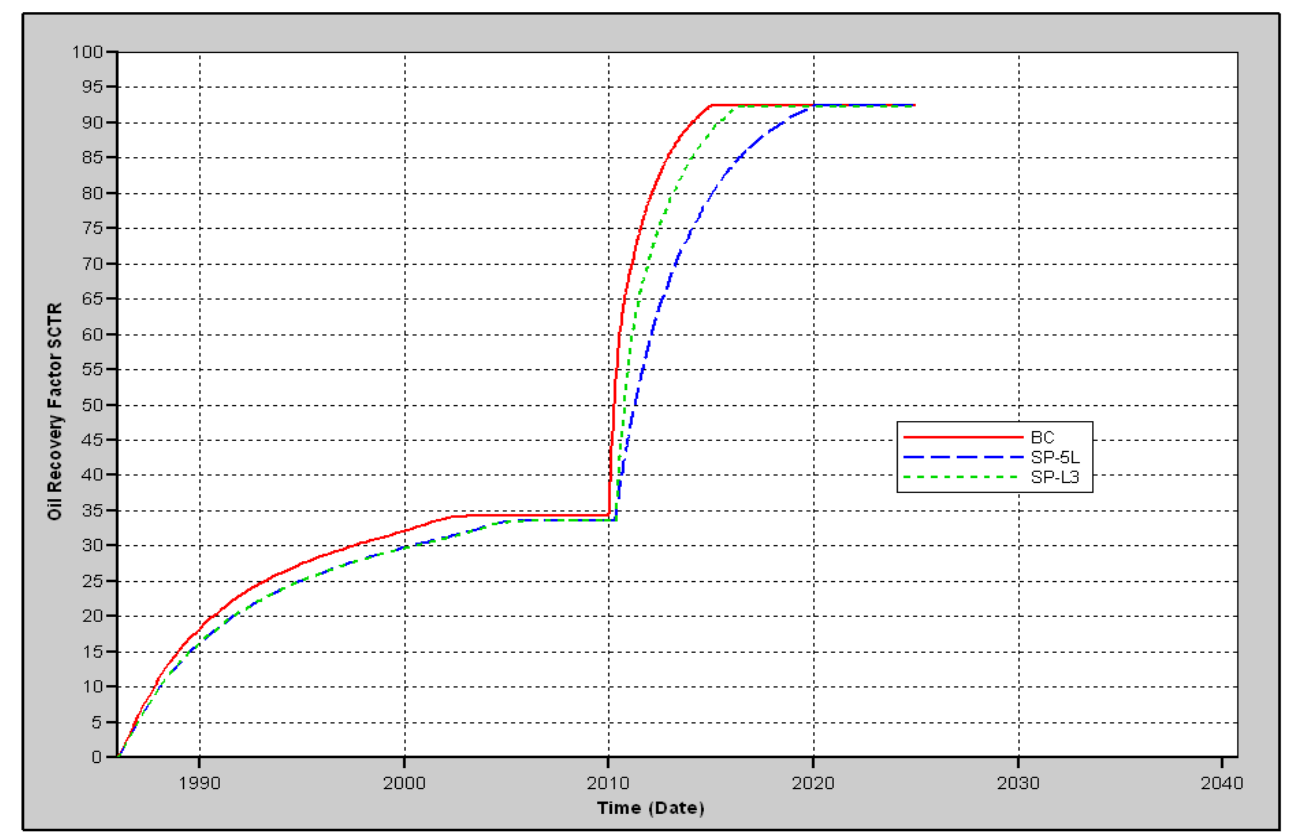

Figure 4.7: Liquid Recovery Factor comparison for SP cases

Table 4.2 shows the severity of having high permeable streak on $\mathrm{CO} 2$ dispersion in the reservoir. As can be seen SP-5L cycles 87.5 mole \% of $\mathrm{CO} 2$, which suggests the inability for the $\mathrm{CO} 2$ to distribute and disperse throughout the reservoir and recover liquid. The situation is not that severe with SP-L3 having a CO2 mole fraction of 62 mole \% in the cycle gas. In this case 24 blocks of the 400 blocks in layer 3 have 1500 md permeability as compared to 120 blocks (24 blocks per layer) in SP-5L.

Table 4.2: Produced Wet Gas composition for BC and SP cases at the start of cycling

\begin{tabular}{|c|c|c|c|}
\hline Component & \multicolumn{3}{|c|}{ Produced Wet Gas Composition, \% } \\
\hline & BC & SP-5L & SP-L3 \\
\hline C1 & 37.9306 & 3.1614 & 21.3098 \\
\hline C2 & 5.7279 & 0.4843 & 3.1128 \\
\hline C3 & 3.6719 & 0.3775 & 2.0346 \\
\hline NC4 & 3.2311 & 0.4988 & 1.9011 \\
\hline NC5 & 1.9739 & 0.5036 & 1.2709 \\
\hline FC6 & 1.7819 & 0.7023 & 1.2561 \\
\hline CO2 & $\mathbf{3 7 . 5 7 2}$ & $\mathbf{8 7 . 4 9 9 9}$ & $\mathbf{6 2 . 0 4 2 9}$ \\
\hline FC10 & 8.1108 & 6.7721 & 7.0719 \\
\hline
\end{tabular}


Similar to the BC model, the other 4 homogeneous layers in SP-L3 will have to some extent CO2 dispersion and distribution throughout the reservoir. This distribution will cause the $\mathrm{CO} 2$ to come in contact with the reservoir liquid in these layers, which eventually vaporizes. This explains the lower amount of $\mathrm{CO} 2$ cycled out in SP-L3 than SP-5L.

The displacement (sweep) efficiency relates to the displacement or mobilization of reservoir liquid at the pore scale. It is a measure of the effectiveness of injected fluid to mobilize the reservoir liquid from the pores in the rock where the injected fluid has contacted the reservoir liquid. There are many factors that affect the displacement efficiency, including: reservoir pressure and temperature, oil composition, fluids phase behavior and properties, saturation history of rock-fluid system, diffusion, solvent flow rate and residence time, slug size, dispersion, dead-end pore volume, and rock pore geometry and structure. (Ghedan, 2009).

It is evident that the displacement efficiency decreases with reservoir heterogeneity as the ability for the $\mathrm{CO} 2$ to mobilize and displace the liquid in the reservoir is compromised by its fraction in the produced gas. However, it is difficult to ascertain which reservoir mechanism or combination of reservoir mechanisms causes the effect.

\subsection{Impact of Reservoir Heterogeneity on Oil Saturation}

Figure 4.8 shows the average liquid saturation for the BC comparison with LP. From Figure 4.8, it can be seen that in the BC, during the pressurization period (2008-2010) there is an initial decrease in average liquid saturation from $18.2 \%$ to a reservoir low of $7.3 \%$, followed by a rapid increase to $11 \%$ at the end of the pressurization phase.

This is explained by how the liquid is displaced by continuous injection of $\mathrm{CO} 2$ into the reservoir, which can be classified as:

- Miscible or multi-contact miscible processes, which occurs at pressures above the minimum miscibility pressures (MMP) in which there is more interchange of components for miscible or multi-contact miscible displacement. 
- Immiscible displacement, which occurs at pressures below the MMP, in which there is less interchange of components or mixing zones between the injected gas and the reservoir fluid.

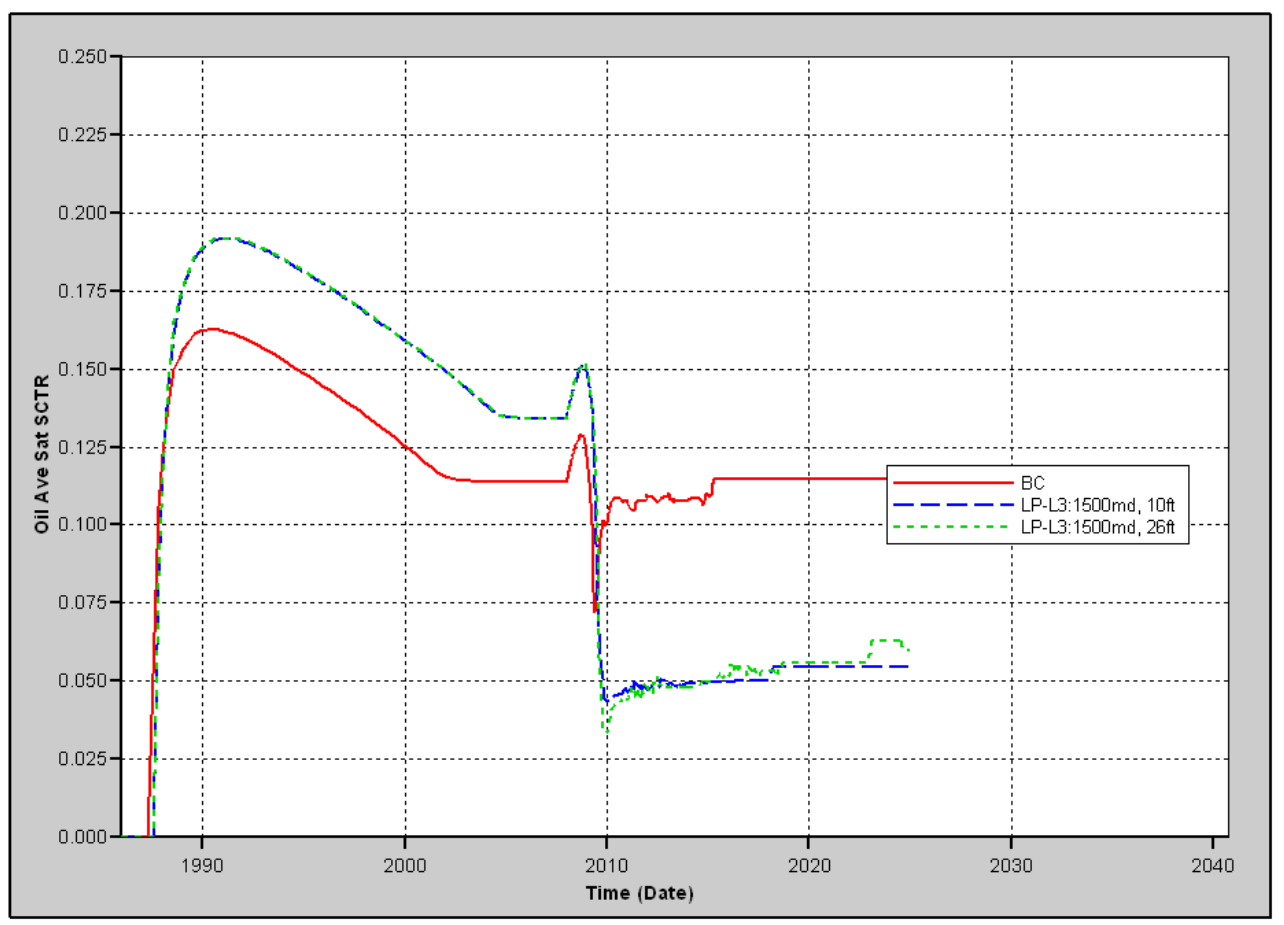

Figure 4.8: Average Liquid Saturation comparison for BC and LP cases

A plot of cumulative $\mathrm{CO} 2$ injected versus the well bottom hole pressure will identify the MMP, which is identified as the point of maximum curvature.(Shedid, Zekri, \& Almhehaideb, 2008) As can be seen with from Figure 4.9, MMP for the BC is estimated as 3000psia. From this figure both immiscible and miscible displacement is separated by this point.

At this point, there is an increase in average liquid saturation (7.3\% to $11 \%)$. This is because in miscible mixing liquid recovery is improved through gas drive, swelling of the oil and decreasing its viscosity. The mass transfer mechanisms by which the $\mathrm{CO} 2$ mixes with the liquid are as follow:

- Solubility (accounts for greater part),

- Diffusion and

- Dispersion 
With $\mathrm{CO} 2$ miscible flooding, $\mathrm{CO} 2$ becomes completely miscible with the resident liquid reducing the Interfacial Tension (IFT) between them to zero thus eliminating the capillary pressure.(Ghedan, 2009)

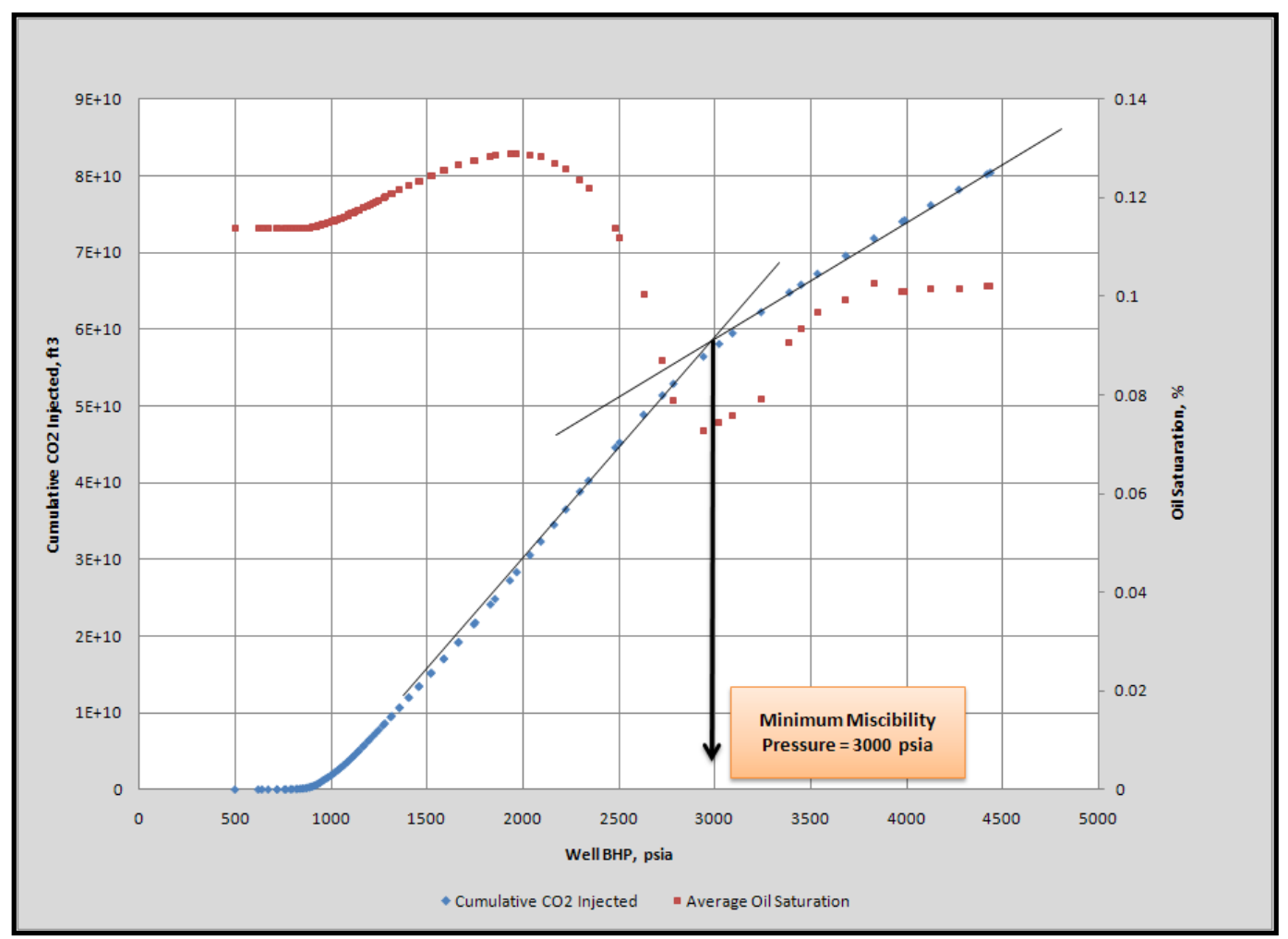

Figure 4.9: Minimum Miscible Pressure for BC

Under CO2 immiscible flooding, IFT between $\mathrm{CO} 2$ and the resident liquid is not zero, retaining the capillary pressure and resulting in some residual liquid saturation and lower liquid recoveries. In addition to pressure maintenance, however, $\mathrm{CO} 2$ immiscible flooding still recovers an extra liquid increment, by many contributing factors including. (Ghedan, 2009)

- Lower interface tensions;

- Viscosity reduction;

- Oil swelling;

- Improvement of formation permeability

- Solution gas flooding;

- Density change of oil and water 
In this research however, liquid recovery from immiscible mixing is not observed as no liquid is produced during reservoir pressurization. Miscibility is observed at the end of the pressurization phase.

It is important of get a visual picture of where the liquid swelling occurs during MMP. Figure 4.10 shows a profile of the $\mathrm{CO} 2$ front for the $\mathrm{BC}$. As can be seen the distribution is uniform in the 5 layers. As $\mathrm{CO} 2$ in is being continuously injected into the reservoir any residual liquid near the injection well region will be vaporize. This is evident by the initial decrease in average liquid saturation from $18.2 \%$ to $7.3 \%$.

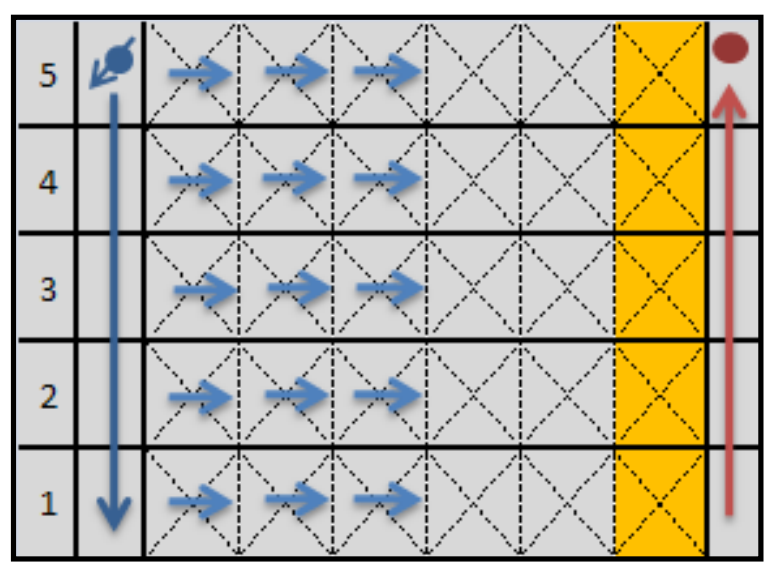

Figure 4.10: BC CO2 Profile

Regions in the reservoir that is a favorable for miscibility is observed at the outskirts of the reservoir and near the production well. This is because with continued injection the $\mathrm{CO} 2$ vaporizes as well as displaces the liquid as far as possible from the injection well and as a result the liquid is displaced to the aforementioned regions. It can be explained that one, the pressure is these regions are at MMP and that there is liquid present. Not only is it the presence of liquid but the mixture/composition that is ideal for miscibility to occur. The presence of these two conditions at the reservoir boundary shown in Figure 4.10 is the reason why miscibility occurs near the production well and the reservoir boundary. To get a visualization of this liquid displacement refer to Appendix B for screen shots of the $\mathrm{BC}$ at the end of pressurization. 
Figure 4.8 also shows the average liquid saturation of the LP-L3:10ft and LP-L3:26ft. This will be discussed alongside Figure 4.11; the average liquid saturation of the LPL cases. In the following discussion LPL-L3 is considered the same as LP-L3:10ft and LP-L3:26ft.

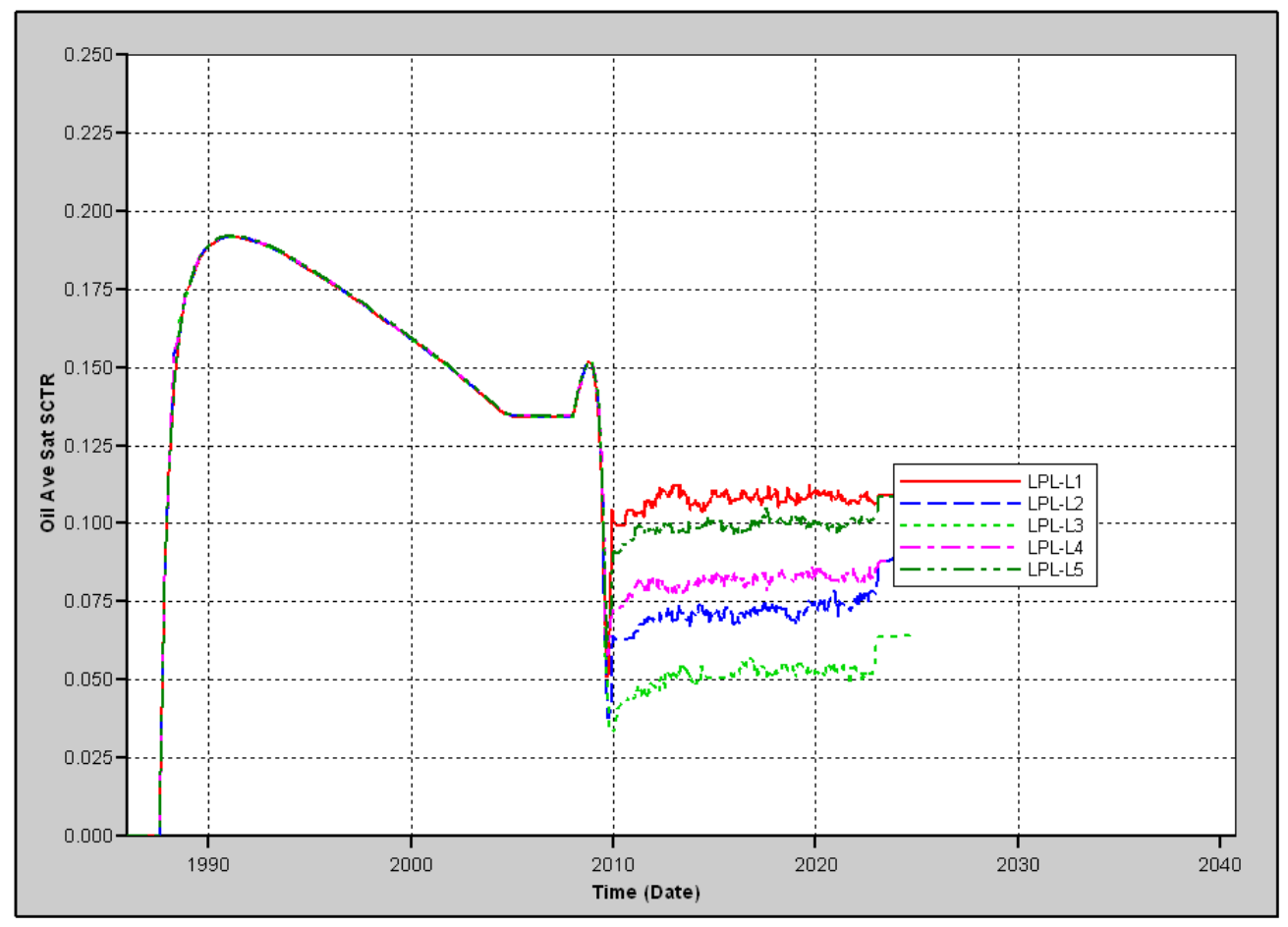

Figure 4.11: Average liquid Saturation comparison for BC and LPL cases

Figure 4.11, shows the effect of high-permeability layer location on average liquid saturation. The first point to note is that there is miscibility occurring, in all LPL cases. Not evident in layer 3, a plot of cumulative $\mathrm{CO} 2$ injected versus well bottom hole pressure (Refer to Appendix C) shows that LPL-L3 has a MMP of 3000 psia. In fact LPL-L1-5 all showed MMP of 3000psia.

Table 4.3 and Figure 4.12 show the mole fraction of the CO2 cycled in the LPL cases and illustrates the movement of $\mathrm{CO} 2$ between the layers. As can be seen LPL-L3 had the highest fraction of $\mathrm{CO} 2$ cycled.-90.6 mole \%. This means the displacement efficiency is the lowest when the high permeable layer is located in the middle. 
Looking at Figure 4.12, when the high permeable layer is located in the middle there is communication between the layers above and below by an extent of 2 layers in both direction. What happens is that as the $\mathrm{CO} 2$ is being injected, the $\mathrm{CO} 2$ will profile outwards in layer 3 at first. With continued injection, the $\mathrm{CO} 2$ being injected into the top and bottom layers (layer 2 and 4) starts moving towards layer 3 as the tendency to flow will be towards the high permeable layer.

Table 4.3: Produced Wet Gas composition for LPL cases at the start of cycling

\begin{tabular}{|c|c|c|c|c|c|}
\hline Component & \multicolumn{5}{|c|}{ Produced Wet Gas Composition, \% } \\
\hline & LPL-L1 & LPL-L2 & LPL-L3 & LPL-L4 & LPL-L5 \\
\hline C1 & 9.2574 & 7.6107 & 6.6294 & 13.7185 & 20.5198 \\
\hline C2 & 1.3042 & 1.098 & 1.0919 & 1.9469 & 2.8109 \\
\hline C3 & 0.8357 & 0.7237 & 0.6183 & 1.2614 & 1.7613 \\
\hline NC4 & 0.7876 & 0.7046 & 0.5197 & 1.1949 & 1.6009 \\
\hline NC5 & 0.5595 & 0.5145 & 0.2585 & 0.8317 & 1.0666 \\
\hline FC6 & 0.6227 & 0.5813 & 0.16 & 0.8741 & 1.0744 \\
\hline CO2 & $\mathbf{7 9 . 6 4 1}$ & $\mathbf{8 2 . 4 0 4 5}$ & $\mathbf{9 0 . 5 5 0 7}$ & $\mathbf{7 3 . 6 4 9 9}$ & $\mathbf{6 4 . 7 5 8 9}$ \\
\hline FC10 & 6.9919 & 6.3626 & 0.1715 & 6.5225 & 6.4072 \\
\hline
\end{tabular}

Eventually the vertical movement extends to the outer layer (layer 1 and 5). As a result the majority of the $\mathrm{CO} 2$ will flow toward and through layer 3 which is connected to the production well thus channeling more $\mathrm{CO} 2$. This results in high $\mathrm{CO} 2$ concentration in the cycled gas. Since $\mathrm{CO} 2$ mass transfer is compromised, little to no $\mathrm{CO} 2$ comes in contact with liquid in the reservoir to cause liquid swelling and thus increasing total liquid saturation. The liquid that is present in the reservoir is the liquid that is immobile that thus cannot be recovered.

When the high permeable layer is located in either layer 1 or layer 5 , there is an improvement in liquid recovery as evident by lower $\mathrm{CO} 2$ concentration in the cycled gas (79.6 mole \% and 64.75 mole \% respectively). From Figure 4.12 the CO2 profile for LPL-L1 and LPL-L5 shows similar trends. It shows that vertical $\mathrm{CO} 2$ movement extends to two layers away from high permeable layer, which allow for more $\mathrm{CO} 2$ to be channeled These cases are not as severe as LPL-L3 since LPL-L3 is in communication with 4 layers as oppose to two layers in the former cases. 

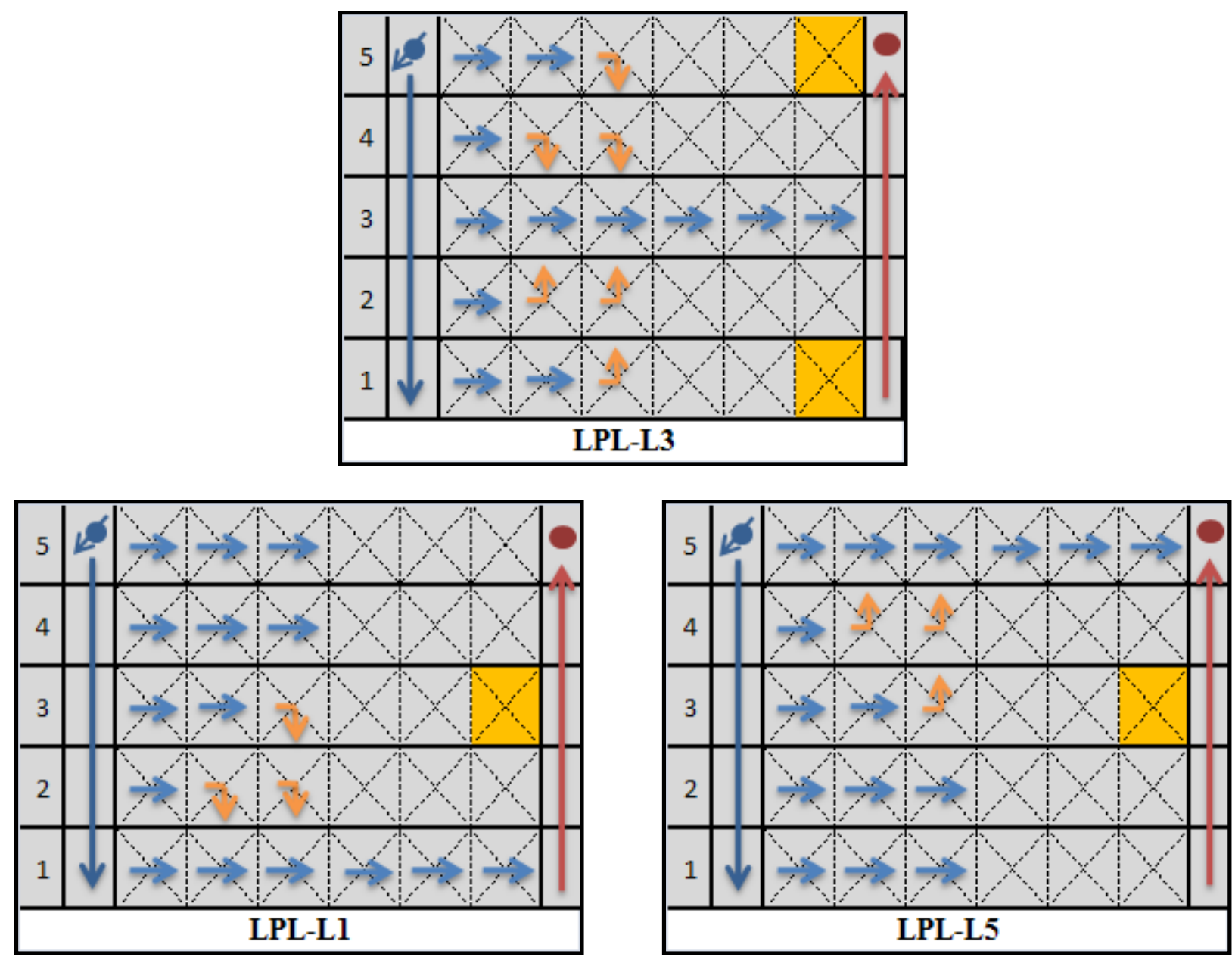

Figure 4.12: LPL CO2 Profile

The two layers furthest away from the high permeable layer have little vertical movement and thus allow the $\mathrm{CO} 2$ to have better mass transfer in their respective layer, when the high permeable layer is located in layer 1 or 5.As such, better recovery is expected for these cases. Also, because of better $\mathrm{CO} 2$ dispersion, the conditions become ideal for $\mathrm{CO} 2$-liquid mixing thus allowing for liquid phase swelling and increase in total liquid volume and recovery.

From the analysis of the liquid movement, it seems that two layers away for the high permeable layer have the ideal condition/conditions for CO2-liquid miscibility and liquid phase swelling. Two layers away from high permeable layer in LPL-L1 and LPL-L5 is layer 3. This layer in the aforementioned cases has shown to have the highest liquid phase swelling. (Refer to Appendix D and E for screen shots of LPL-L1 and LPL-L5) 
Figure 4.13 compares the average liquid saturation between the BC and SP-5L and SP-L3. Both SP cases show miscibility during pressurization at the same MMP of 3000 psia. Refer to Appendix C. In both SP cases the average liquid saturation drops from $15 \%$ to $6 \%$ at which point $\mathrm{CO} 2$-liquid miscibility occurs causing liquid swelling- an average liquid saturation increase of $2 \%$ to $8 \%$.

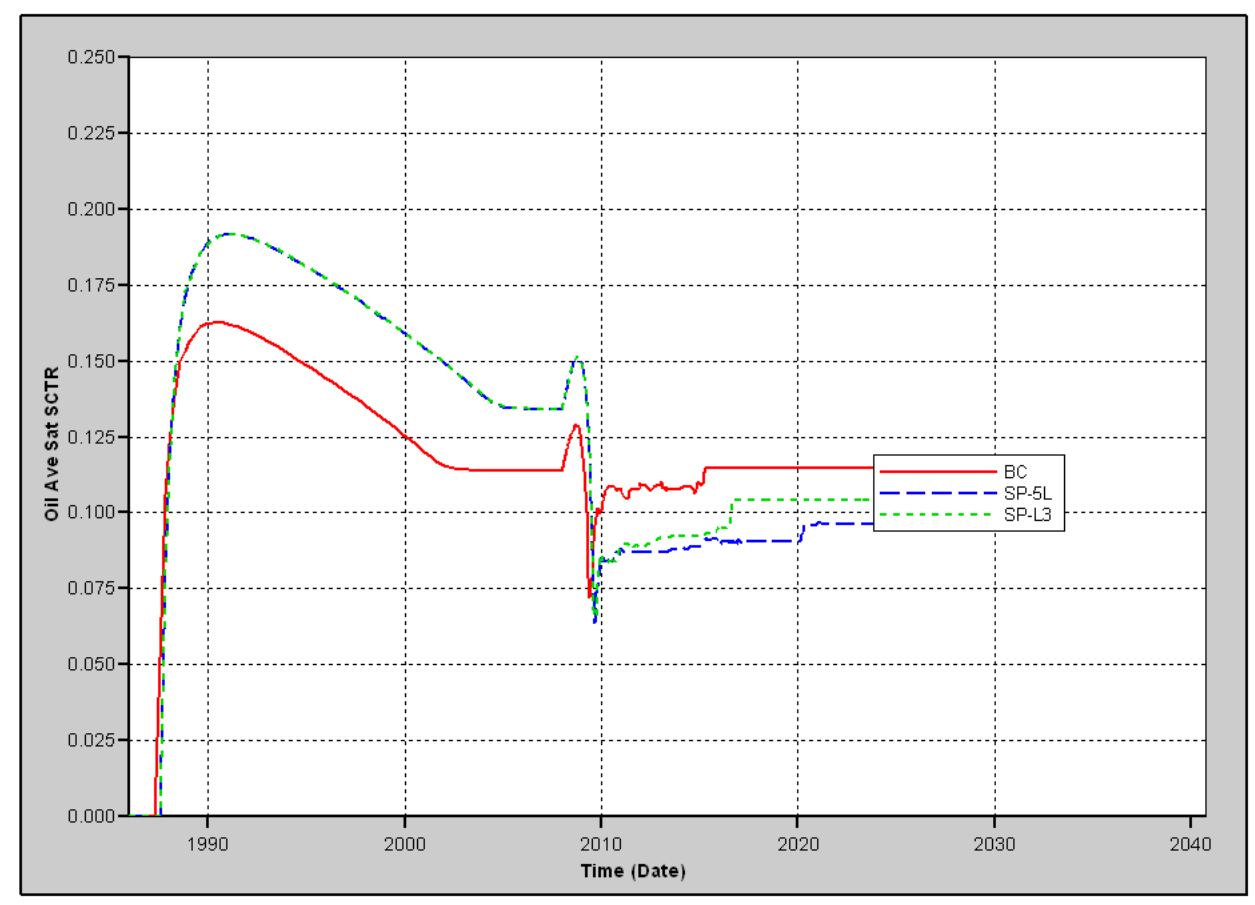

Figure 4.13: Average liquid Saturation comparison for BC and SP cases

Table 4.4 shows the severity of mass transfer with the SP. Having the streaks in all 5 layers, 87.5 mole $\%$ of $\mathrm{CO} 2$ in cycled through the reservoir compared to 62 mole $\%$ by having streak in layer 3 , both of which is significantly higher than the BC. The extremity the SP system is having the streak located such that the injection and production well is connected.

Figure 4.14 shows the $\mathrm{CO} 2$ profile in the SP case - a highly conductive path is available for easy $\mathrm{CO} 2$ movement from the injection to production well. Little $\mathrm{CO} 2$ is distributed elsewhere in the reservoir, however in the SP-5L case there will be a homogeneous-type distribution in each layer as the effective permeability in each layer is the same. As a result the ideal condition/conditions for liquid phase swelling occur around the reservoir boundary as the $\mathrm{CO} 2$ displaces the liquid to the reservoir boundary before $\mathrm{CO} 2$-liquid miscibility can occur. 
In the SP-L3, layers 1, 2, 4 and 5 all exhibit homogeneous-type behavior as liquid phase swelling occurs around the reservoir boundary, hence the reason the similarity to SP-5L.

Table 4.4: Produced Wet Gas composition for SP cases at the start of cycling

\begin{tabular}{|c|c|c|c|}
\hline Component & \multicolumn{3}{|c|}{ Produced Wet Gas Composition, \% } \\
\hline & BC & SP-5L & SP-L3 \\
\hline C1 & 37.9306 & 3.1614 & 21.3098 \\
\hline C2 & 5.7279 & 0.4843 & 3.1128 \\
\hline C3 & 3.6719 & 0.3775 & 2.0346 \\
\hline NC4 & 3.2311 & 0.4988 & 1.9011 \\
\hline NC5 & 1.9739 & 0.5036 & 1.2709 \\
\hline FC6 & 1.7819 & 0.7023 & 1.2561 \\
\hline CO2 & $\mathbf{3 7 . 5 7 2}$ & $\mathbf{8 7 . 4 9 9 9}$ & $\mathbf{6 2 . 0 4 2 9}$ \\
\hline FC10 & 8.1108 & 6.7721 & 7.0719 \\
\hline
\end{tabular}

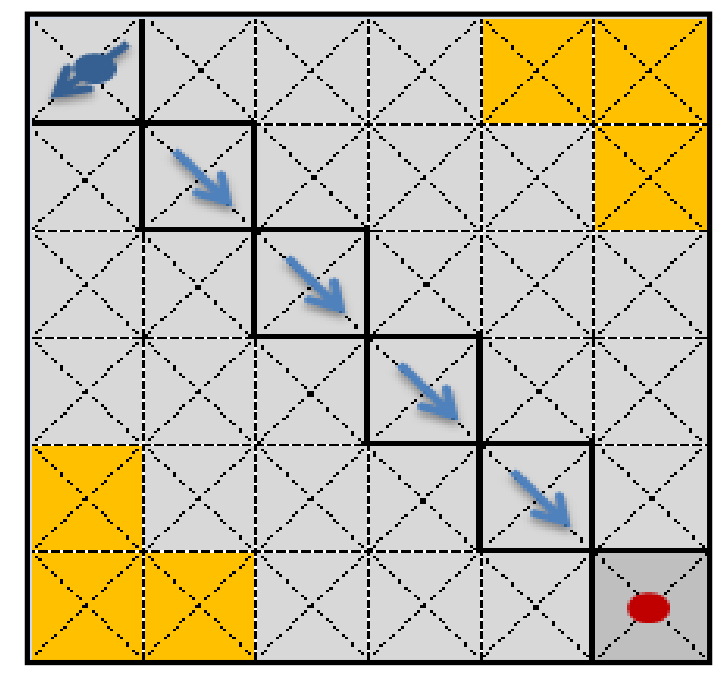

Figure 4.14: SP CO2 Profile

\subsection{Impact of Petrophysical Properties on Liquid Recovery and Oil Saturation}

As defined in section 2.8, porosity is directly proportional to the in place hydrocarbon. That is as porosity increases so to the in place hydrocarbon and vice versa. Therefore, from Figure 4.15, the higher the porosity value the higher the in-place hydrocarbon and as a result the longer it will take 
for the reservoir to be depleted to abandonment pressure of 500psia. It is for this reason why there is a shift at the start of injection.

During the pressurization period as the porosity value increases more $\mathrm{CO} 2$ is required to achieve 4500 psia. POR-16\% took 6-months longer than the BC, whilst POR-20\% took one year longer than $\mathrm{BC}$ to achieve such pressure. This is because with increasing porosity the greater the reservoir inventory to store more $\mathrm{CO} 2$ before reaching 4500 psia. The cycling period for all porosity cases however, was 5 years. The general shape of all plots in question is similar and thus the parameter does not improve or hamper liquid recovery.

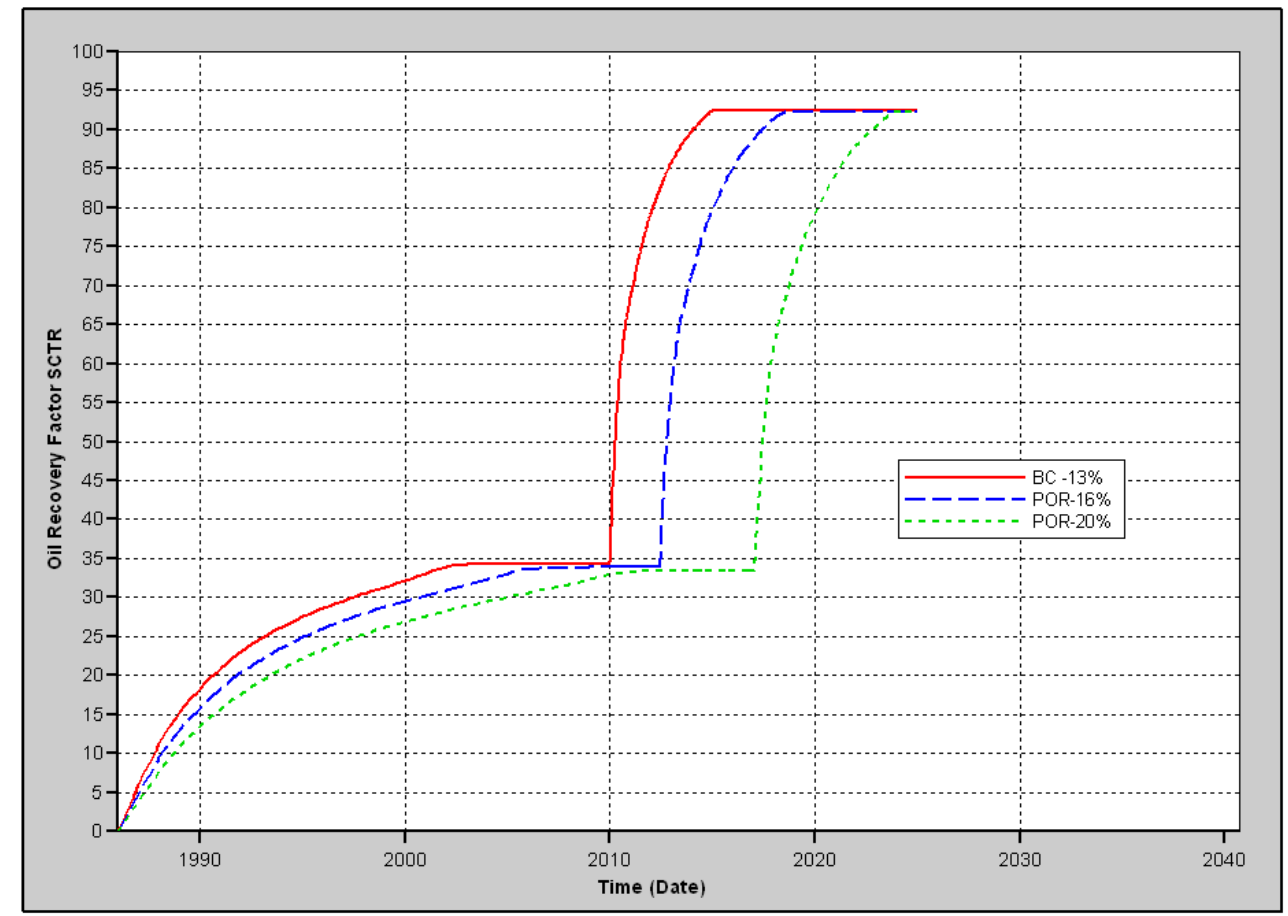

Figure 4.15: Liquid Recovery Factor comparison for porosity cases

This shift is also shown in Figure 4.16; however a number of differences are observed during pressurization. These are as follow:

- There is a slight decrease in the maximum average liquid saturation attained as porosity increases. 
- As porosity increases condensate revaporization decreases as is evident by the lowest oil saturation value attained in each case. BC - 7.2 \%, POR-16\% -7.45\% and POR-20\%$7.5 \%$

- There is also a reduction in miscibility as porosity increases, which is shown by the immediate increase in average liquid saturation from $7.5 \%$ to POR-13\% (BC) $-11 \%$ POR-16\% - $10.7 \%$ and POR-20\%-10.5\%. As mentioned before with increasing porosity value more $\mathrm{CO} 2$ is required to pressurize the reservoir, hence one might expect that with increasing porosity values $\mathrm{CO} 2$-reservoir liquid miscibility increases as more $\mathrm{CO} 2$ in available in the reservoir.

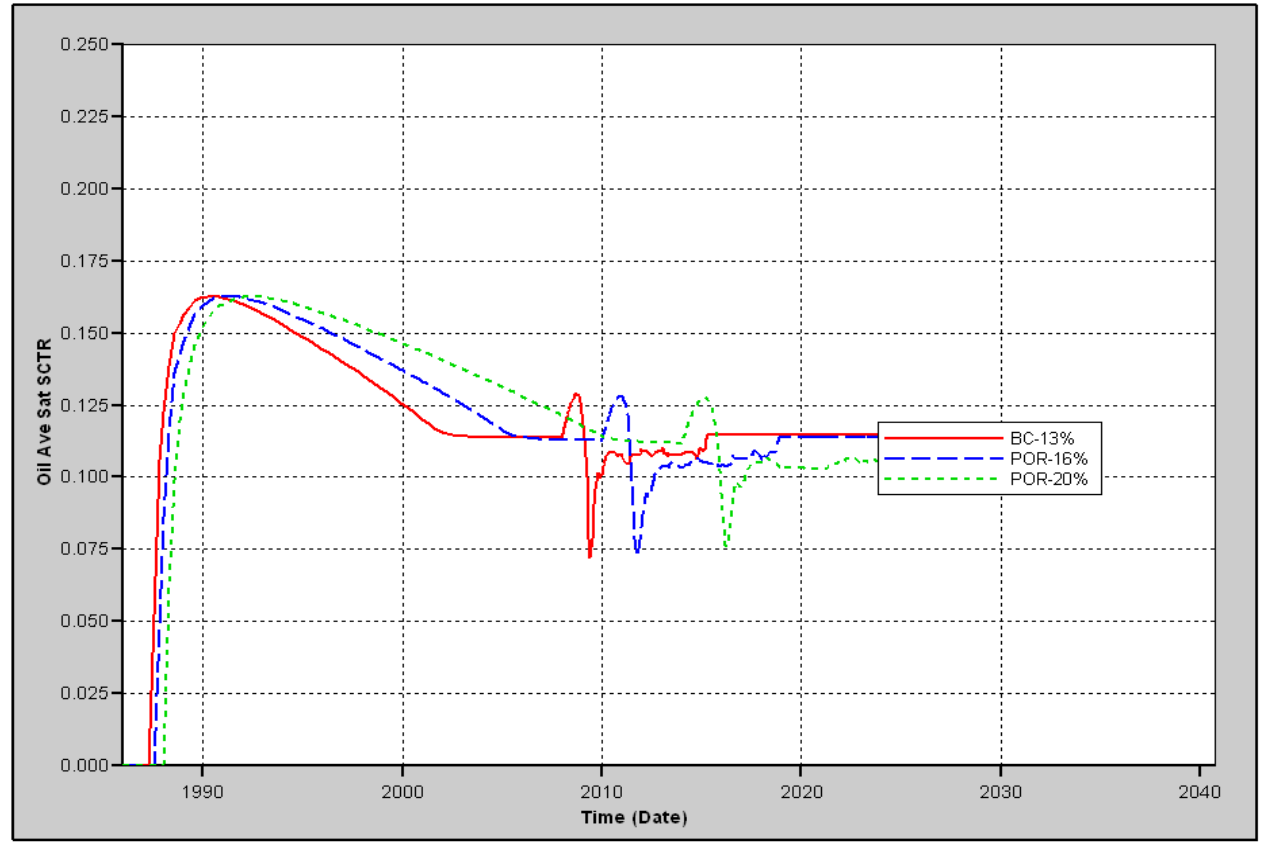

Figure 4.16: Average Liquid Saturation comparison porosity cases

These differences are explained in terms of the phase behavior that occurs between $\mathrm{CO} 2$ and reservoir liquid and the effect of porous media in $\mathrm{CO} 2$ dispersion and diffusion throughout the reservoir. This should be the subject for further analysis.

Section 2.8 also states that the absolute permeability is defined as the ability to flow or transmit fluids through a rock, conducted when a single fluid, or phase, is present in the rock. Therefore the higher the permeability value the easier the ability to flow through a rock. In this section, 3 permeability cases are being investigated: BC-150md, Perm-70md and Perm 250md. 
Permeability however, does not affect in-place hydrocarbon (equation 2.1) and as a result the liquid recovery will not change with permeability variations Figure 4.20. Figure 4.20 shows the impact permeability has on average liquid saturation. During reservoir pressuring, the miscibility decreases as permeability decrease. As explained earlier, various factors affect $\mathrm{CO} 2$-liquid miscibility and this should be the subject of further investigation

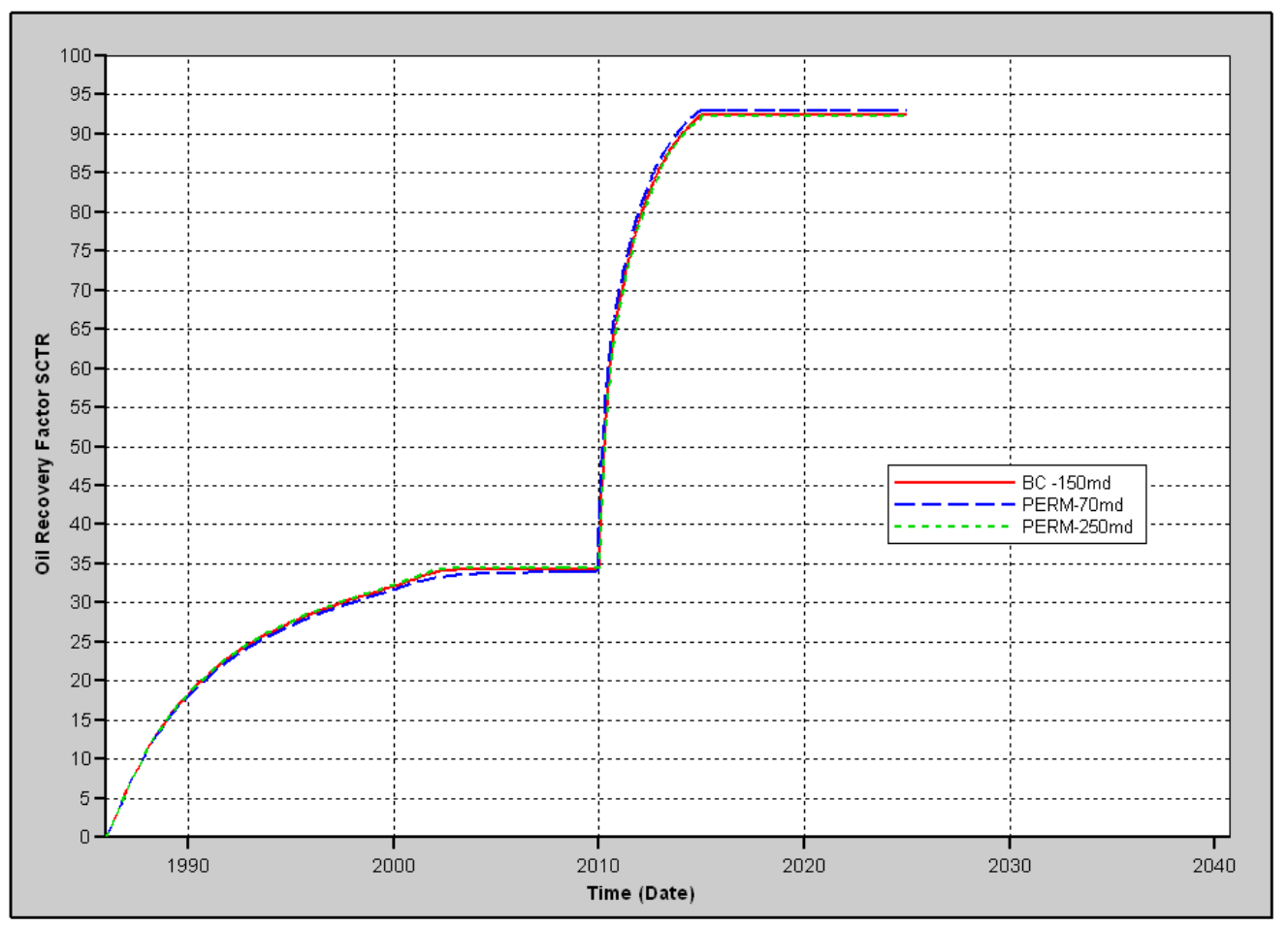

Figure 4.17:Liquid Recovery Factor comparison for permeability cases 


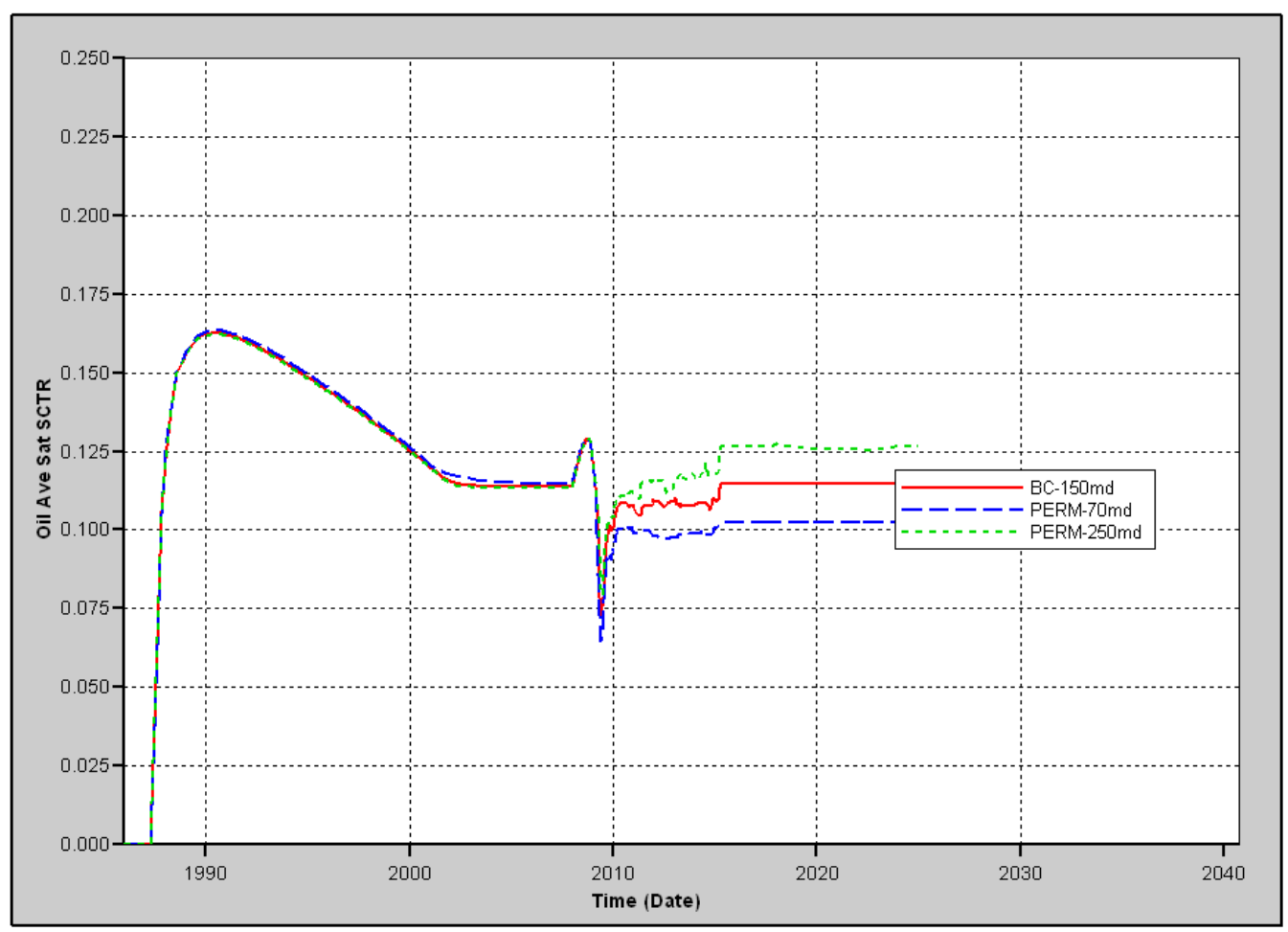

Figure 4.18: Average Liquid Saturation comparison for permeability cases

\subsection{Impact of Injection Rate on Liquid Miscibility}

It is thought that injection rate will impact $\mathrm{CO} 2$ diffusion and dispersion, its interaction with the reservoir liquid and ultimate liquid recovery. A lower injection rate of 45.5 MMSCFD is used for comparison with the BC, which has an injection rate of 110 MMSCFD. Figure 4.19 and Figure 4.20 show that injection rate has no impact of average liquid saturation and liquid recovery. The only difference that is observed it that the 45.5 MMSCFD rate is skewed to the right, indicating that lower injection rates require longer time for reservoir pressurization. 


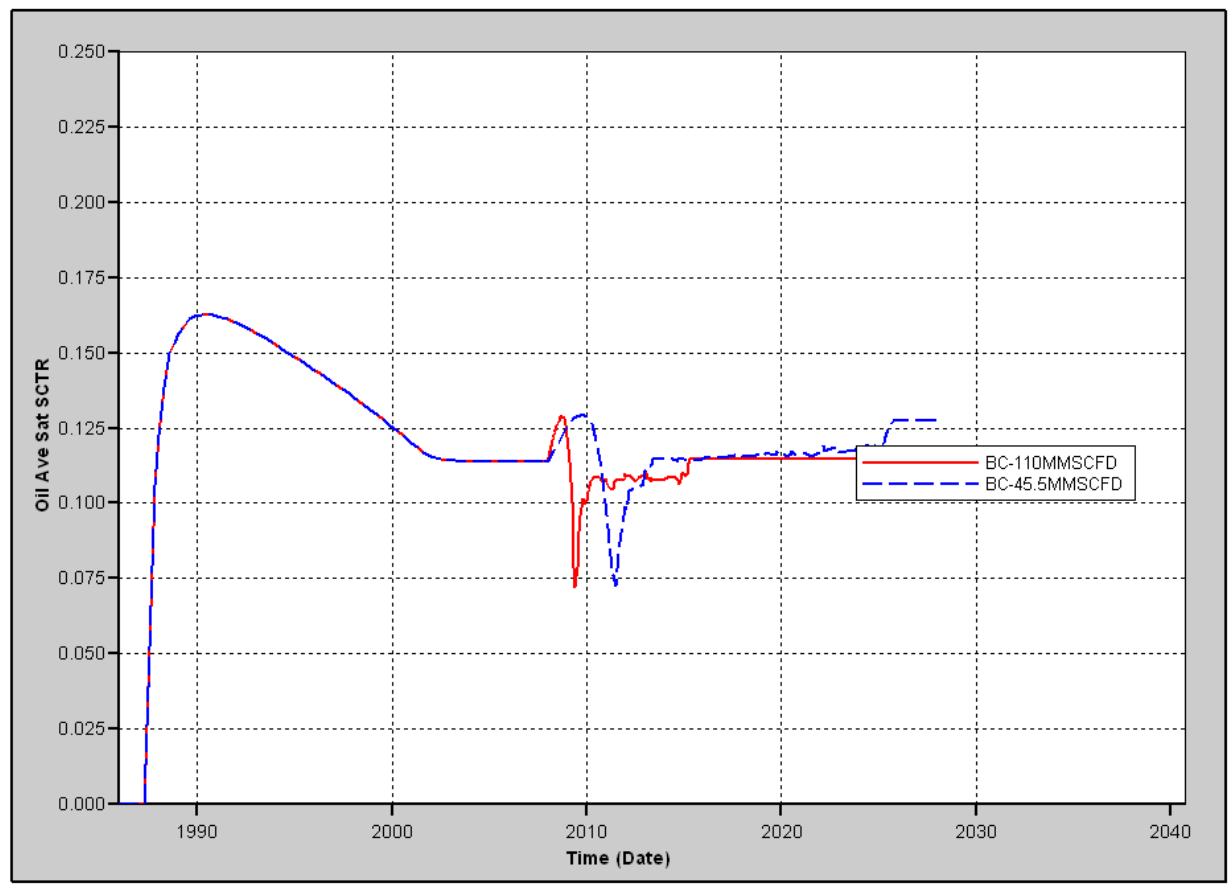

Figure 4.19: Average Liquid Saturation comparison for gas injection rate cases

In Figure 4.19, miscibility is observed and to the same extent in both cases, from average liquid saturation of $7.2 \%$ increasing to $11 \%$.

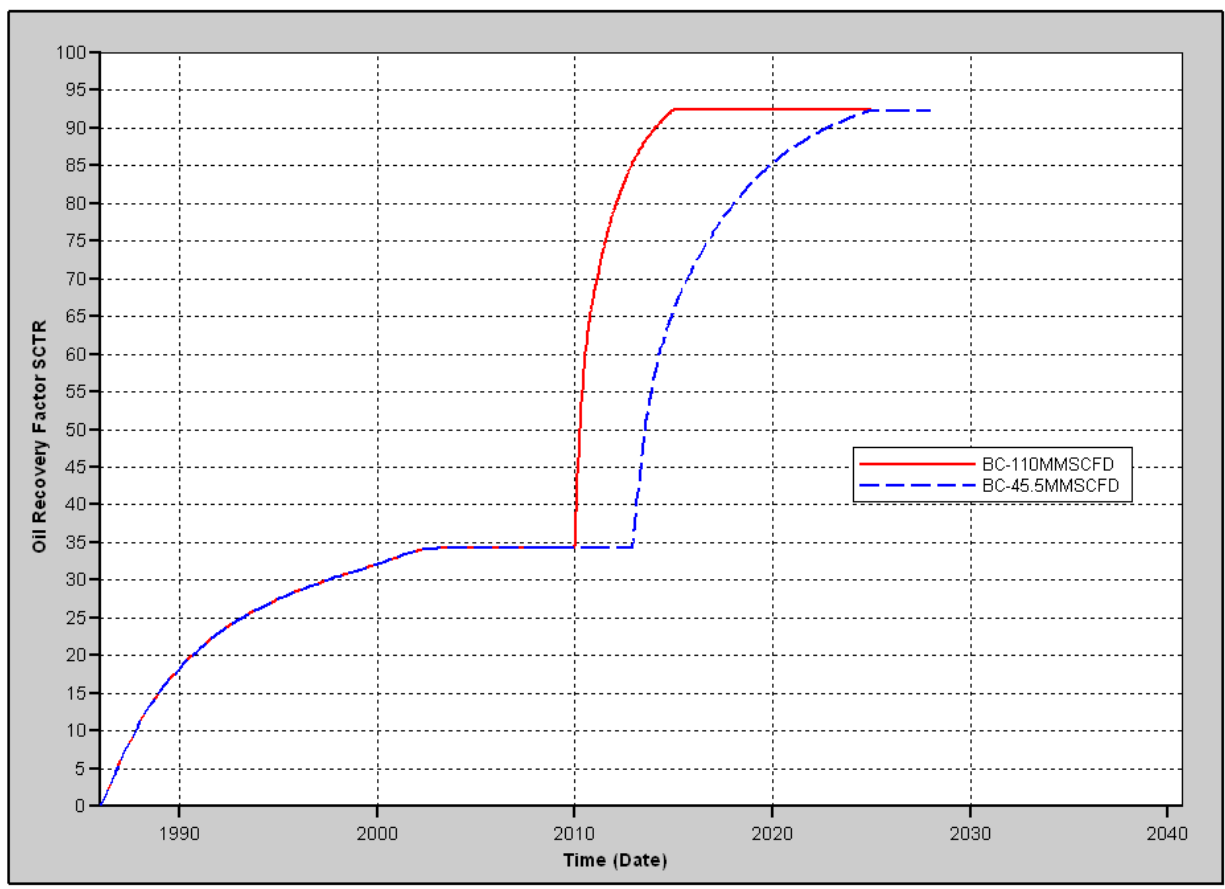

Figure 4.20: Liquid Recovery Factor comparison for gas injection rate cases 


\subsection{Impact of Injection Gas on Liquid Recovery}

To ascertain the use of $\mathrm{CO} 2$ as a lean gas alternative for condensate recovery, methane $(\mathrm{C} 1)$ and nitrogen (N2) were used as injection gases. In these cases the cycling was done for a 5-year period and not until the liquid recovery reaches the BC liquid recovery after the 5-year cycle period, which is the 'basis of comparison'. The first observation made is that all the injection gases improved condensate recovery, Figure 4.21, C1 having a condensate recovery $84 \%$ while N2 achieved a 53\% recovery. As such it can be explained that recovery using various injection gases can be attributed to pressure maintenance above the dew point, so that condensed vapors can reenter its vapor phase, become mobile and thus recovered. Once the injection gas vaporizes the condensate, it becomes enriched with the vaporized condensate due to mass transfer.

Secondly, CO2 is able to have better liquid recovery that both $\mathrm{C} 1$ and N2. This reason can be attributed to the phase behavior effects that occur when $\mathrm{CO} 2$ mixes with reservoir fluid. The $\mathrm{CO} 2$ is shown to be able to revaporize the liquid phase more efficiently than the other 2 injection gases.

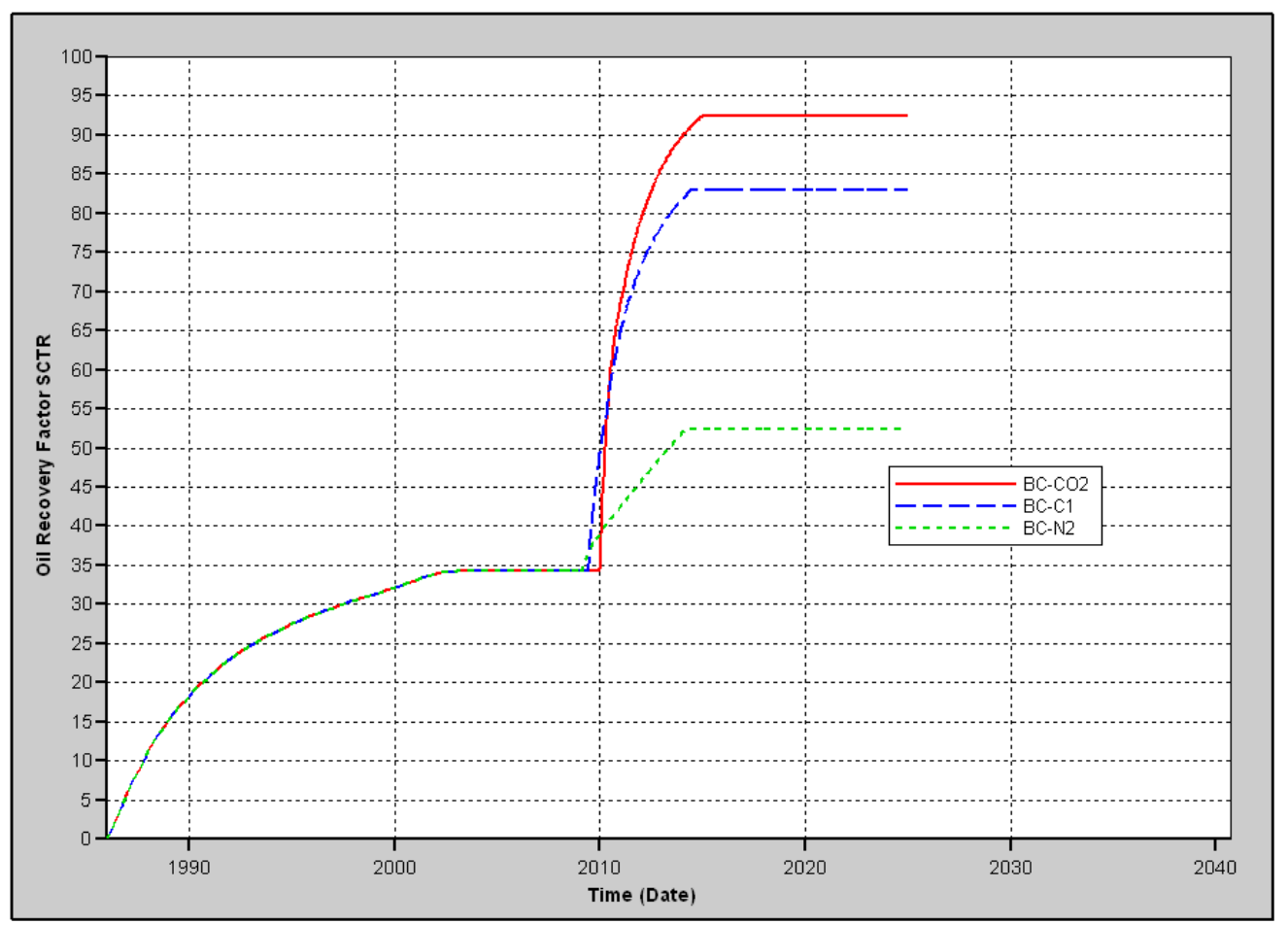

Figure 4.21: Liquid Recovery Factor comparison for injection gas cases 
Another reason for the reduction in liquid recovery in $\mathrm{C} 1$ and $\mathrm{N} 2$ is the effect these gases have on dew point pressure. Both $\mathrm{C} 1$ and $\mathrm{N} 2$ have shown to increase this pressure value.(Al-Anazi, Sharma, \& Pope, 2004). However, the use of CO2 as an injection gas has shown to decrease the dew point pressure (Figure 4.2). Increasing the dew point pressure will ultimately impact the cost effectiveness in maintaining a reservoir above the dew point to prevent condensation. As a result the increase in dew point will reduce the amount of condensate being recovered.

Table 4.5 shows the impact of injection gas on composition of the produced wet gas. For easy comparison the $\mathrm{C} 7+(\mathrm{FC} 10)$ fractions will be discussed. On this basis it can be seen that $\mathrm{CO} 2$ is able to vaporize more of the heavy ends than either $\mathrm{C} 1$ or $\mathrm{N} 2.8 .1$ mole $\%$ of FC10 is able to be vaporized and produced with $\mathrm{CO} 2$ as compared to 6.3 moles \% and 1.3 mole $\%$ for $\mathrm{C} 1$ and $\mathrm{N} 2$ respectively.

Table 4.5: Produced Wet Gas Composition for Various Injection Gas at Start of Cycling

\begin{tabular}{|c|c|c|c|}
\hline Component & \multicolumn{3}{|c|}{ Produced Wet Gas Composition, \% } \\
\hline & $\mathrm{BC}$ & $\mathrm{C} 1$ & $\mathrm{~N} 2$ \\
\hline $\mathrm{N} 2$ & 0.0000 & 0.0000 & 56.7812 \\
\hline $\mathrm{C} 1$ & 37.9306 & 78.2462 & 29.8287 \\
\hline $\mathrm{C} 2$ & 5.7279 & 5.4362 & 5.0616 \\
\hline $\mathrm{C} 3$ & 3.6719 & 3.5897 & 3.1576 \\
\hline $\mathrm{NC} 4$ & 3.2311 & 3.0834 & 2.1577 \\
\hline $\mathrm{NC} 5$ & 1.9739 & 1.7764 & 0.9948 \\
\hline FC6 & 1.7819 & 1.5392 & 0.7112 \\
\hline CO2 & 37.572 & 0.0276 & 0.0241 \\
\hline FC10 & $\mathbf{8 . 1 1 0 8}$ & $\mathbf{6 . 3 0 1 3}$ & $\mathbf{1 . 2 8 3 1}$ \\
\hline
\end{tabular}

\subsection{Carbon Dioxide Sequestration}

Table 4.6 shows the cumulative $\mathrm{CO} 2$ sequestered into depleted gas-condensate reservoir. This table compares the BC with 2 other cases, SP (SP-5L) and LP (LPL-L3). Sum 80BCF CO2 is stored in the BC compared to 93.6 BCF and 94.6 BCF in the SP and LP cases respectively. The 
amount of $\mathrm{CO} 2$ that can be stored in a reservoir is a function of not exceeding the initial reservoir pressure. In this case the reservoir had an initial reservoir pressure of 4500psia.

Table 4.6: Volume of $\mathrm{CO} 2$ sequestered in a Depleted Gas-Condensate reservoir

\begin{tabular}{|c|c|c|c|}
\hline \multirow{2}{*}{ Case } & \multicolumn{2}{|c|}{ Well Bottom-hole Pressure (psia) } & $\begin{array}{c}\text { Cumulative Gas Injected. } \\
\text { SC } \\
\text { (ft3) }\end{array}$ \\
\cline { 2 - 4 } BC & Inj_1 & Prod_1 & $\mathbf{8 0 , 5 1 9 , 9 5 4 , 4 3 2}$ \\
\hline SP & 4498.16 & $4,284.69$ & $\mathbf{9 3 , 6 0 9 , 3 6 9 , 6 0 0}$ \\
\hline LP & 4495.59 & $4,312.92$ & $\mathbf{9 4 , 6 0 4 , 1 4 8 , 7 3 6}$ \\
\hline
\end{tabular}

During injection the location in the reservoir which experiences this pressure (4500psia) first is at the injection well. As such Table 4.6 presents the Well bottom hole pressure at Inj_1. This pressure is used so as to not compromise the reservoir integrity in storing the $\mathrm{CO} 2$ in terms of $\mathrm{CO} 2$ leaching, seepage and leaking.

Comparing the quantity stored in the heterogeneous reservoirs to the $\mathrm{BC}$ show a surplus of $14 \mathrm{BCF}$ being stored in the former cases, which is as a result of the additional 5 months that is required to attain the injection well bottom hole pressure of 4500 psia. For the same time period as the BC, i.e 2 years; SP is able to store $80,519,987,200 \mathrm{ft}^{3}$ while LP is able to store $80,524,148,736 \mathrm{ft}^{3}$, which compares to the BC.

However, what this also shows that in the heterogeneous cases, it takes longer for the reservoir to pressurize to 4500 psia allowing for more $\mathrm{CO} 2$ to be injected in the reservoir. It indicates that the $\mathrm{CO} 2$ is able to migrate away from the injection well faster than the BC. So, the high permeable layer and streak are able to provide easy movement of injected CO2 away from the injection well thus distributing the pressure throughout the reservoir efficiently and effectively. This is evident by the higher pressures at the production well (Table 4.6) for the heterogeneous case than that in BC. 
Table 4.8 and Table 4.7 show the impact of the cycle period on enhanced liquid recovery and how does this enhanced recovery impact $\mathrm{CO} 2$ sequestration. From Table 4.8, the cycle period accounts for $64 \%$ of the $92.3 \%$ liquid recovered is all cases.

Table 4.7: Summary of Liquid Recovery

\begin{tabular}{|c|c|c|c|c|}
\hline \multirow{2}{*}{ Case } & \multicolumn{3}{|c|}{ Cumulative Liquid Produced, bbls } & \multirow{2}{*}{$\begin{array}{l}\text { Fraction Recovery as a } \\
\text { Result of CO2 Cycling } \\
\qquad(\%)\end{array}$} \\
\hline & Reservoir Depletion & Total Recovery & CO2 Cycling & \\
\hline $\mathrm{BC}$ & $4,532,862$ & $12,348,048$ & $7,815,187$ & $63.29 \%$ \\
\hline SP & $5,062,376$ & $13,950,332$ & $8,887,956$ & $63.71 \%$ \\
\hline LP & $5,054,285$ & $13,859,993$ & $8,805,708$ & $63.53 \%$ \\
\hline
\end{tabular}

The cycling period does not allow the reservoir to drop below the saturation pressure of the reservoir, 3881 psia but some pressure drop is experienced as the heavy ends of the produced gas is removed before cycling, thus a lower cycle rate than production rate. Since the pressure does not drop below the saturation pressure the revaporized liquid enriches the cycled gas and be recovered.

Table 4.8: Volume of CO2 stored after Enhanced Condensate Recovery (ECR)

\begin{tabular}{|c|c|c|c|}
\hline Case & $\begin{array}{c}\text { Cumulative Gas Injected. SC } \\
(\mathrm{ft} 3)\end{array}$ & $\begin{array}{c}\text { Fraction increase in } \\
\text { storage } \\
(\%)\end{array}$ & $\begin{array}{c}\text { Total CO2 } \\
\text { sequestered } \\
(\mathrm{ft} 3)\end{array}$ \\
\hline BC & $12,099,944,450$ & $15.03 \%$ & $\mathbf{9 2 , 6 1 9 , 8 9 8 , 8 8 2}$ \\
\hline SP & $15,179,939,840$ & $16.22 \%$ & $\mathbf{1 0 8 , 7 8 9 , 3 0 9 , 4 4 0}$ \\
\hline LP & $14,519,992,320$ & $15.35 \%$ & $\mathbf{1 0 9 , 1 2 4 , 1 4 1 , 0 5 6}$ \\
\hline
\end{tabular}

To translate this enhanced liquid recovery into improved $\mathrm{CO} 2$ sequestration, pure $\mathrm{CO} 2$ is injected into the reservoir after the cycle period until the well bottom hole pressure reaches 4500 psia. Table 4.8 shows the additional $\mathrm{CO} 2$ that can be sequestered after enhanced liquid recovery. From this table an additional $12 \mathrm{BCF}$ of $\mathrm{CO} 2$ can be sequestered in the $\mathrm{BC}, 15 \mathrm{BCF}$ and $14.5 \mathrm{BCF}$ for the SP and LP respectively. This represents an average of $15 \%$ additional $\mathrm{CO} 2$ that can be sequestered after enhanced recovery. 


\section{CONCLUSIONS AND RECOMMENDATIONS}

The main focus of this research was to develop a model with a practical injection plan for enhanced liquid recovery and how does enhanced liquid recovery impact the amount of carbon dioxide being sequestered. Based on the results, the following conclusions and recommendations were made.

1. From the PVT analysis when carbon dioxide comes into contact with reservoir fluid the dew point decreases at the point of contact, the liquid-volume percent (liquid saturation) decreases, the compressibility factor decreases and the two-phase envelope diagram shrinks with increasing carbon dioxide composition. All these trends show the positive impact sequestering carbon dioxide have on liquid recovery.

2. The major mass transfer phenomenon by which carbon dioxide displaces reservoir liquid in by carbon dioxide-reservoir liquid miscible mixing. A minimum miscibility pressure of 3000 psia is observed.

3. Petrophysical properties and injection rate have shown little impact on enhanced liquid recovery.

4. Based on the injection schedule developed carbon dioxide has shown to recover $9 \%$ more liquid than when methane is used as an injection gas and $40 \%$ more liquid than when nitrogen is used.

5. Enhanced liquid recoveries in excess of $90 \%$ are achieved with carbon dioxide cycling.

6. Enhanced liquid recovery by carbon dioxide cycling has shown to increase the amount of carbon dioxide being sequestered into a gas-condensate reservoir by $15 \%$.

Based on the results obtained and conclusions made the following recommendations should be considered for further investigation: 
1. The phase behavior that occurs when the carbon dioxide mixes with the gas-condensate is not fully investigated in this research. The results showed that the carbon dioxide is miscible with the condensate, however it seems that there needs to a 'right' carbon dioxide and condensate composition or a particular fraction of carbon dioxide or fraction range by which the carbon dioxide behaves as a liquid thus increasing total liquid volume. It is also not certain what phase/ phases are present in the carbon dioxide-gascondensate mixture and based on what phase is present whether it causes liquid phase swelling or not.

2. The ability for carbon dioxide to sweep the entire reservoir is compromised when the reservoir contains heterogeneities, that is the displacement efficiency decreases with reservoir heterogeneity. As a result this may compromise liquid recovery. Optimizing well patterns and well placements could be further investigated to improve condensate recovery in heterogeneous gas-condensate reservoir.

3. Phase behavior is highly dependent on gas type composition. Accuracy in composition leads to accuracy in predicting phase behavior. In this investigation, it was assumed that the carbon dioxide injection stream was essentially $100 \%$ pure. In practice, however, carbon dioxide captured from flue gas stacks is likely to contain other gases. The effect of these impurities should be considered in further work on this subject. Furthermore, natural gas may also contain inorganic compounds such as hydrogen sulfide and nitrogen and the effect of these should also be investigated.

4. Miscibility is as a result of carbon dioxide mixing with the heavy end components in the reservoir $-\mathrm{C} 7+$ fractions. In this investigation the $\mathrm{C} 7+$ fraction was $6.88 \%$. By investigating various gas-condensate compositions (lean gas-condensate, rich gascondensate, etc.), a detailed picture can be painted on how carbon dioxide injection impacts liquid recovery in gas-condensate reservoirs.

5. Carbon dioxide has a critical temperature of $31.1^{\circ} \mathrm{C}\left(88^{\circ} \mathrm{F}\right)$ and pressure of $73 \mathrm{~atm}$ (1071psia) (Appendix G). The reservoir temperature in this investigation was $200^{\circ} \mathrm{F}$, 
which states that carbon dioxide in is the supercritical phase at any pressure. Gascondensate reservoirs whose temperatures are below the critical temperature could be the subject of further investigation. 


\section{REFERENCES}

Adisoemarta, P. S., Frailey, S. M., \& Lawal, A. S. (2004). Measured Z-Factor of CO2--Dry Gas/Wet Gas/Gas Condensates for CO2 Storage in Depleted Gas Reservoirs. SPE/DOE Symposium on Improved Oil Recovery. Tulsa: SPE.

Al-Abri, A., Sidiq, H., \& Amin, R. (2009). Enhanced Natural Gas and Condensate Recovery by Injection of Pure SCCO2, Pure CH4 and Their Mixtures: Experimental Investigation. Annual Technical Conference and Exibition. New Orleans: SPE.

Al-Anazi, H. A., Sharma, M. M., \& Pope, G. A. (2004). Revaporization of Condensate with Methane Flood. SPE International Petroleum Conference. Puebla: SPE.

Al-Mahros, F. M., \& Tojoa, G. H. (1987). Analysis of Phase Behavior of Khuff Gas Condensae System in Bahrain field SPE 15766. Bahrain: SPE.

Barrufet, M. A., Bacquet, A., \& Falcone, G. (2009). Analysis of the Storage Capacity for CO2 Sequestration of a Depleted Gas Condensate Reservoir and a Saline Aquifer. Canadian Interantional Petroleum Conference. Calgary: PETSOC.

Besserer, G. J., \& Serra, W. (1979). An Efficient Phase Behavior package for Use in Compositional Rerservoir Simulation Studies SPE 8288. Ann. Tech. Conf. and Exhib. Las Vegas: SPE.

Bette, S., \& Heineman, R. F. Compositional Modeling of High Temperature Gas Condensate Reservoir with Water Vaporization. SPE 18422. SPE Symp. on Res. Simulation. Houston.

Carbon Dioxide Utilization. (1997). IEA Greenhouse Gas R\&D Programme, Table 6. International Energy Agency, IEA.

Chaback, J. J., \& Williams, M. L. (1994). P-X Behavior o fRich Gas Condensate in admixture with CO2 and (N2 +CO2). SPE 24132. Tulsa: SPE.

Coats, K. H., \& Smart, G. T. (1986). Application of a Regression-Based EOS PVT Program to Laboratory Data. (SPE 11197-1982 ). In SPE Reservoir Eng (pp. 277-299).

Coats, K. (1985). Simulation of Gas Condensate Reservoir Performance (SPE 10512 - 1982). JPT, 1870-1886.

Cole, F. (1969). Reservoir Engineering Manual. Houston: Gulf Publishing Company. 
Conrad, P., \& Gravier, J. (1980). Peng-Robinson Equation of State Checks the Validity of PVT Experiments. Oil \& Gas Journal, 72-86.

Craft, B., Hawkins, M., \& Terry, R. (1991). Applied Reservoir Engineering, 2nd Edition. Englewood Cliffs: Prentice Hall.

Danesh, A. (2007). PVT and Phase Behaviour of Petroleum Reservoir Fluids . Netherlands: Elsevier.

Donohoe, C. W., \& Buchanan, R. D. (1981). Economic Evaluation of cycling gas-condensate reservoirs with nitrogen. $J P T$, 263-270.

Douglas, E. K., \& Bohle, G. A. (1987). Third SPE Comparative Solution Project: Gas Cycling of Retrograde Condensate Reservoirs. JPT , 981-997.

Drohm, J. K., Goldthrope, W. H., \& Trengove, R. (1988). Enhancing the Evaluation of PVT Data. OSEA 88174. 7th Offshore South East Asia, (pp. 626-635).

Firoozbadi, A., Hekim, Y., \& Katz, D. L. (1978). Reservoir Depletion Calculations for Gas Condensate using Extended analysis in the Peng Robinson Equaiton of State. J. Cand. Chem. Eng., (pp. 610-615).

Freeze, A., \& Cherry, J. (1979). Groundwater. Englewood Cliffs: Prentice Hall.

Furniual, S. R. (1993). Successful Prediction of Condensate Well bore Behavior Using EOS General from Black Oil Data. SPE 26683. Offshore European Conf. Aberdeen: SPE.

Ghedan, S. (2009). Global Laboratory Experience of CO2-EOR Flooding. SPE/EAGE Reservoir Charazcterization and Simulation COnference. Abu Dhabi: SPE.

Goricnik, B., Sarapa, M., \& Csisko, M. (1995). Phase equilibria in a rich-gas condensate-CO2 and natural gas mixtures. NAFTA, Vol 46, 371-377.

Grigg, R. (2005 ). "Long-term CO2 Storage: Using Petroleum Industry Experience". In D. Thomas, \& S. Benson, Carbon Dioxide Capture for Storage in Deep Geologic Formations. Elsevier Ltd.

Hernandez, I., Farrouq Ali, S. M., \& Brentsen, R. G. (1999). First steps for developing an improved recovery method for a gas condensate reservoir. CSPG and Petroleum Society Joint Convention, Digging Deeper, Finding a Better Bottom Line. Calgary.

(1998). Impacts of the Kyoto Protocol on the US Energy Markets and Economic Activity. Washington : U.S. Department of Energy. 
International Energy Agency Greenhouse Gas Program. Sponsored by European Union Commission, 20 countries and multiple companies. (n.d.). Retrieved from wwTv.ieagreen.org.uk Kenyon, D. E., \& G. Alda, B. (1987). Third SPE Comparative Solutin Project: Gas Cycling of Retrograde Condensate Reservoirs, SPE 12278. SPE.

Kilgren, K. H. (1966). Phase Behaviour of a High-Pressure Condensate Reservoir Fluid. JPT , 1001-1005.

Klotz, J. A. (1953). Condensate Production. JPT, Vol. 5, 27-29.

Li, S., Zheng, X., Dai, Z., Luo, K., Chen, G., \& Liu, N. (2001 ). Investigation of Revaporization of Retrograde Condensate SPE 68170. SPE Middle East Show. Manama: SPE.

Luo, K., Li, S., Zheng, X., Chen, G., Dai, Z., \& Liu, N. (2001). Experimental Investigation into Revaporization of Retrograde Condensate by Lean Gas Injection SPE 68683. SPE Asia Pacific Oil and Conference and Exhibition. Jakarta: SPE.

Martin. (1979). Cubic Equation of state Which? Ind. and Eng. Chem. Fund, 80-81.

McCain Jr., W., \& Bridges, B. (1994 ). Volatile Oils and Retrograde Gases - What's the Difference? Petroleum Engineer International , 35-36.

Moses, P. L. (1986). Engineering Applications of Phase Behaviour of Crude Oil and Condensate Systems. JPT .

Nguyen, D. (2003). Carbon Dioxide Geological Sequestration: Technical and Economic Reviews, SPE 81199. San Antonio: SPE.

Peng, D. Y., \& Robenson, D. B. (1976). A new two-constant equation of state. Ind. Chem. Fund Vol. 15 , 1, 59-64.

Raghavan, R., \& JR., J. (1996). Depletion Performance of Gas Condensate Reservoirs. JPT , 725731.

Redlich, O., \& Kwong, J. N. (1949). On the thermodynamics of solution V. An Equation of state, Fugacities of gaseous solution. Chem. Review , 44, 233-244.

Saker, R., Danesh, A. S., \& Todd, A. C. (1991). Phase Behavior Modeling of Gas Condensate Fluids using an equation of state, SPE 22714. Dallas: SPE.

Sänger, P. J., \& Hagoort, J. (1998). Recovery of gas-condensate by nitrogen injection compared with methane injection. SPEJ. 
Shedid, A. S., Zekri, A. Y., \& Almhehaideb, R. (2008). Optimization of Carbon Dioxide Flooding For a Middle-Eastern Heterogeneous Oil Reservoir. Canadian International Petroleum Conference/SPE Gas Technology Symposium 2008 Joint Conference. Calgary: PETSOC.

Shtepani, E. (2006). CO2 Sequestration in Depleted Gas/Condensate Reservoirs. Annual Technical Conference and Exibition. San Antonio: SPE.

Sigmund, P. M., \& Cameron, A. M. (1977). Recovery of retrograde condensed liquids by revaporization during dry gas injection. J Can. Pet. Tech., (pp. 64-77).

Smith, L. R., \& Yarborough, L. (1968). Equilibrium Revaporization of retrograde condensate by dry gas injection. SPEJ.

Soave, G. (1972). Equilibrium constants from modified Redlich-Kwong equation of state. Chem. Eng. Sci. Vol. 27 , 27, 1197-1203.

(1997). UNFCC: Protocol adopted by the Third Conference of Parties (COP-3) to the United Nations Framework Convention on Climate Change. Kyoto.

Vogel, J. L., \& Yarborough, L. (1980). Effect of nitrogen on the phase behavior and properties of reservoir fluids SPE 8815. Enhanced oil Recovery Symp. Tulsa.

Whitson, C. H., \& Torp, S. B. (1983). Evaluating Condensate Volume Depletion Data. JPT , 610620.

Willhite, G. (1998). Enhanced Oil Recovery. Richardson: SPE Textbook Series 6.

Williams, A. C., \& Zana, E. N. (1980). Use of the Peng-Robinson equation of state to predict hydrocarbon phase behavior and miscibility for fluid displacement SPE 8817. Enhance Oil Recovery Sym. Tulsa.

Xie, X. (2009). The Impact of Carbon Geological Sequestration, SPE 120333. San Antonio: SPE.

Zudkevitch, D. a. (n.d.). Correlation and prediction and vapor liquid equilibria with the RedlichKwong equation of state. AICHe J. , 496-498. 


\section{APPENDIX}

\section{APPENDIX A: Additional PVT Results}

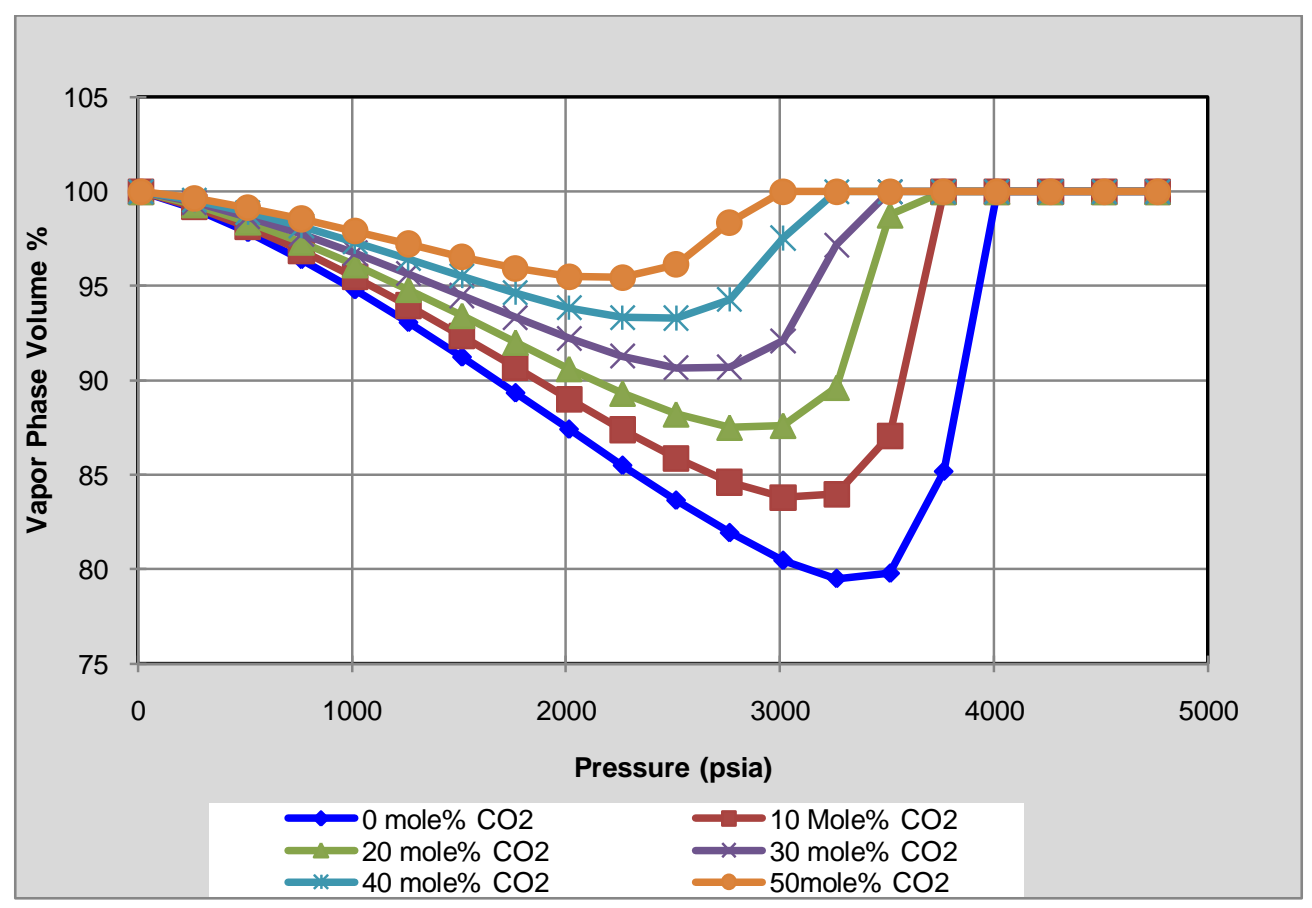

Figure A- 1: Vapor Phase Volume \% for GC and GC-CO2 mixtures

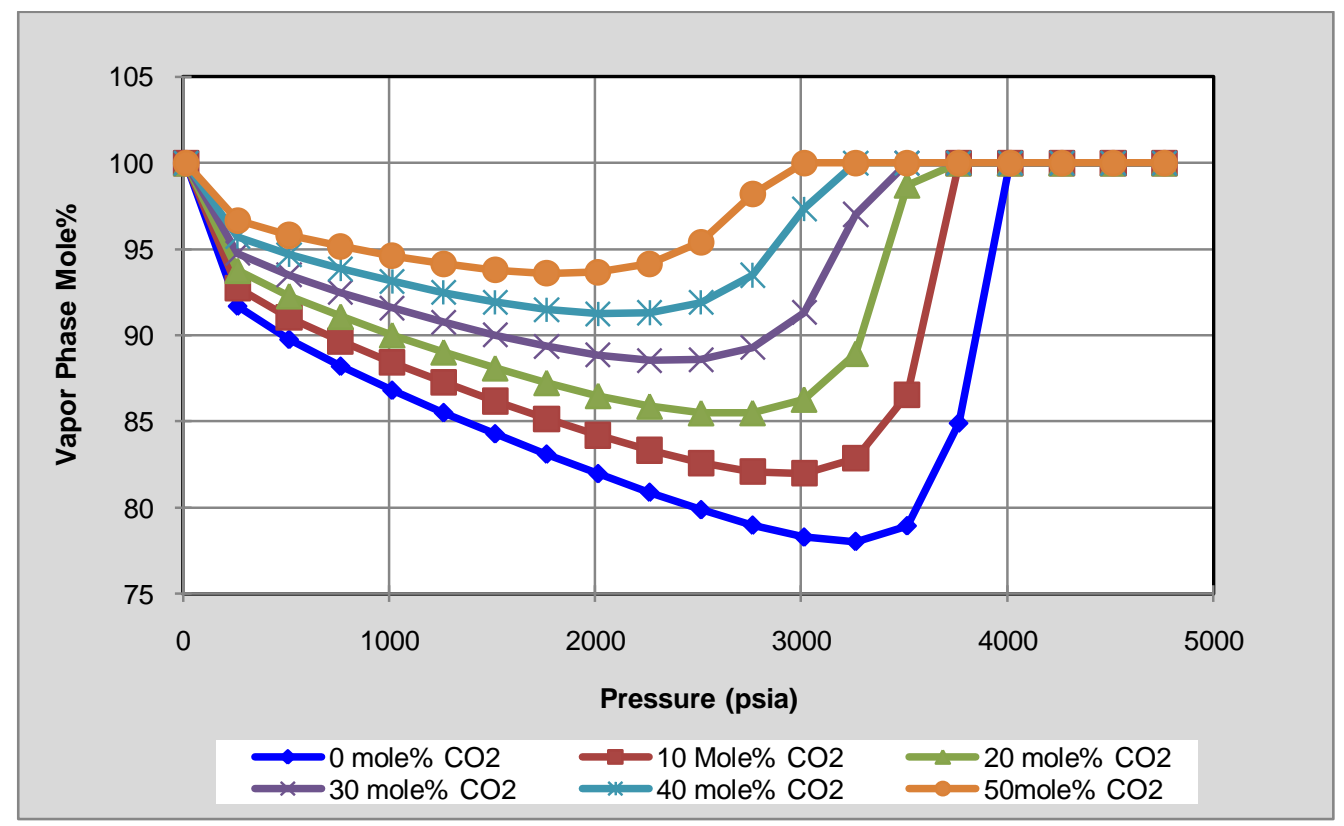

Figure A- 2: Vapor Phase Mole \% for GC and GC-CO2 mixtures 


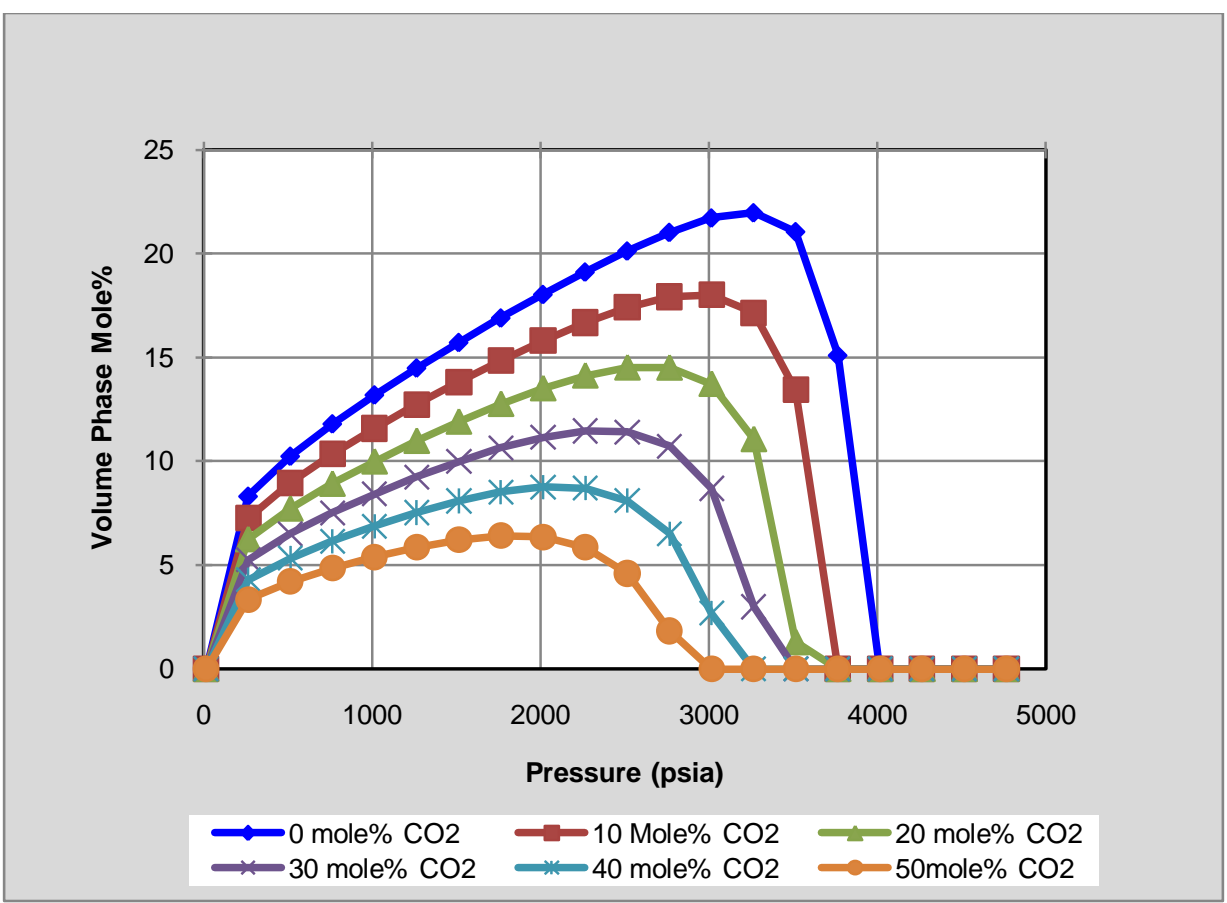

Figure A- 3: Liquid Phase Mole \%for GC and GC-CO2 mixtures

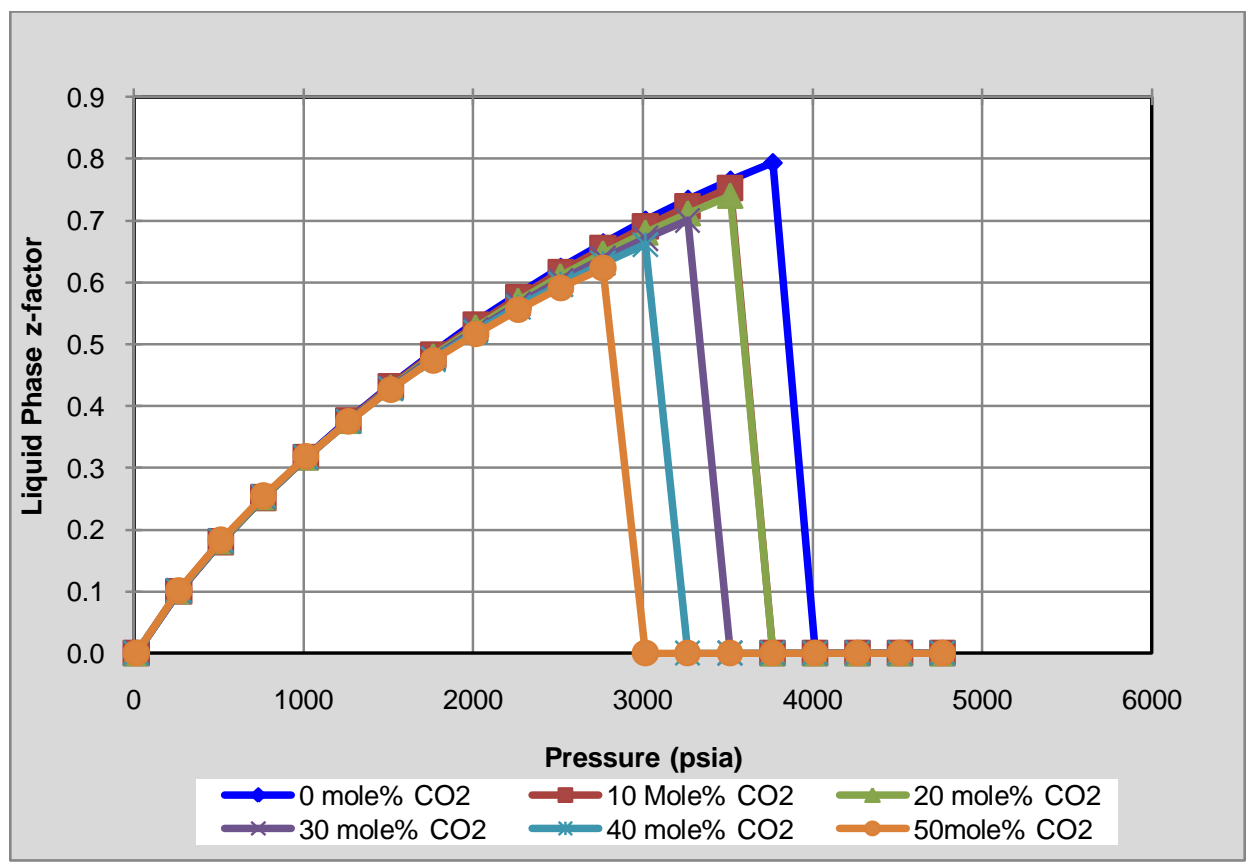

Figure A- 4: Liquid Phase z-factor 


\section{APPENDIX B: BC screen shots at the end of injection}

BC screen-shots at the end of injection showing the near production well and reservoir boundary experiencing $\mathrm{CO} 2$-liquid miscibility in all layers

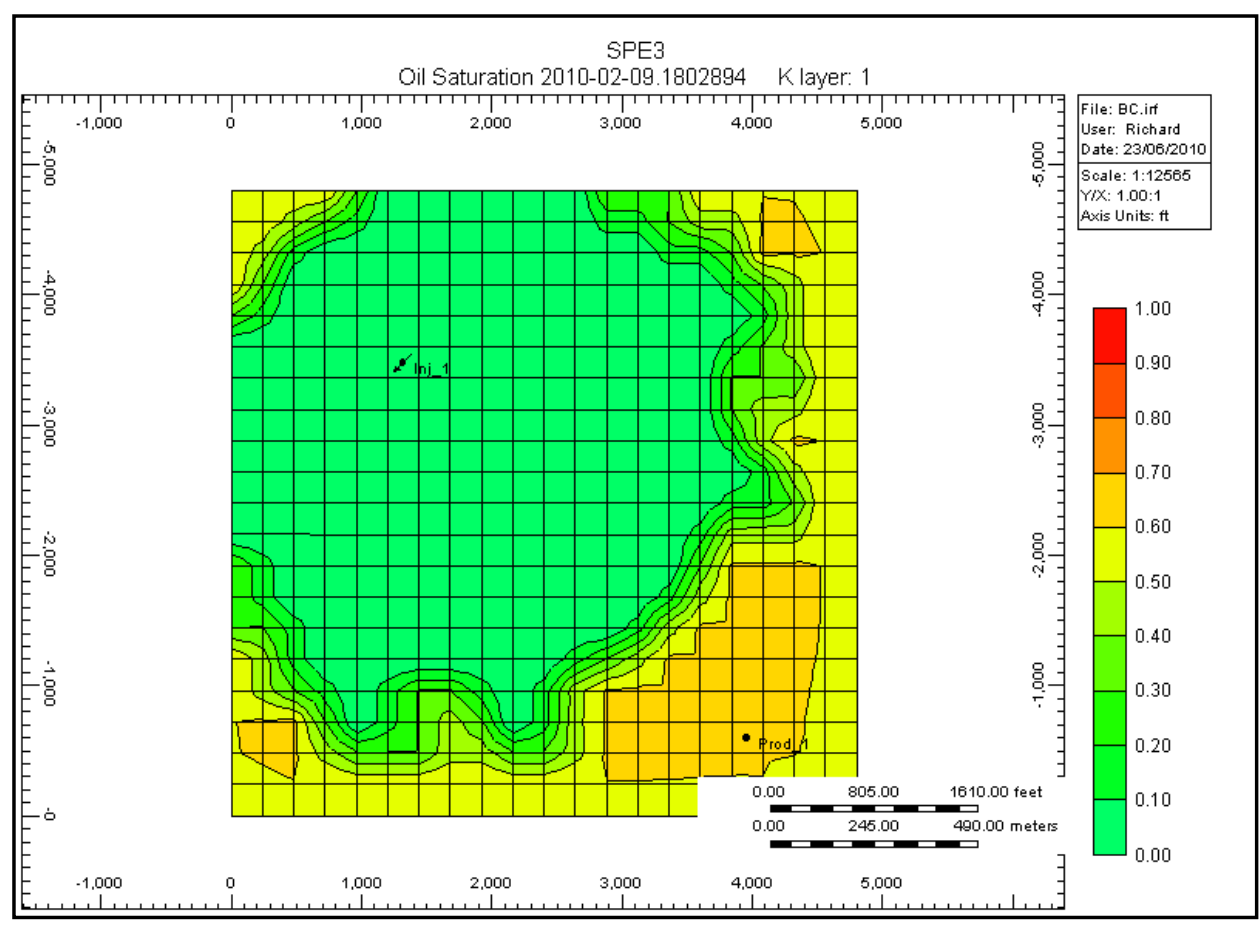

Figure B- 1: Screen-shot for Layer 1 at the end of pressurization period

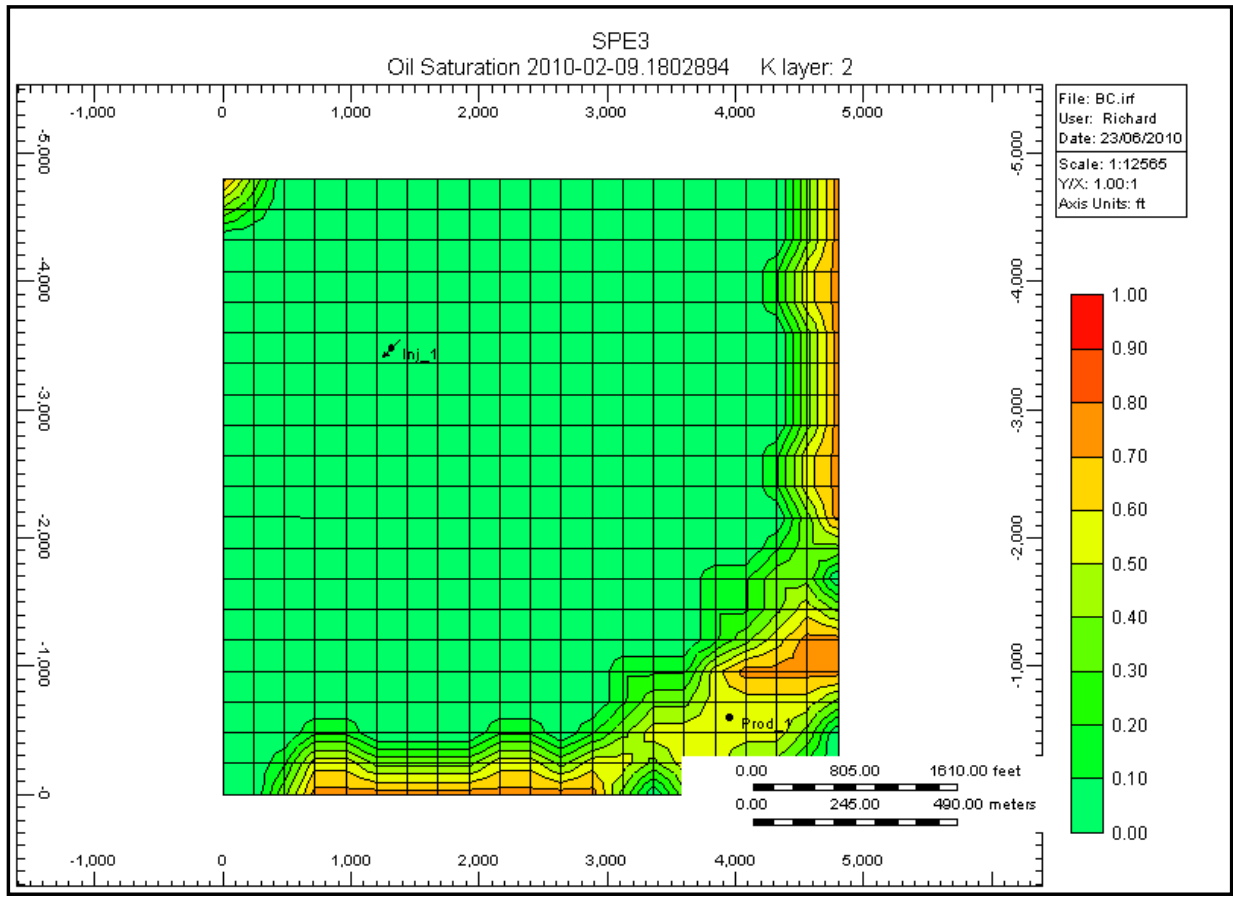

Figure B- 2: Screen-shot for Layer 2 at the end of pressurization period 


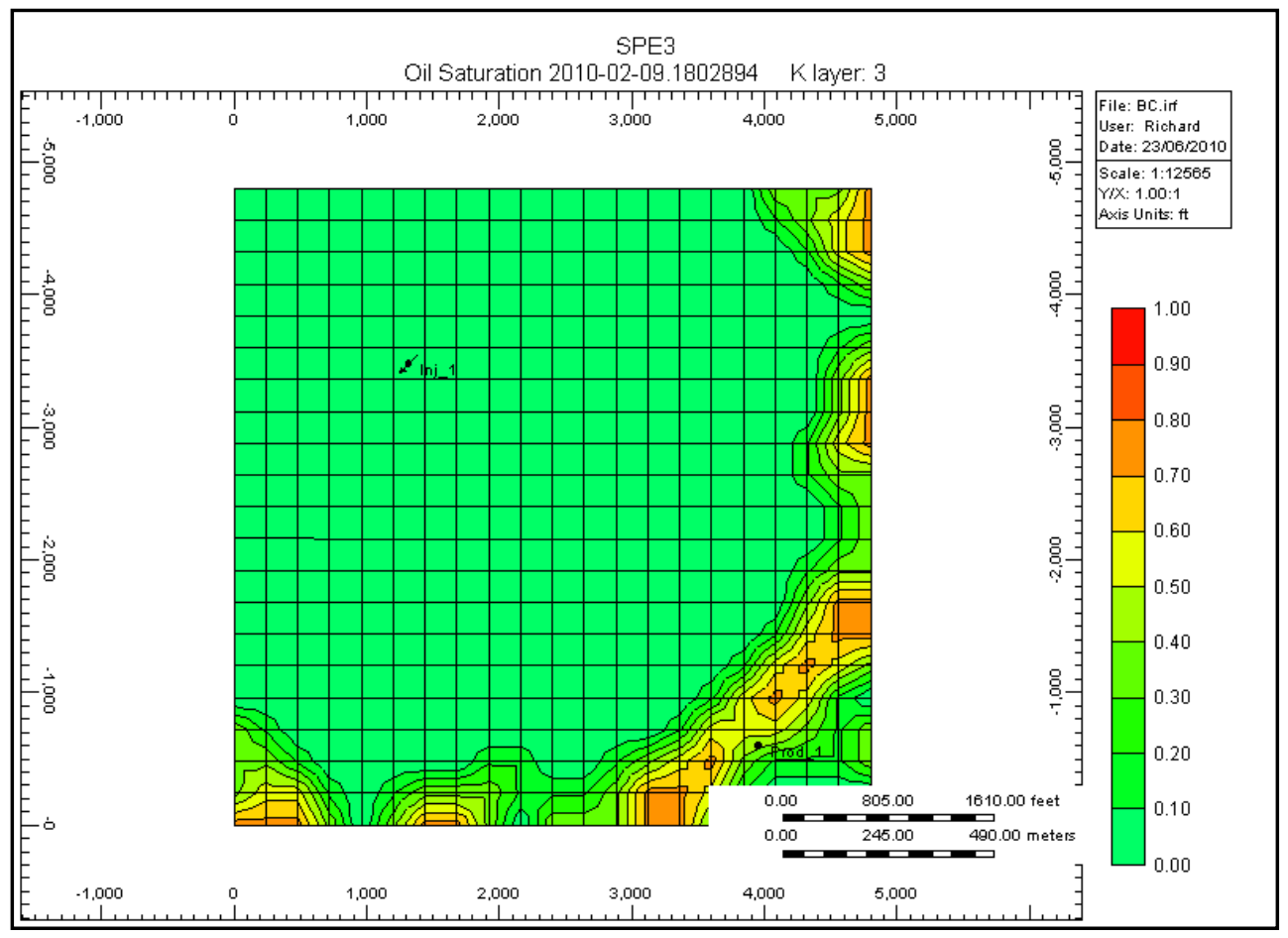

Figure B-3: Screen-shot for Layer 3 at the end of pressurization period

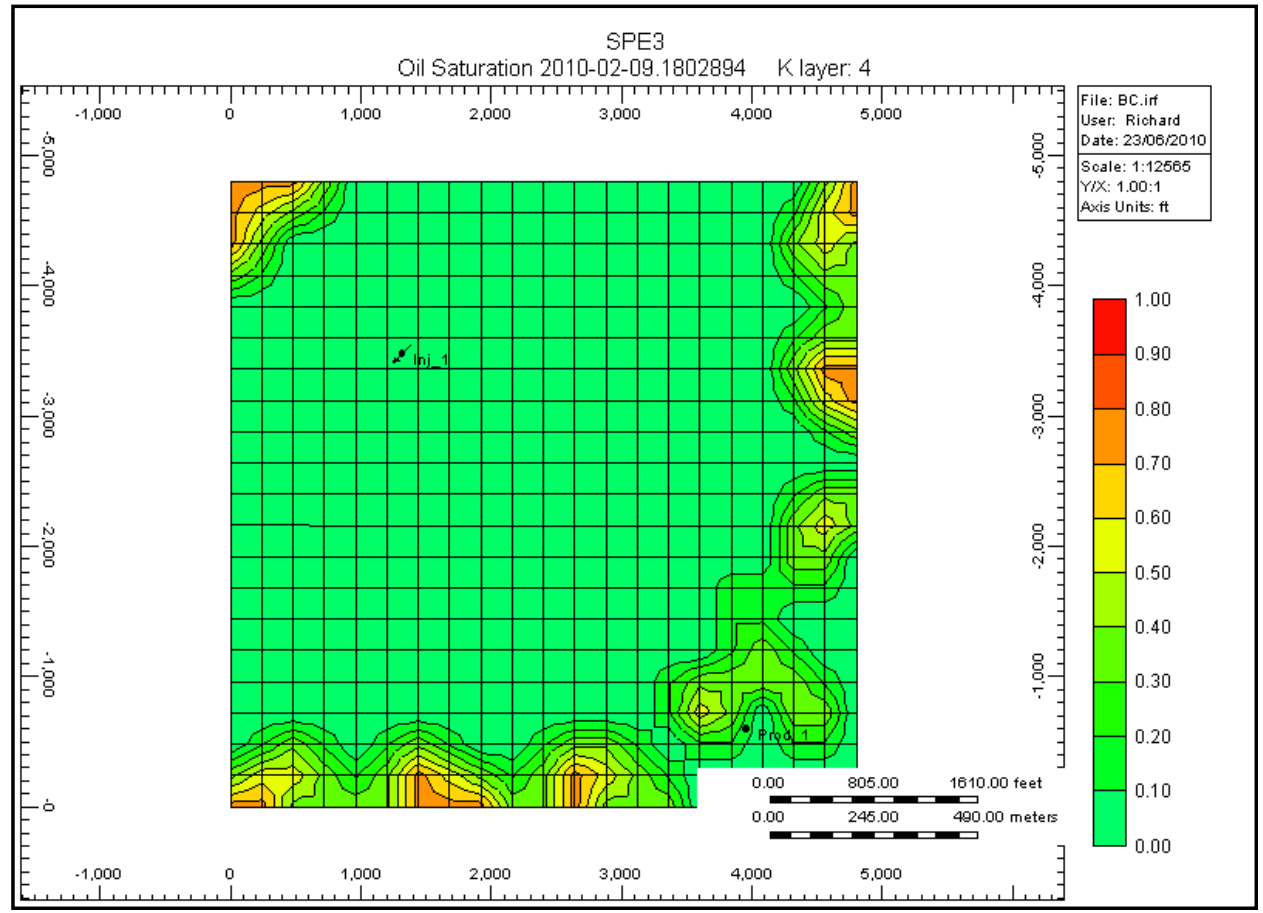

Figure B- 4: Screen-shot for Layer 4 at the end of pressurization period 


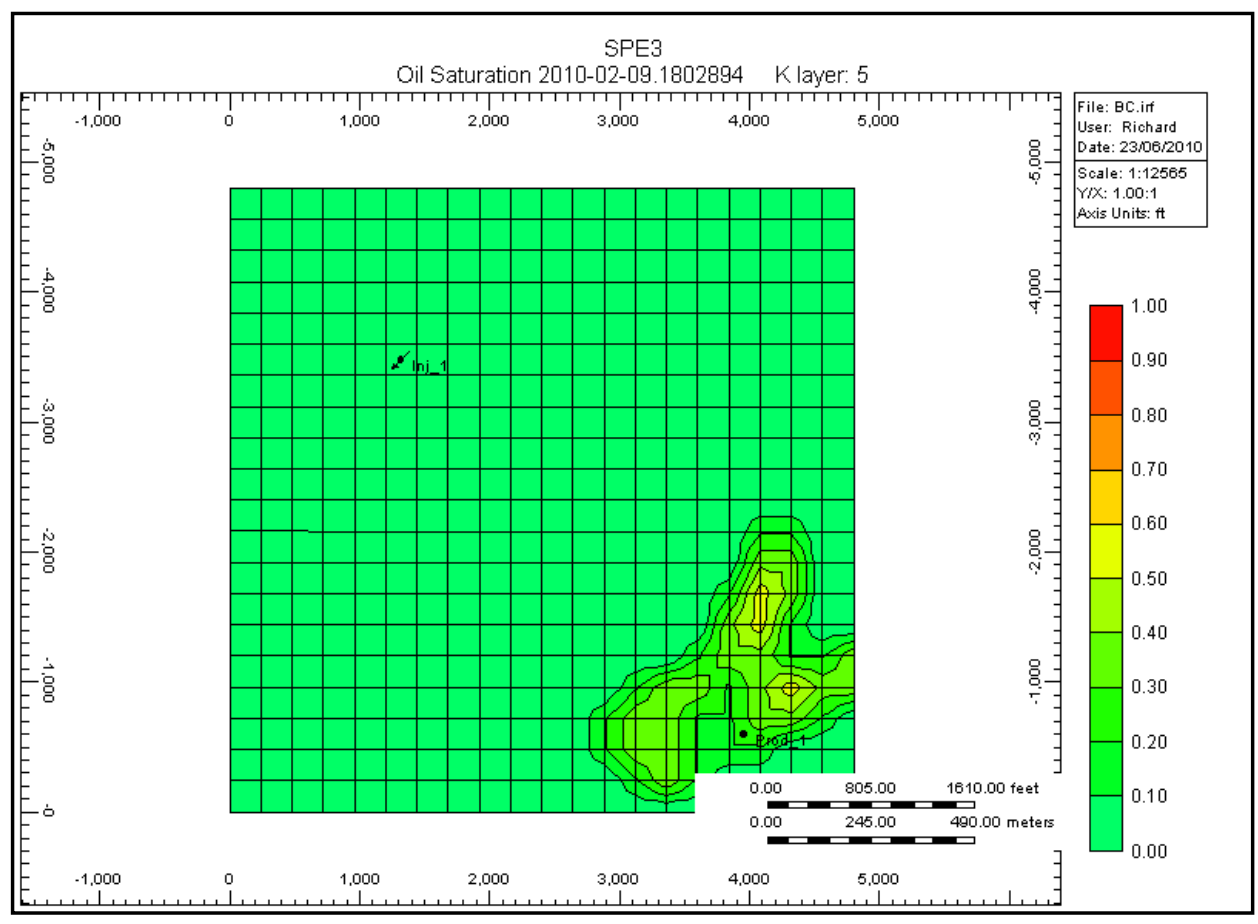

Figure B- 5: Screen-shot for Layer 5 at the end of pressurization period 


\section{APPENDIX C: MMP plots}

The following are MMP plots referenced in the body of the project

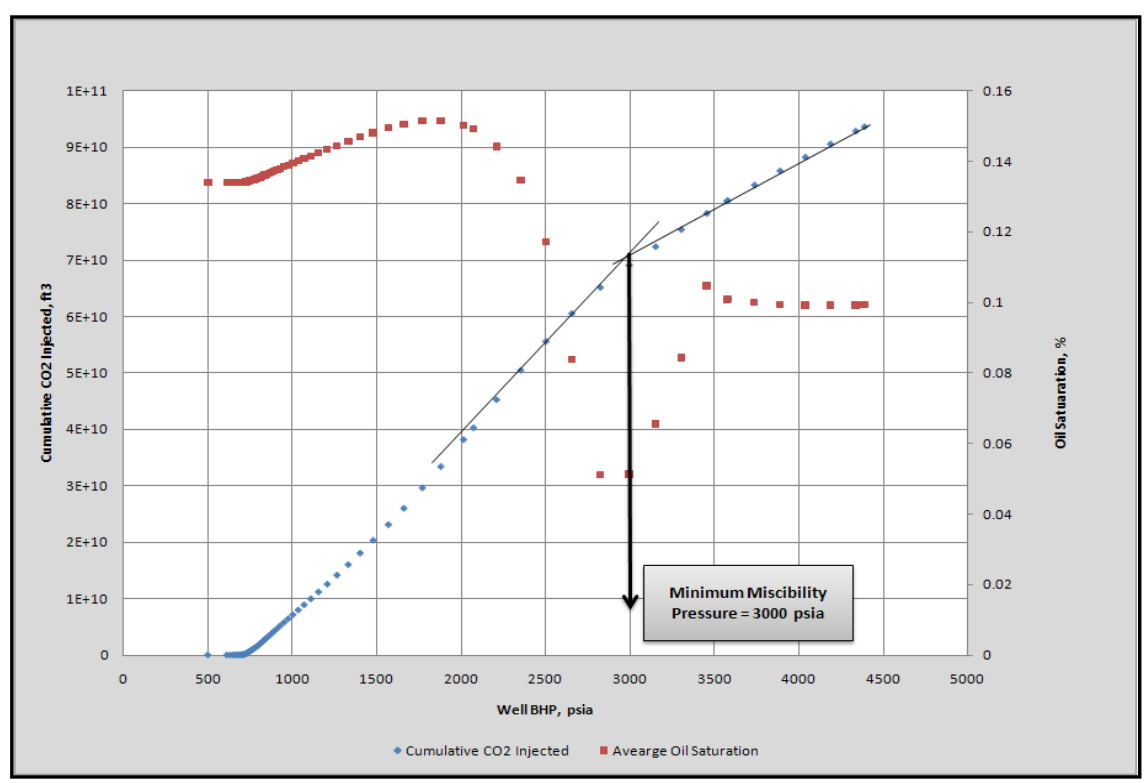

Figure C- 1: MMP for LPL layer 1

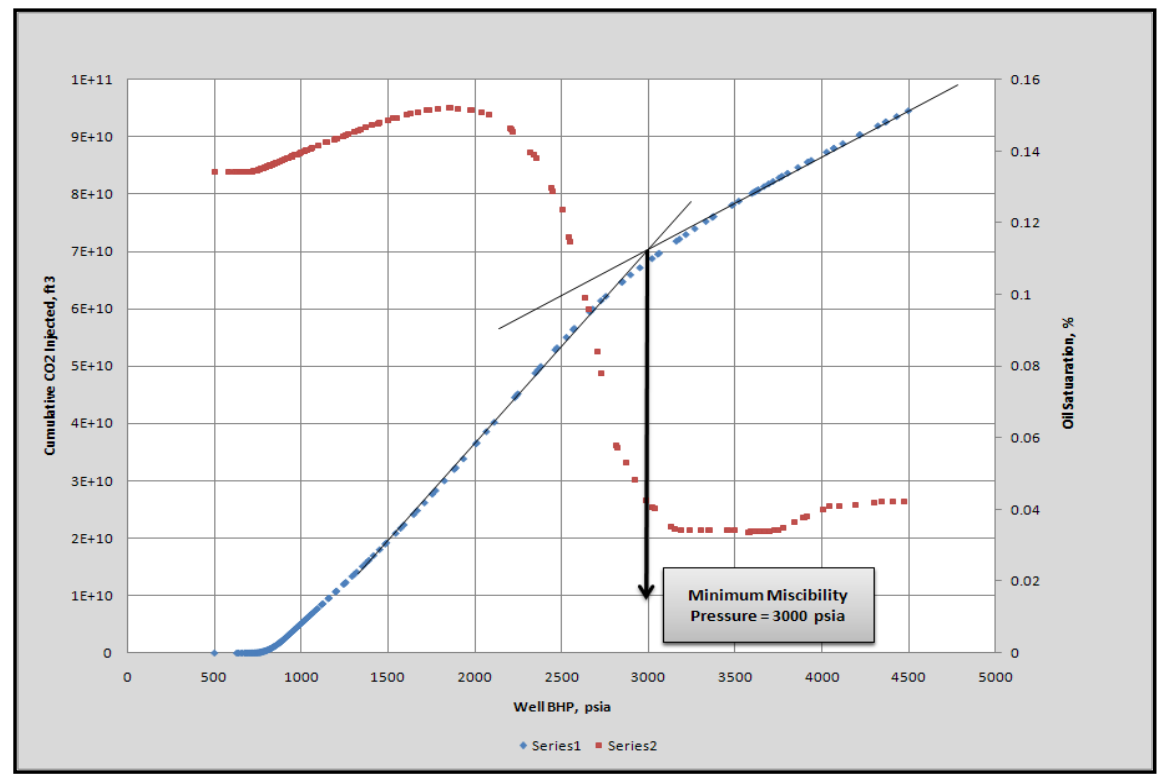

Figure C- 2: MMP for LPL layer 3 


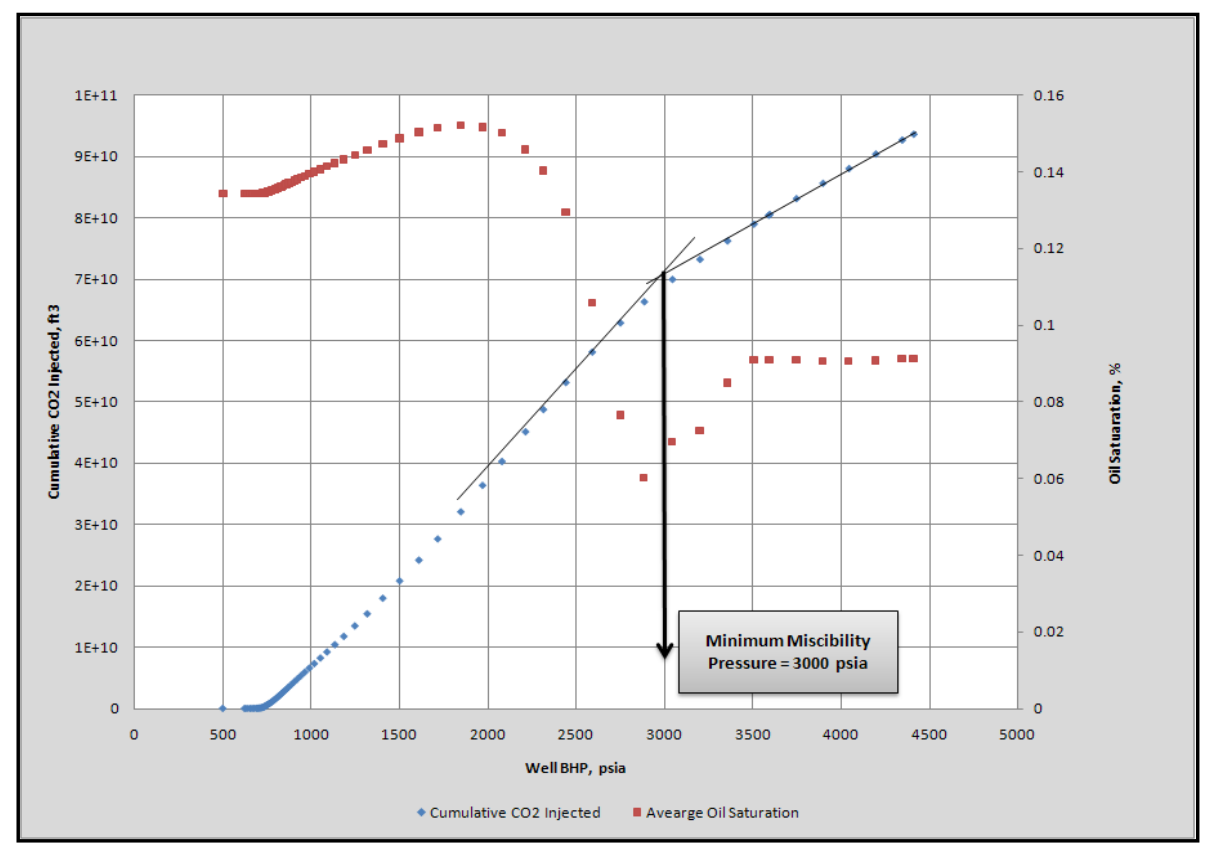

Figure C- 3: MMP for LPL layer 5

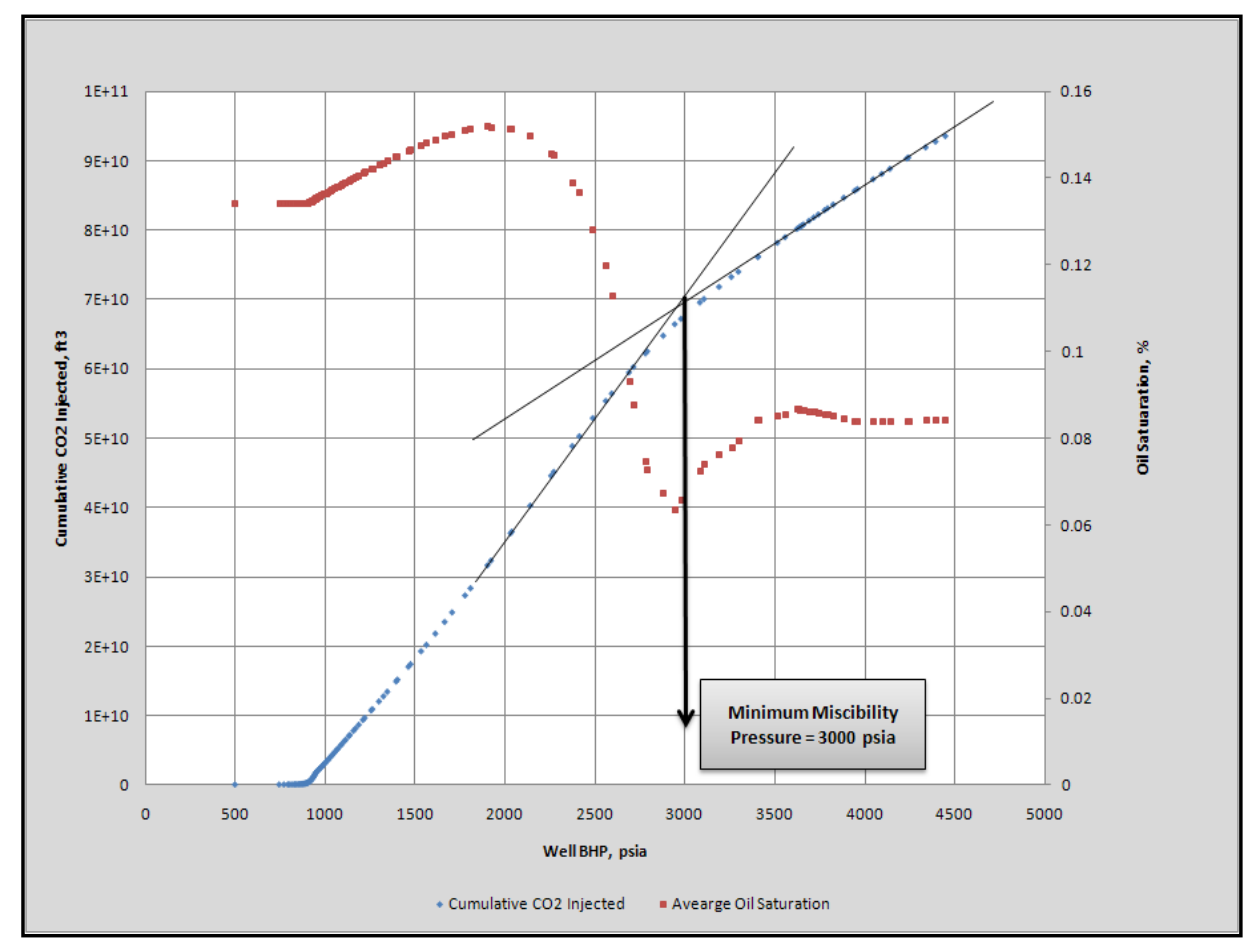

Figure C- 4: MMP plot for SP-5L 


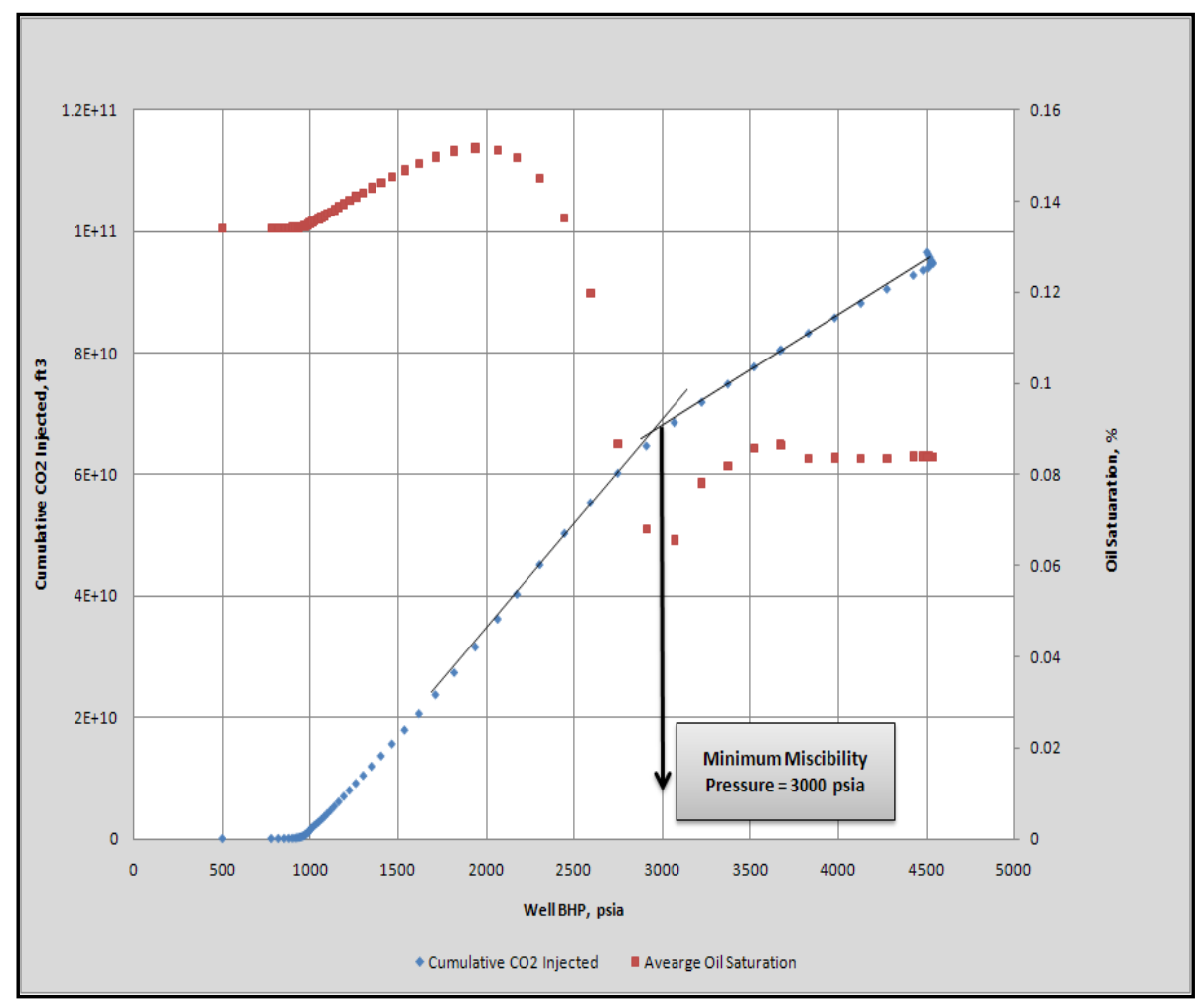

Figure C- 5:MMP plot for SP-L3 


\section{APPENDIX D: LPL-L1 screen shots at the end of injection period}

LPL-L1 screen-shots at the end of injection period showing the near production well and reservoir boundary experiencing $\mathrm{CO} 2$-liquid miscibility

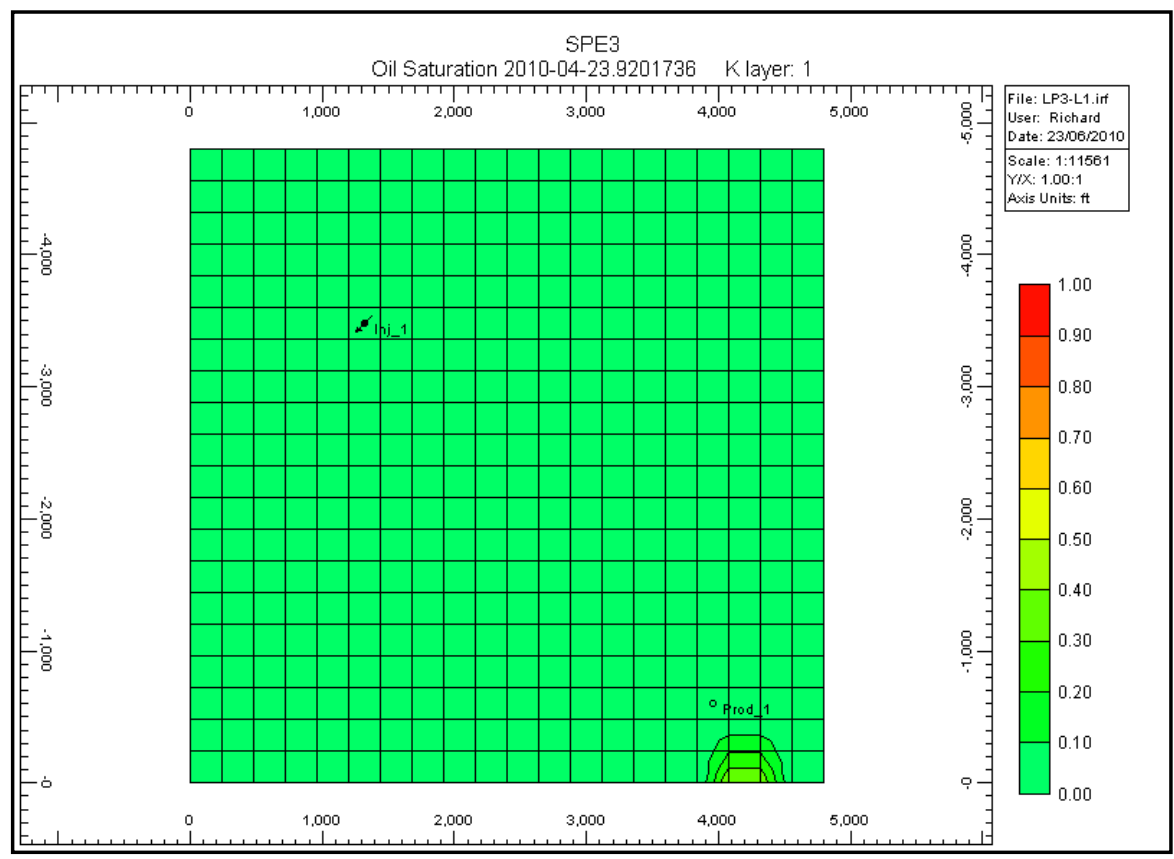

Figure D- 1: Screen-shot for Layer 1 at the end of pressurization period

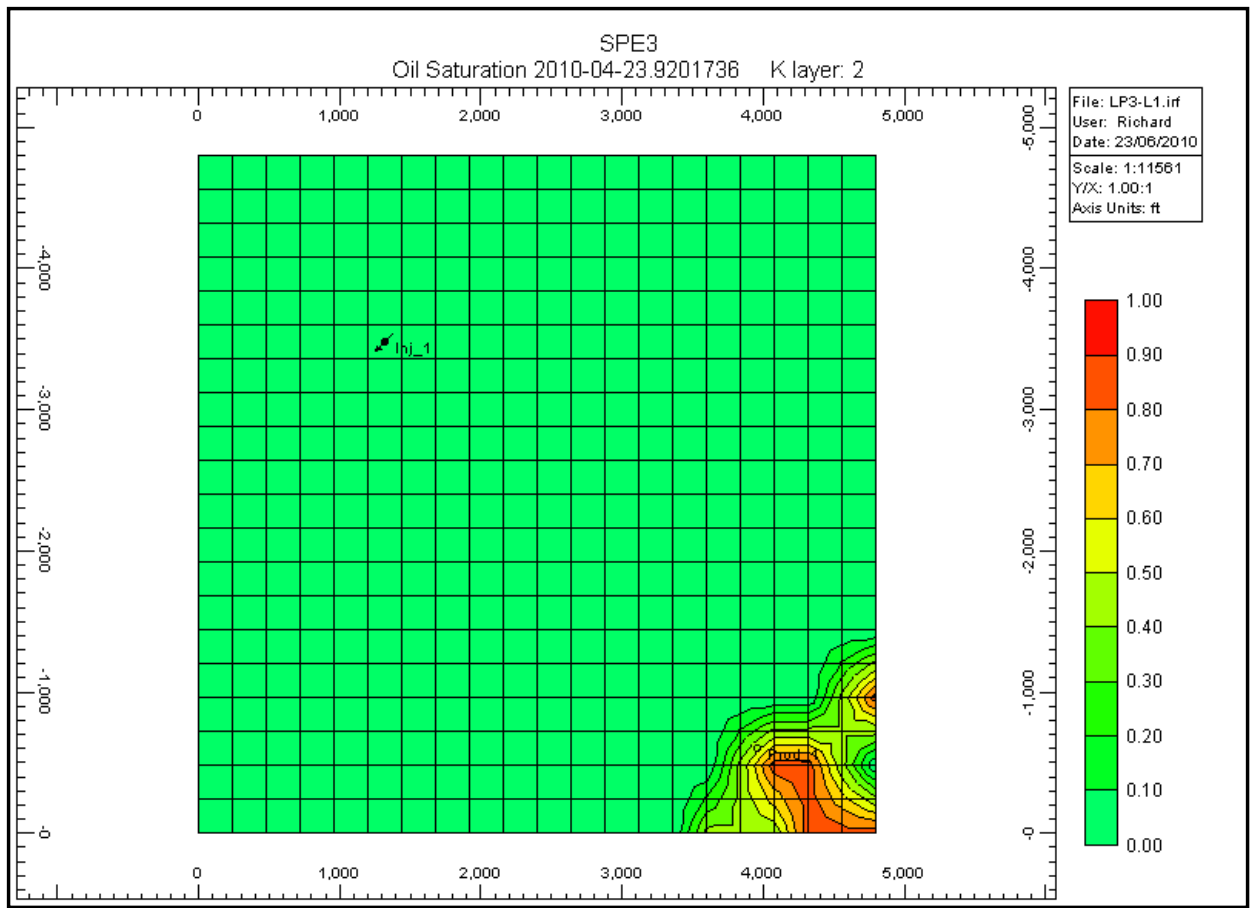

Figure D- 2: Screen-shot for Layer 2 at the end of pressurization period 


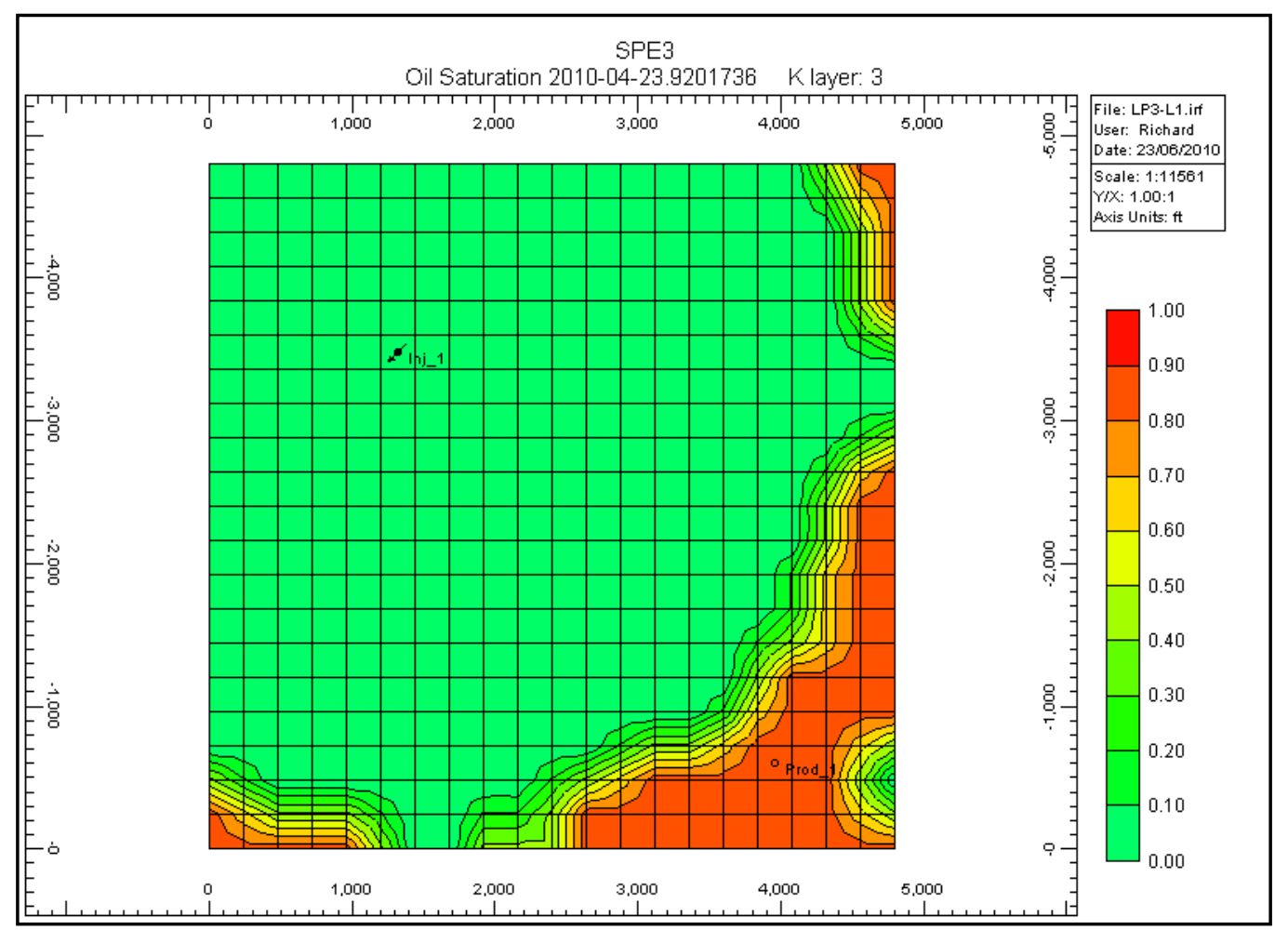

Figure D- 3: Screen-shot for Layer 3 at the end of pressurization period

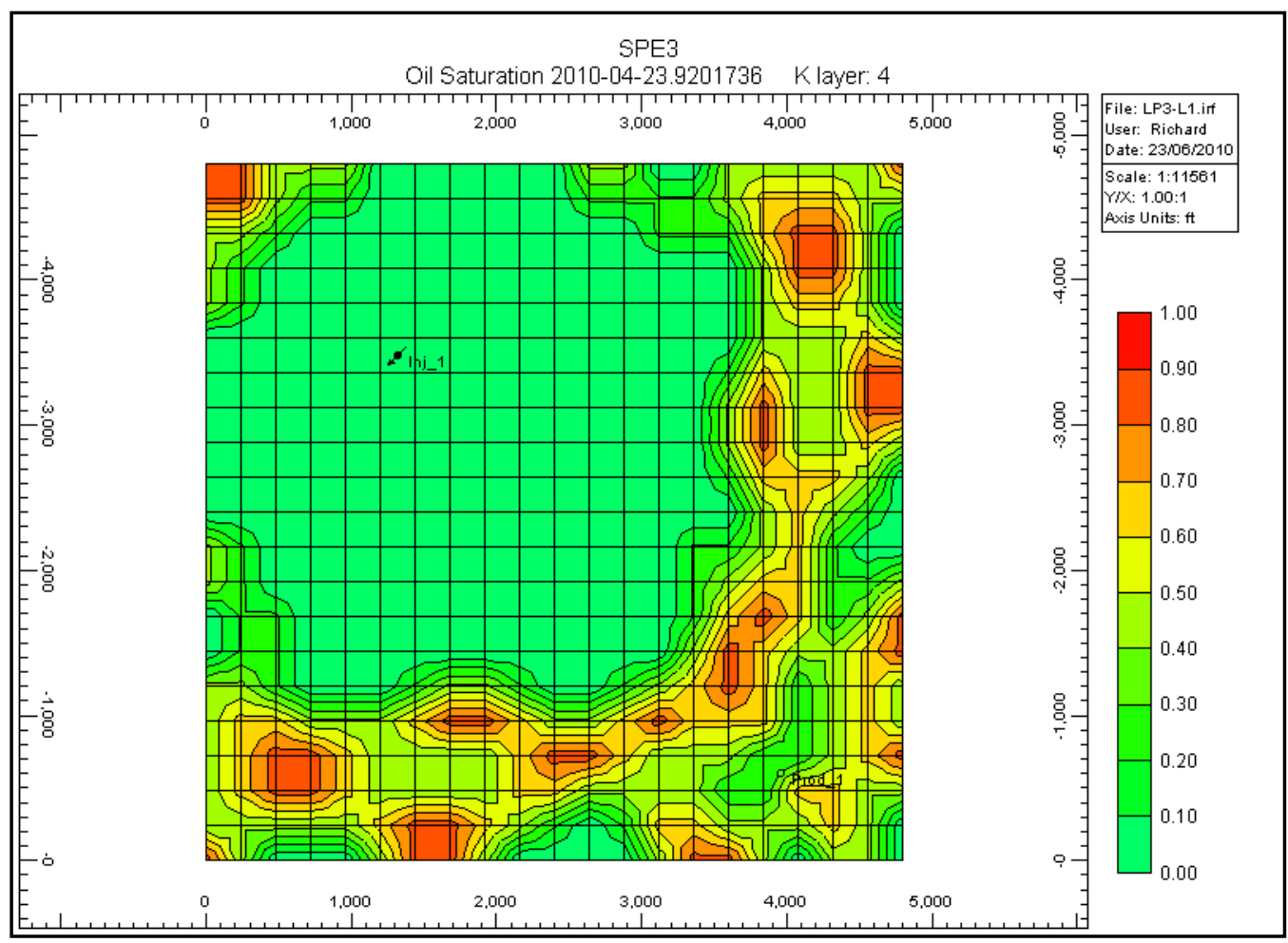

Figure D- 4: Screen-shot for Layer 4 at the end of pressurization period 


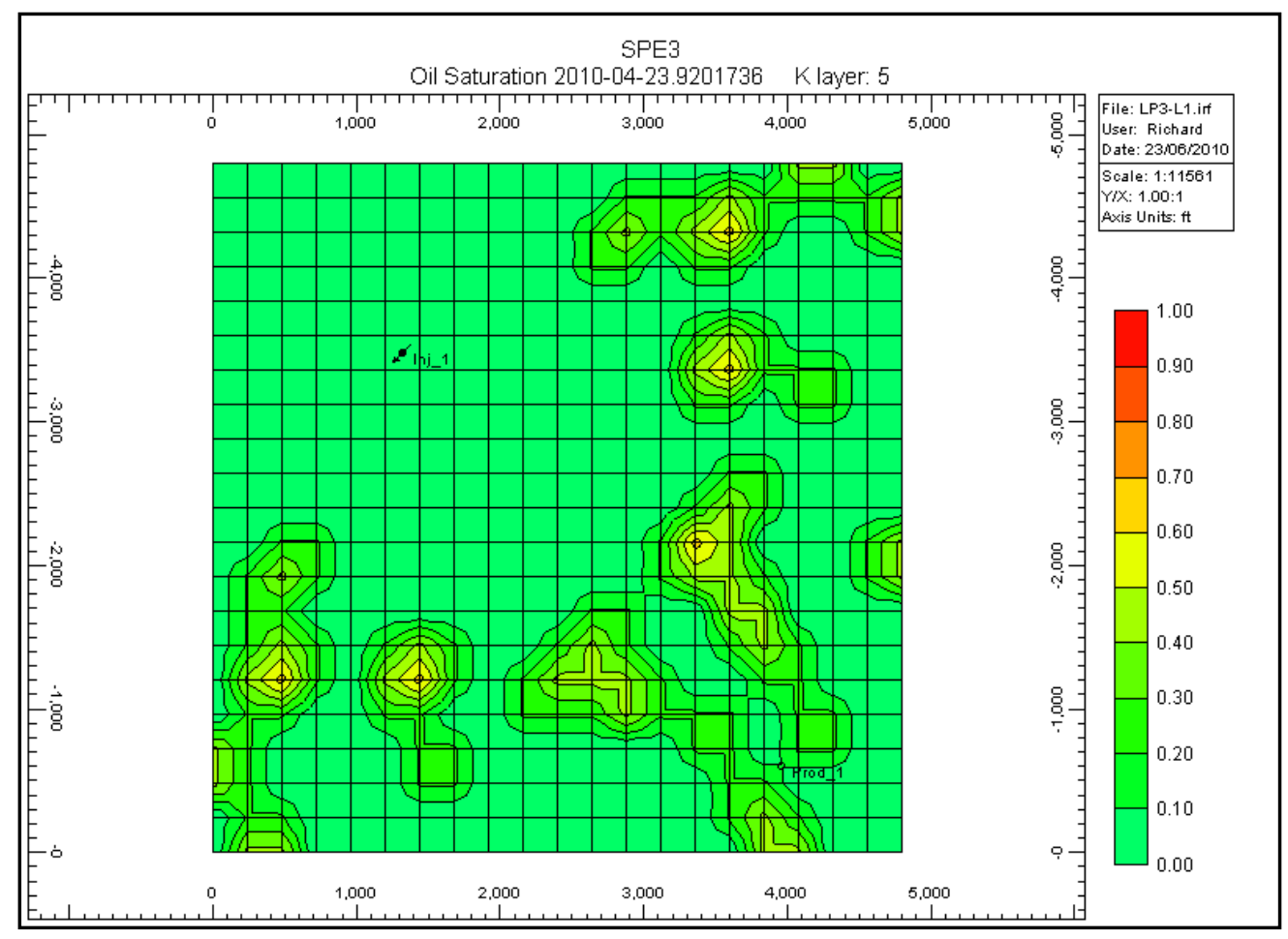

Figure D- 5: Screen-shot for Layer 5 at the end of pressurization period 


\section{APPENDIX E: LPL-L5 screen-shots at the end of injection period}

LPL-L5 screen-shots at the end of injection period showing the near production well and reservoir boundary experiencing $\mathrm{CO} 2$-liquid miscibility

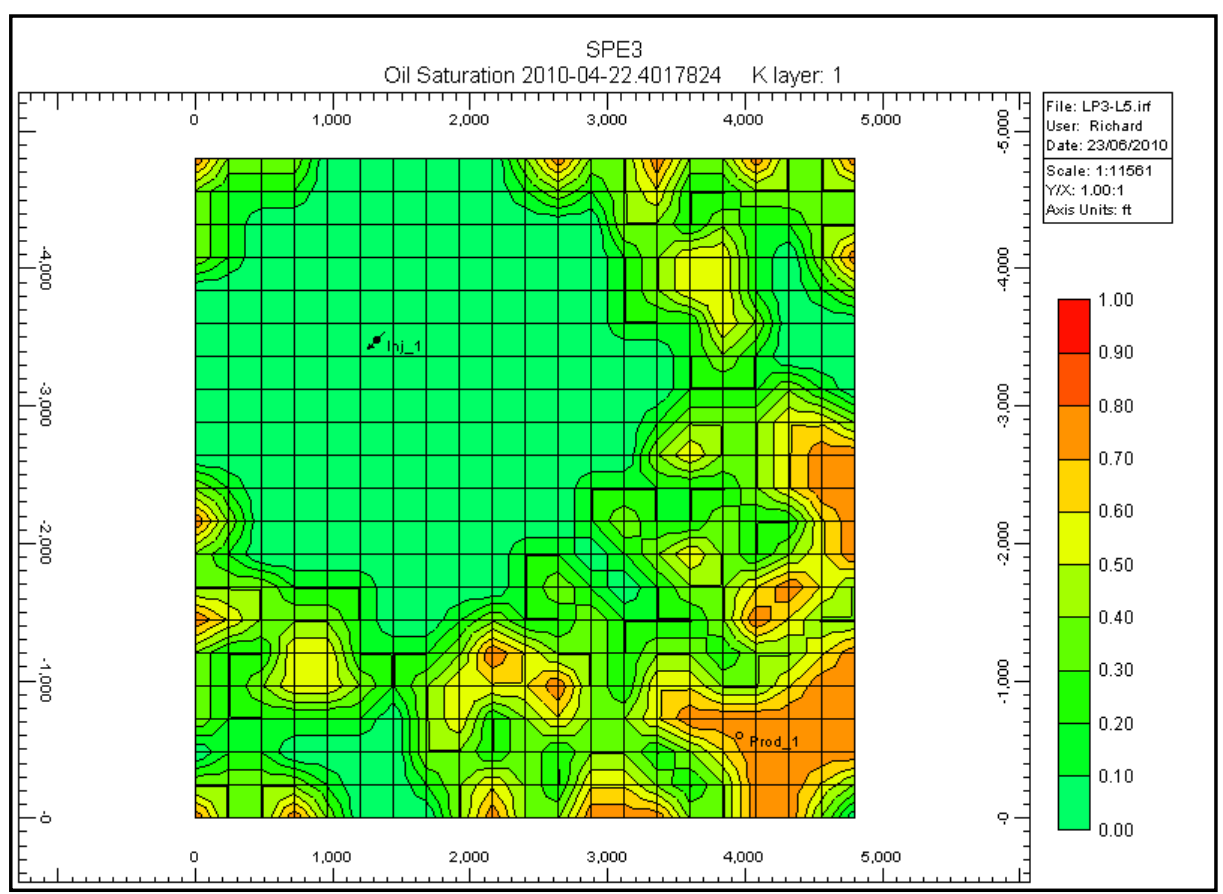

Figure E- 1: Screen-shot for Layer 1 at the end of pressurization period

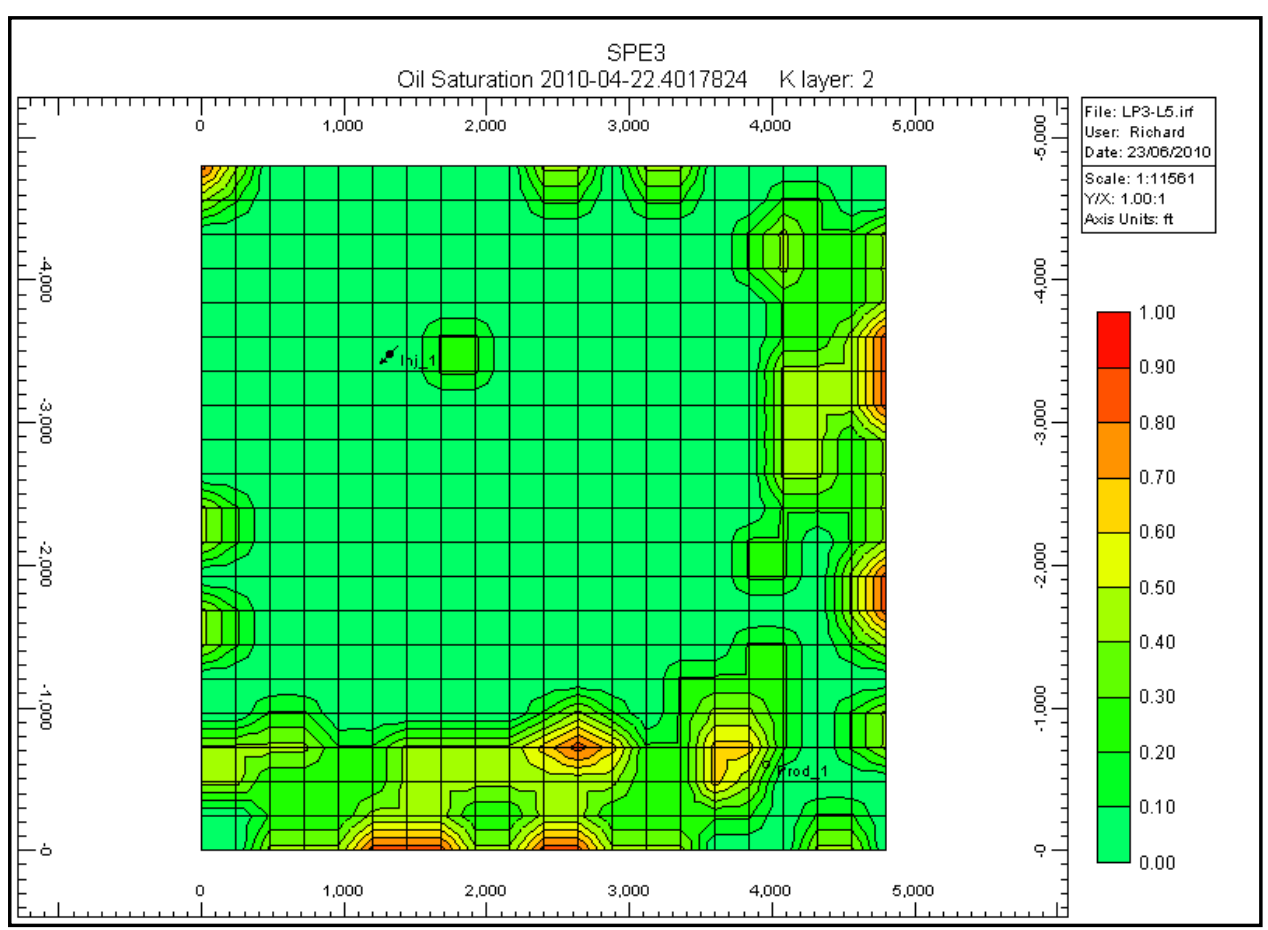

Figure E- 2: Screen-shot for Layer 2 at the end of pressurization period 


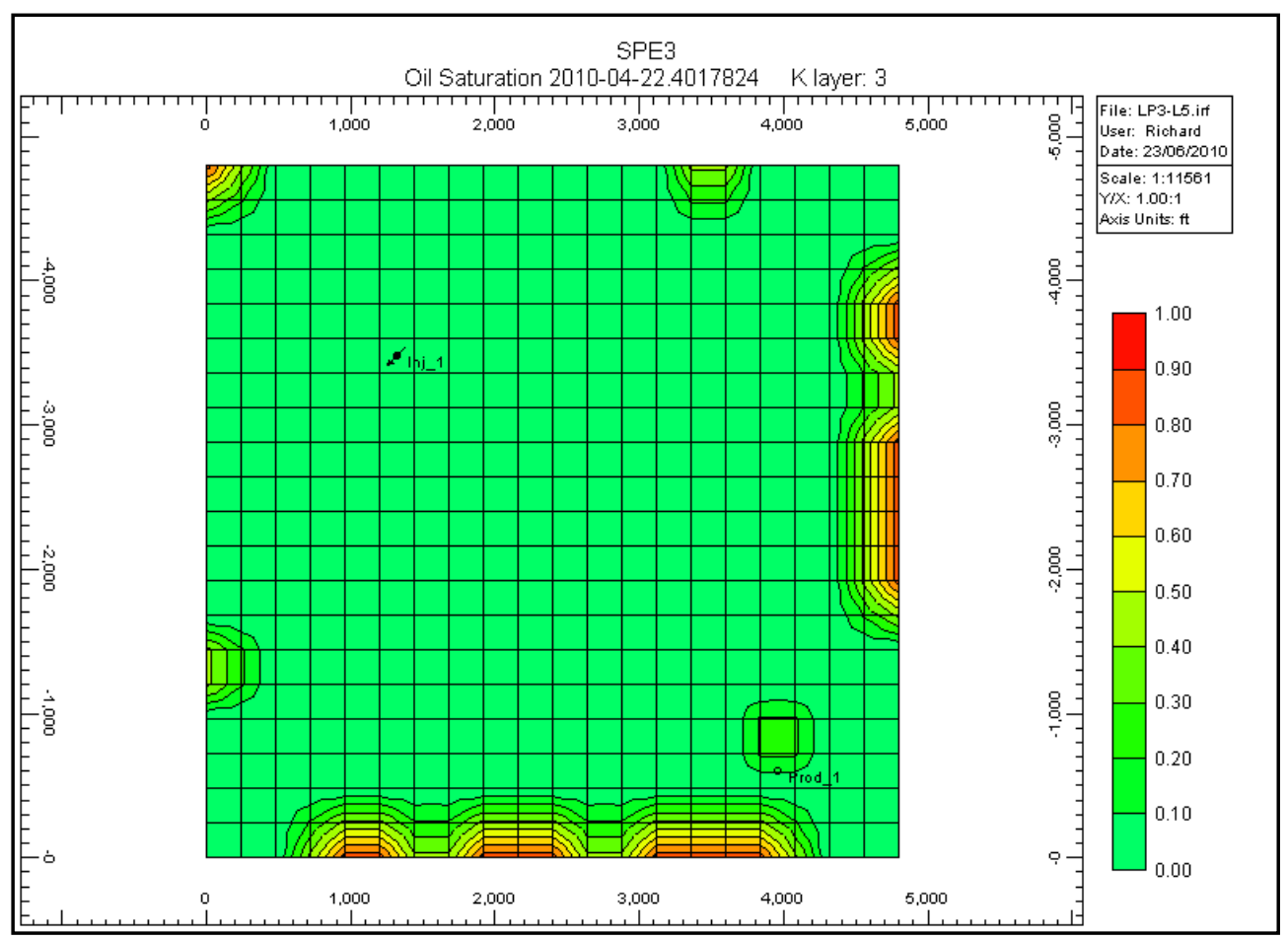

Figure E- 3: Screen-shot for Layer 3 at the end of pressurization period

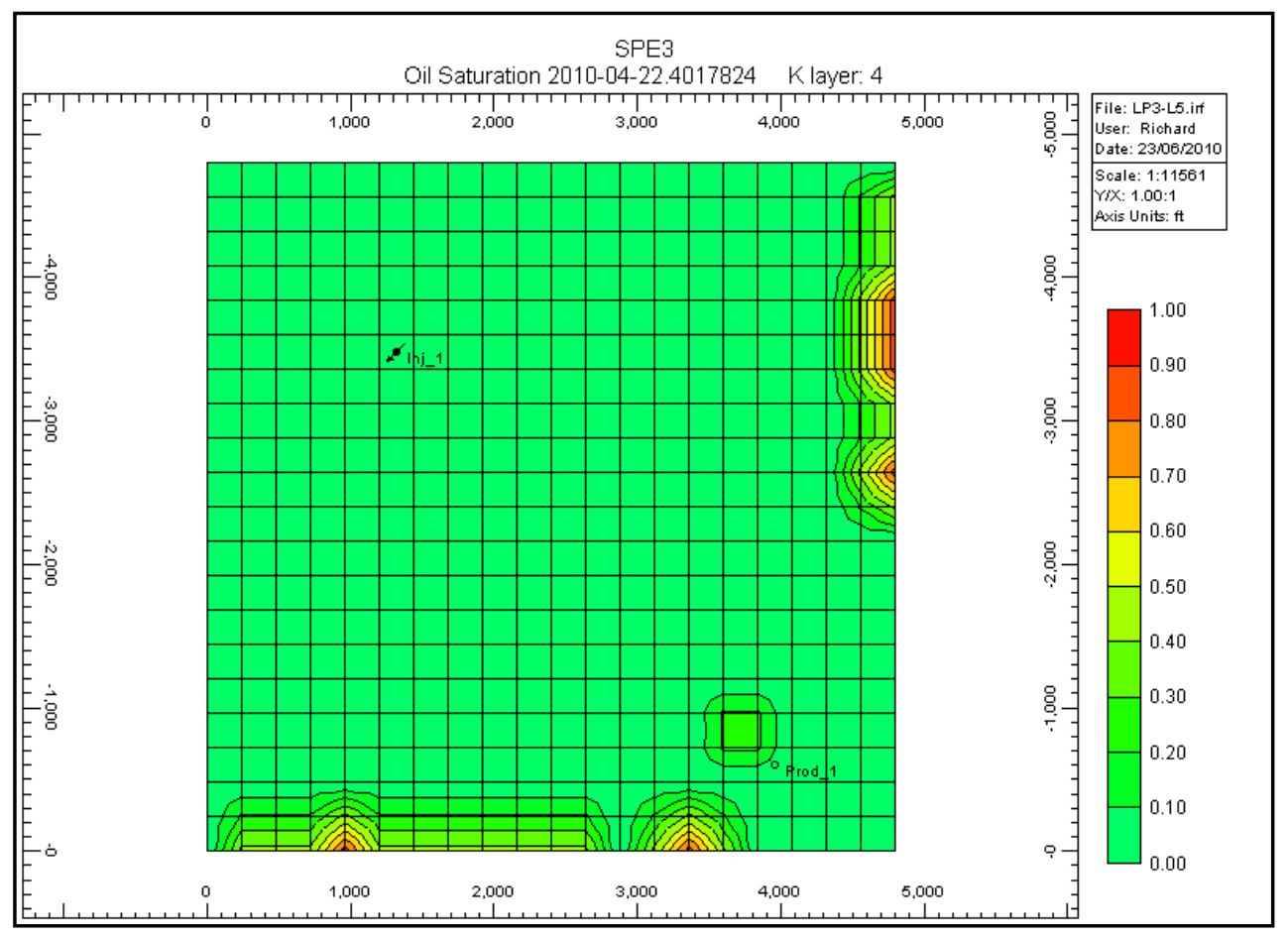

Figure E- 4: Screen-shot for Layer 4 at the end of pressurization period 


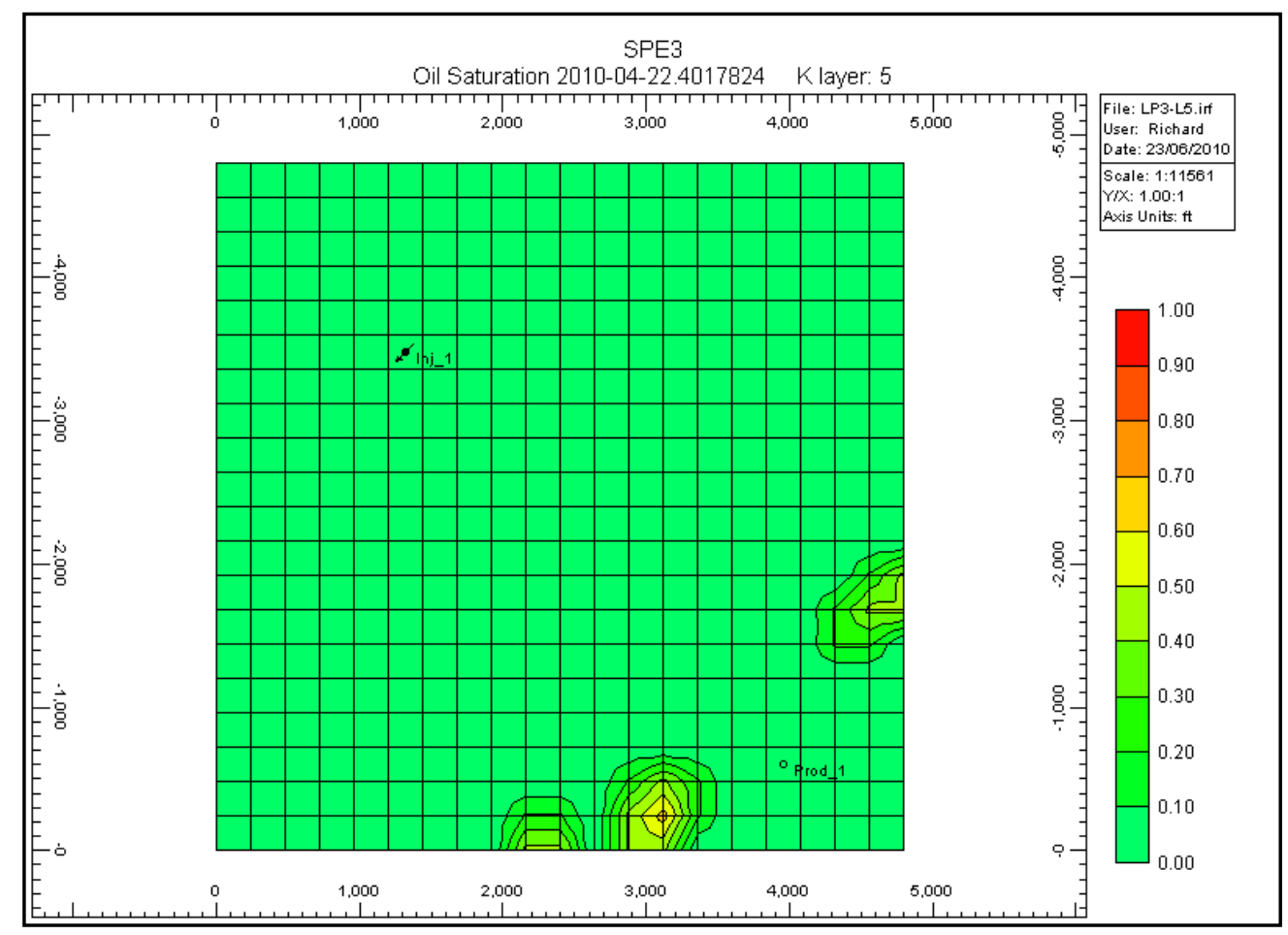

Figure E- 5: Screen-shot for Layer 5 at the end of pressurization period 


\section{APPENDIX F: SP-5L screen-shots at the end of injection period}

SP-5L screen-shots at the end of injection period showing the near production well and reservoir boundary experiencing CO2-liquid miscibility

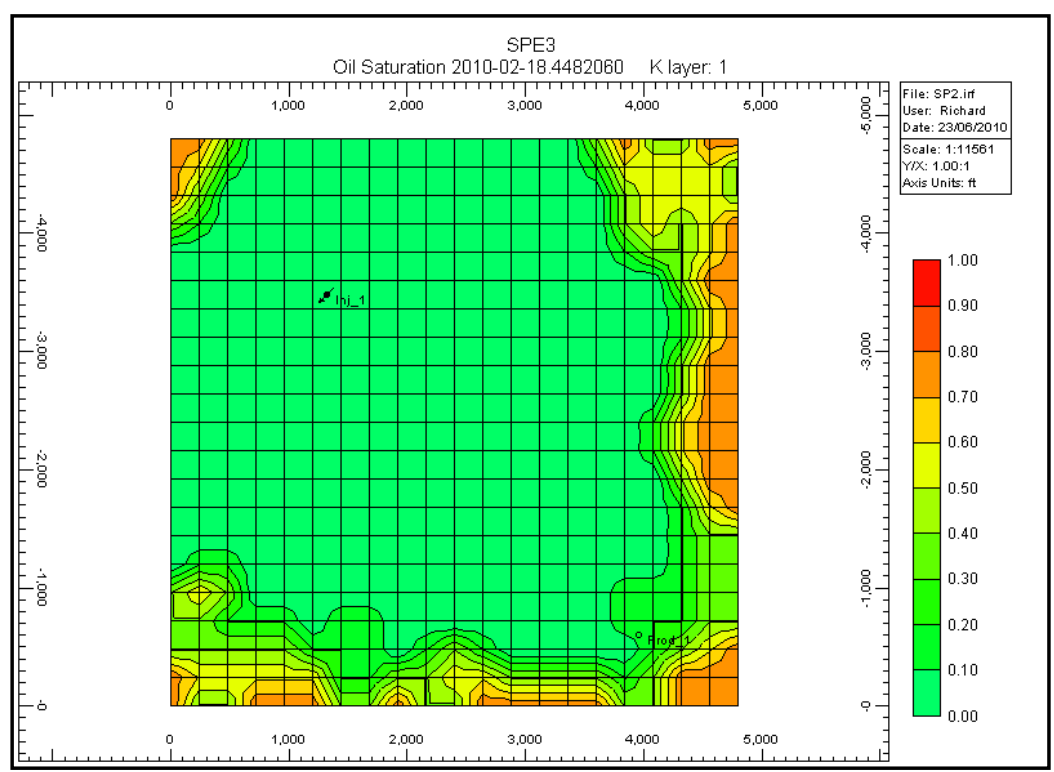

Figure F-1: Screen-shot for Layer 1 at the end of pressurization period

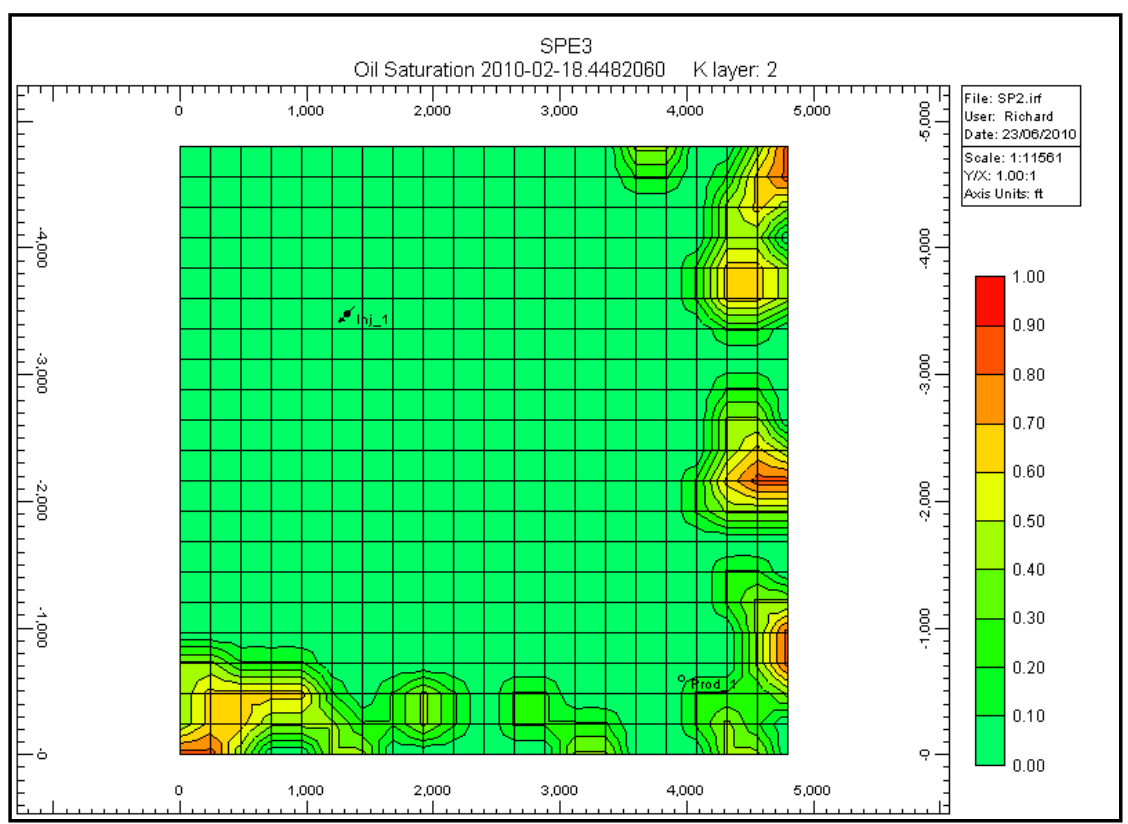

Figure F-2: Screen-shot for Layer 2 at the end of pressurization period 


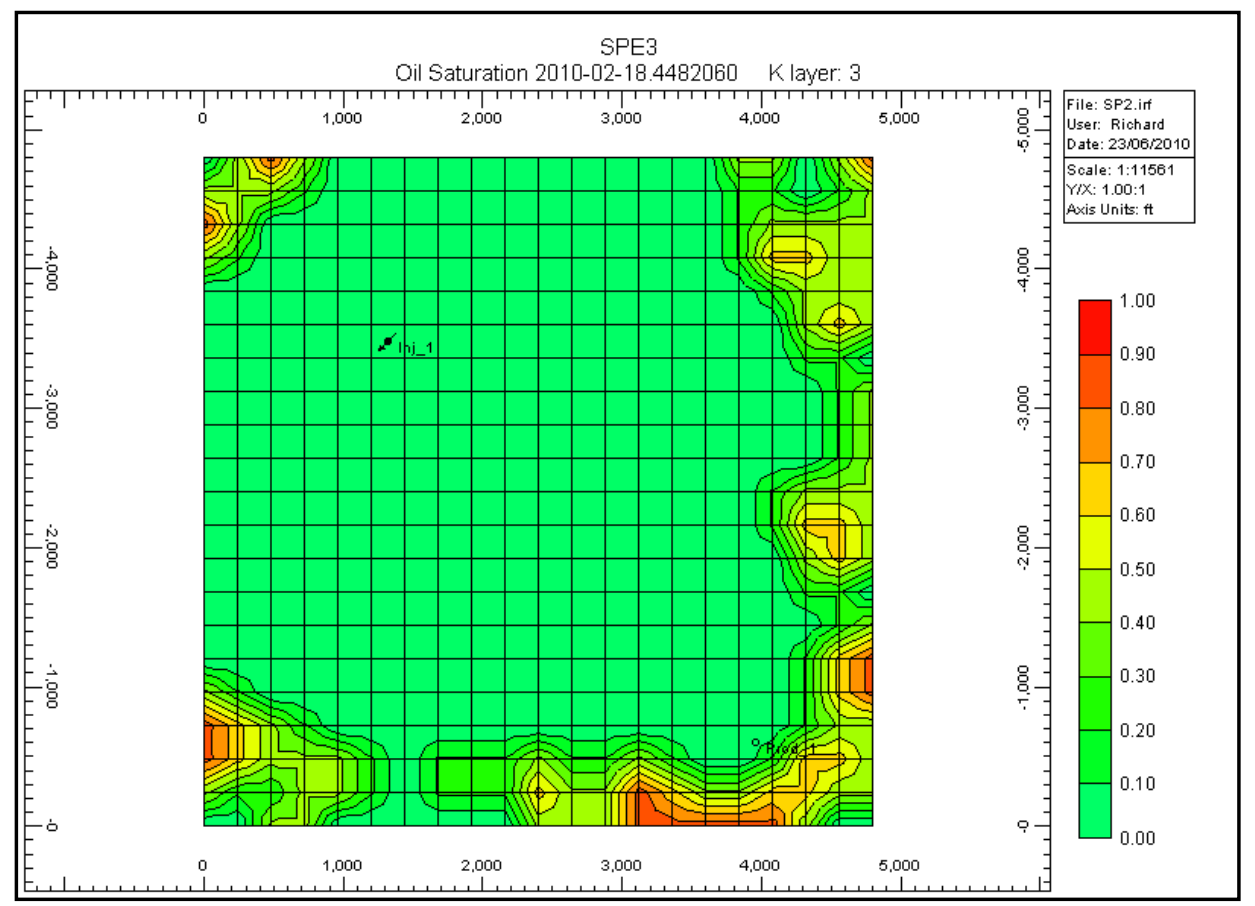

Figure F- 3: Screen-shot for Layer 3 at the end of pressurization period

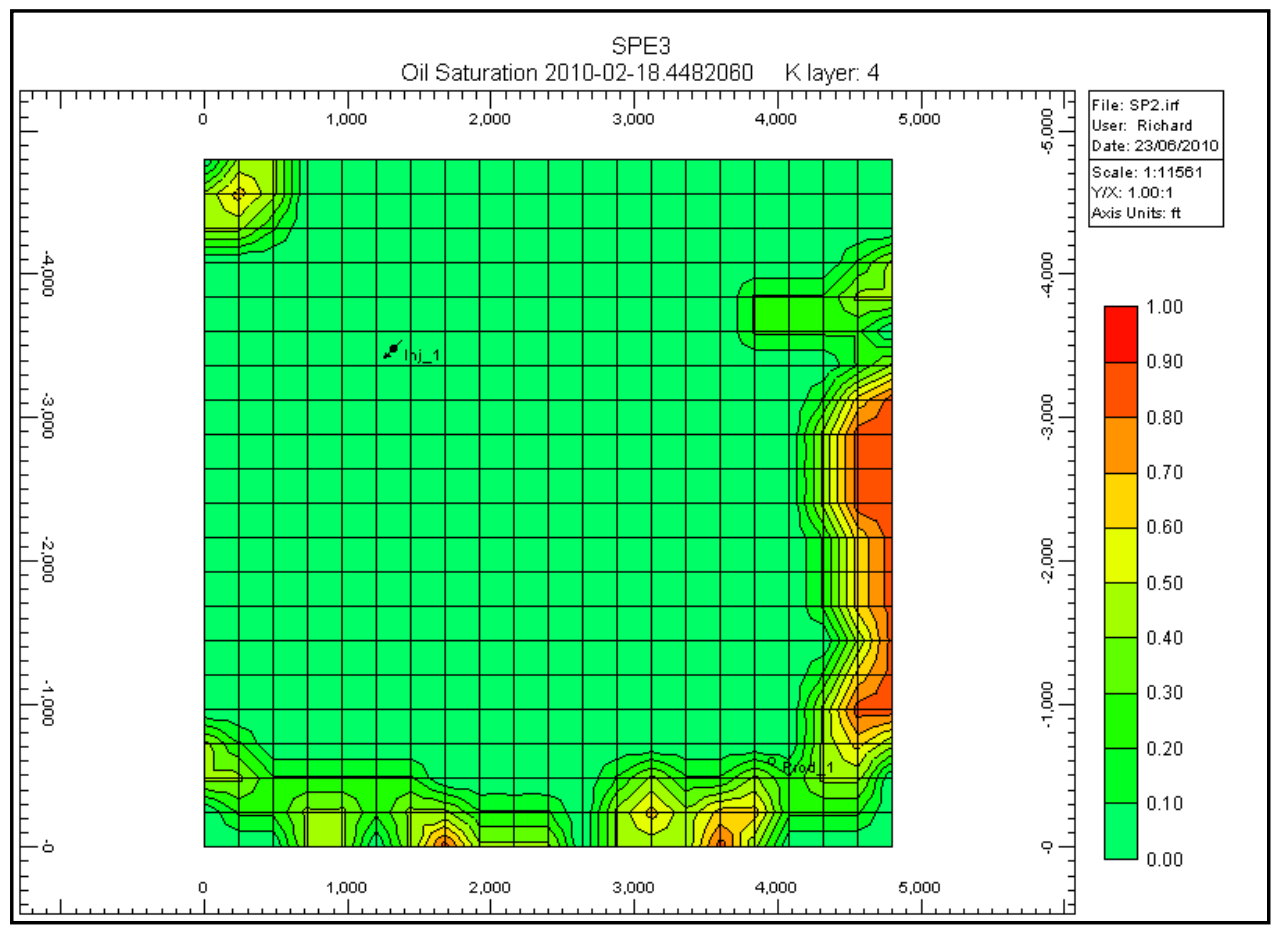

Figure F- 4: Screen-shot for Layer 4 at the end of pressurization period 


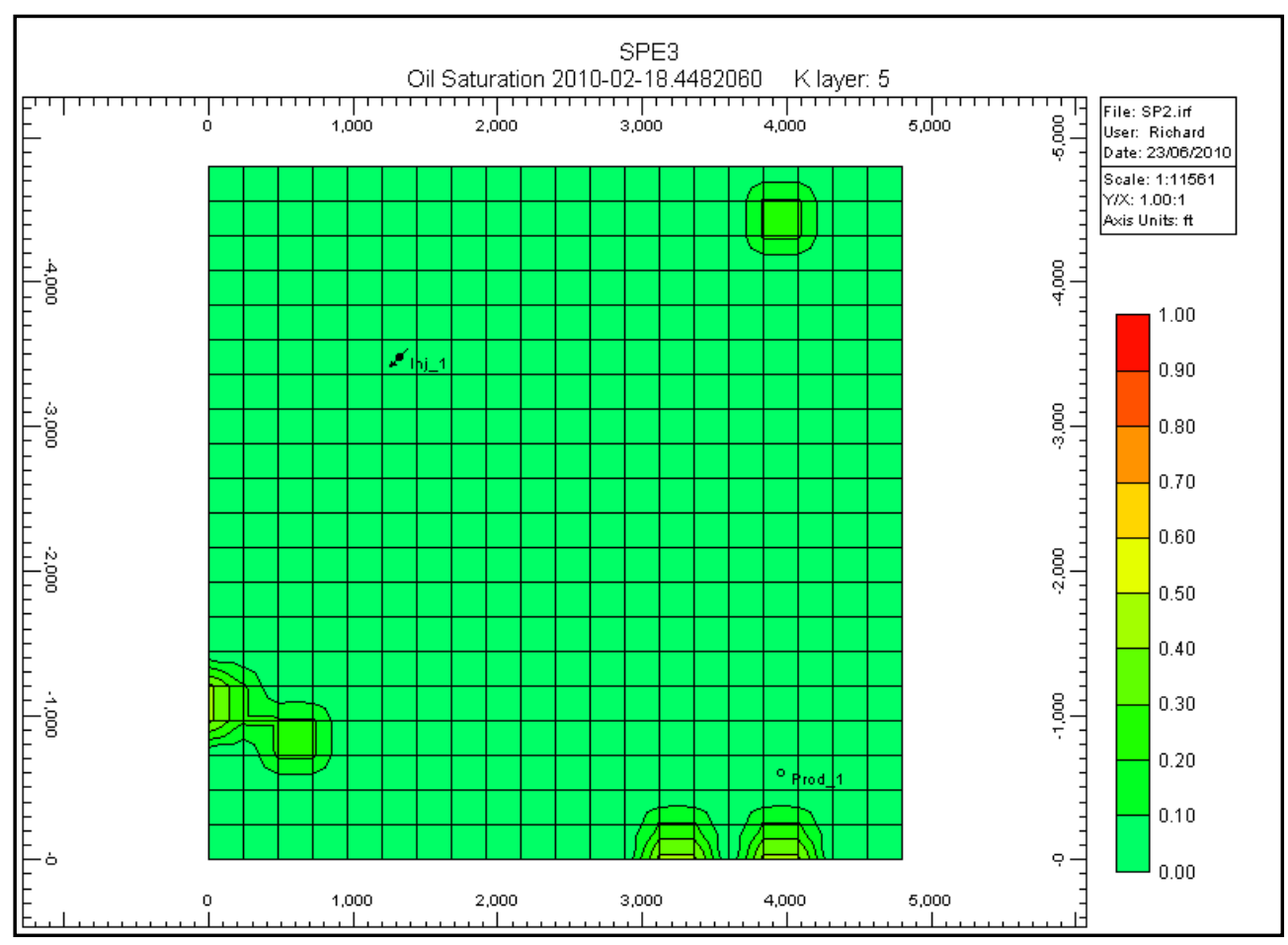

Figure F- 5: Screen-shot for Layer 5 at the end of pressurization period 


\section{APPENDIX G: Pressure-Temperature Diagram for pure CO2}

The following figure shows the pressure-temperature diagram for pure carbon dioxide.

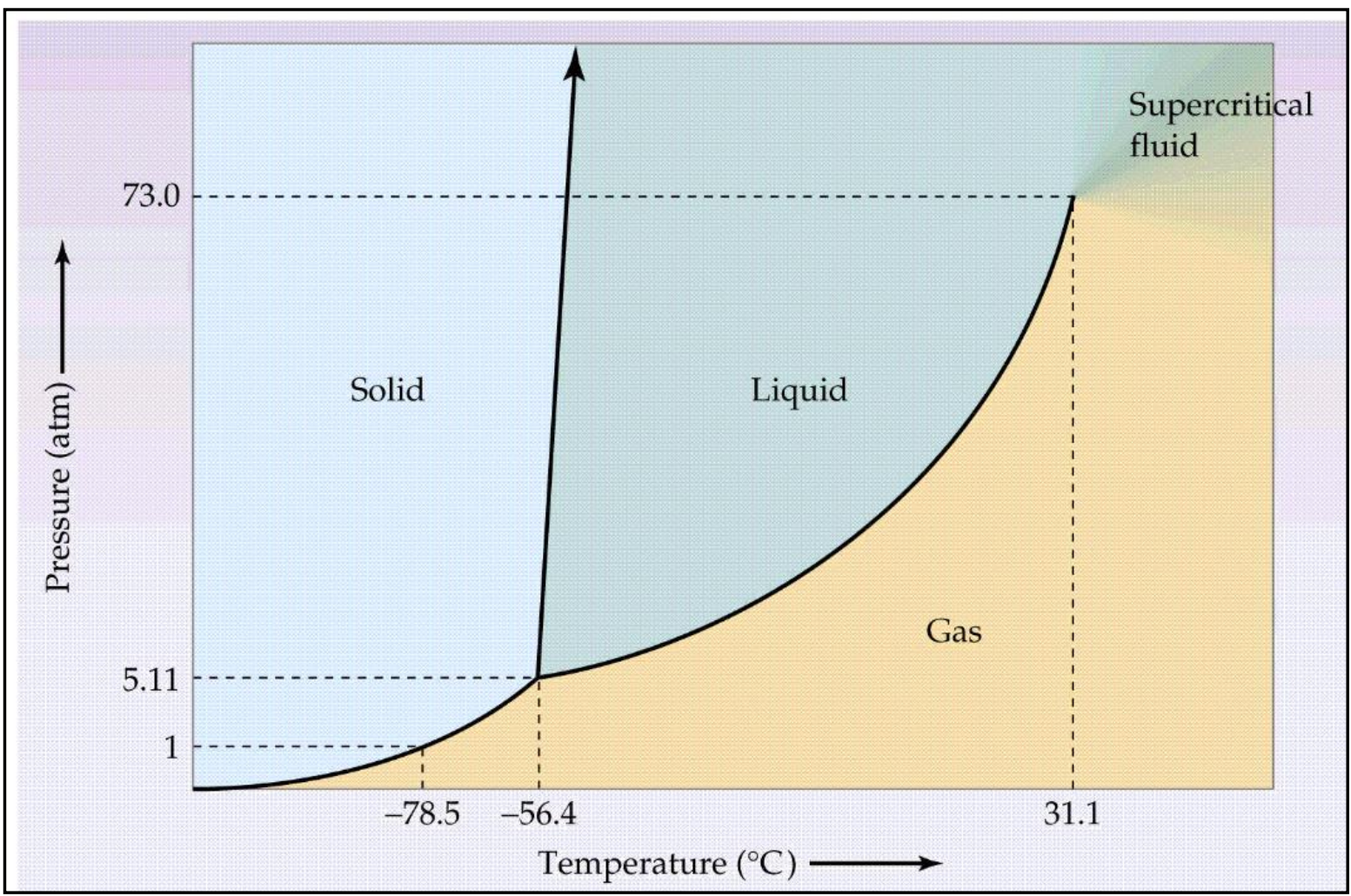

Figure G- 1: Pressure-Temperature Diagram for pure CO2 